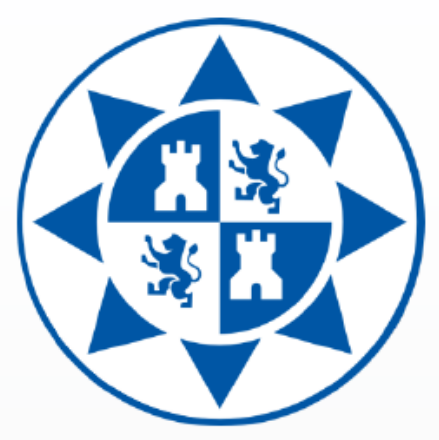

UNIVERSIDAD POLITÉCNICA DE CARTAGENA DEPARTAMENTO DE CIENCIA Y TECNOLOGÍA AGRARIA ÁREA DE GENÉTICA

\title{
Instruments of Functional
Genomics for the Improvement \\ Instruments of Functional
Genomics for the Improvement of Flower Characteristics in Ornamentals
}

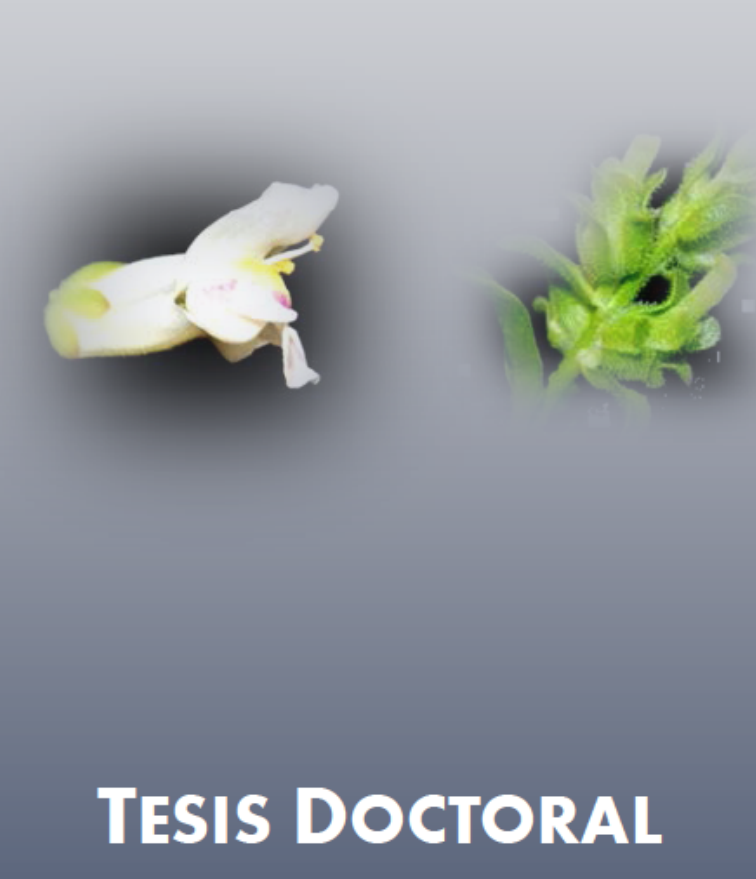

María Manchado Rojo 



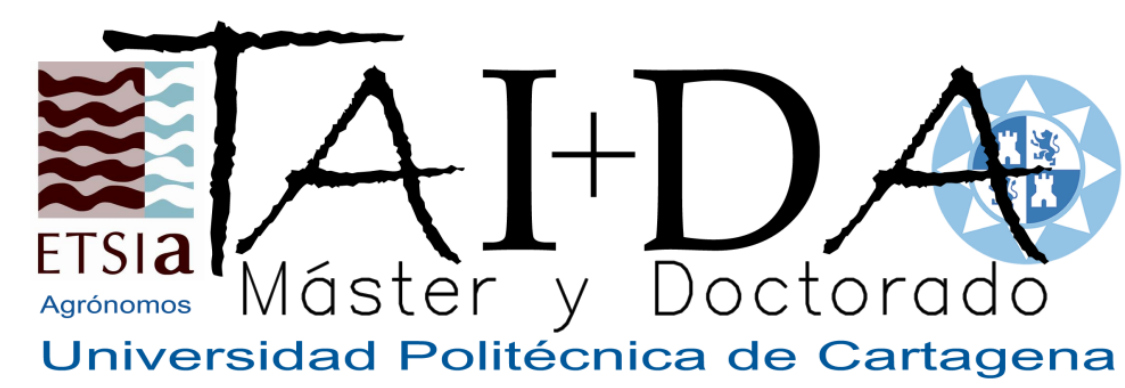

\section{Instruments of Functional Genomics for the Improvement of Flower Characteristics in Ornamentals}

Tesis Doctoral presentada por

Dña. María Manchado Rojo

para la obtención del Título de Doctor

\section{AUTORIZACIÓN DE LA PRESENTACIÓN DE LA TESIS DOCTORAL}

Comisión Académica del programa de Doctorado

Programa Oficial de Doctorado Técnicas Avanzadas en Investigación y Desarrollo Agrario y Alimentario

Escuela Técnica Superior de Ingeniería Agronómica

Universidad Politécnica de Cartagena

Directores de la Tesis Doctoral

Dra. Julia Weiss

Dr. Marcos Egea Gutiérrez-Cortines

Departamento de Ciencia y Tecnología Agraria

Área de Genética

Universidad Politécnica de Cartagena 



\section{CONFORMIDAD DE SOLICITUD DEAUTORIZACIÓN DE DEPÓSITO DE TESIS DOCTORAL POR EL/LA DIRECTOR/A DE LA TESIS}

$D^{a}$. Julia Weiss, directora, y D. Marcos Egea Gutiérrez-Cortines, co-director, de la Tesis doctoral "INSTRUMENTS OF FUNCTIONAL GENOMICS FOR THE IMPROVEMENT OF FLOWER CHARACTERISTICS IN ORNAMENTALS"

\section{INFORMA:}

Que la referida Tesis Doctoral, ha sido realizada por Da. María Manchado Rojo, dentro del programa de doctorado Técnicas Avanzadas en Investigación y Desarrollo Agrario y Alimentario, dando mi conformidad para que sea presentada ante la Comisión de Doctorado para ser autorizado su depósito.

La rama de conocimiento en la que esta tesis ha sido desarrollada es:

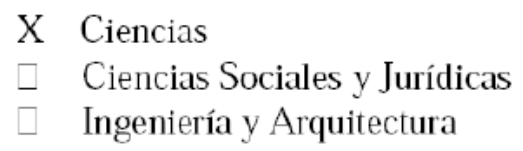

En Cartagena, a 15 de junio de 2015

LA DIRECTORA DE LA TESIS

Julia

Rosl|

Weiss

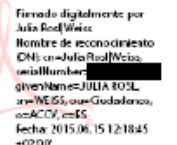

Fdo.: Julia Weiss
EL CO-DIRECTOR DE LA TESIS
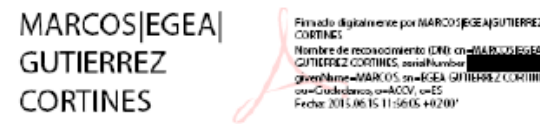

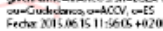

Fdo.: Marcos Egea Gutiérrez-Cortines

COMISIÓN DE DOCTORADO 



\section{CONFORMIDAD DE DEPÓSITO DE TESIS DOCTORAL POR LA COMISIÓN ACADÉMICA DEL PROGRAMA}

D/D ${ }^{a}$. Francisco Artés Hernández, Presidente/a de la Comisión Académica del Programa Técnicas Avanzadas en Investigación y Desarrollo Agrario y Alimentario.

\section{INFORMA:}

Que la Tesis Doctoral titulada, "Instruments of functional genomics for the improvement of flower characteristics in ornamentals", ha sido realizada, dentro del mencionado programa de doctorado, por $\mathrm{D}^{\mathrm{a}}$. María Manchado Rojo,

bajo la dirección y supervisión de la Dra. Julia Weiss y el Dr. Marcos Egea GutiérrezCortines.

En reunión de la Comisión Académica de fecha 15/06/2015, visto que en la misma se acreditan los indicios de calidad correspondientes y la autorización del Director de la misma, se acordó dar la conformidad, con la finalidad de que sea autorizado su depósito por la Comisión de Doctorado.

La Rama de conocimiento por la que esta tesis ha sido desarrollada es:

$\mathrm{X}$ Ciencias

$\square$ Ciencias Sociales y Jurídicas

$\square$ Ingeniería y Arquitectura

En Cartagena, a 15 de junio de 2015

EL PRESIDENTE DE LA COMISIÓN ACADÉMICA DEL PROGRAMA

FRANCISCO DE ASIS| ARTES|HERNANDEZ

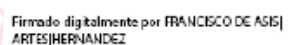

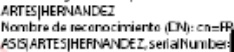

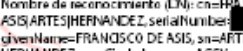

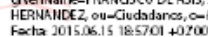

Fdo: Dr. Francisco Artés Hernández

\section{COMISIÓN DE DOCTORADO}





\section{Agradecimientos}

Quisiera expresar mi más sincero agradecimiento a todas las personas que han estado a mi lado durante la realización de los trabajos que han permitido la presentación de esta tesis.

En primer lugar, a mis directores, la Dra. Julia Weiss y el Dr. Marcos Egea-Cortines, no sólo por sus directrices en la línea de investigación, sino también por su inestimable ayuda y apoyo sin la que creo no hubiese sido posible la finalización de este trabajo, así como por su calidad humana, estando ahí siempre que los he necesitado, tanto en lo profesional como en lo personal. Una vez más, gracias por todo!

A todas las personas que han formado parte de 'la familia de genética' durante el tiempo que yo he 'vivido con ellos', Luciana y Perla, por su amabilidad y disposición siempre que necesité ayuda de

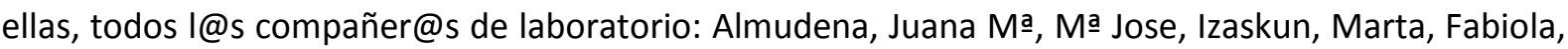
Pablo... por los buenos momentos que he hemos pasado, que siempre perdurarán sobre aquellos cuando se nos resistían las clonaciones o las RT-qPCRs y de los que también aprendimos mucho.

A todas las personas, que sin estar expresamente nombradas, han estado ahí para ayudarme en lo que ha podido, técnicos de laboratorio, compañeros de otros laboratorios y/o departamentos, personal del SAIT...

Y como no, a mi familia, por apoyar siempre mis sueños y hacer lo posible por ayudarme a conseguirlos! 



\section{Contents}

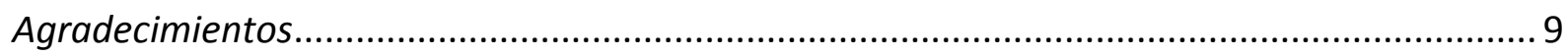

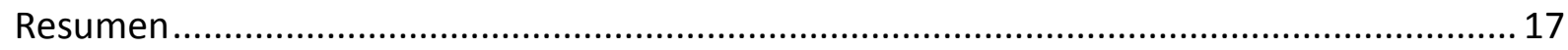

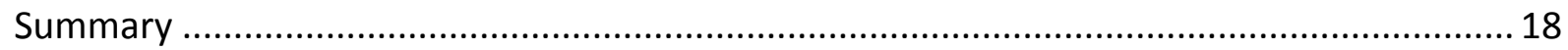

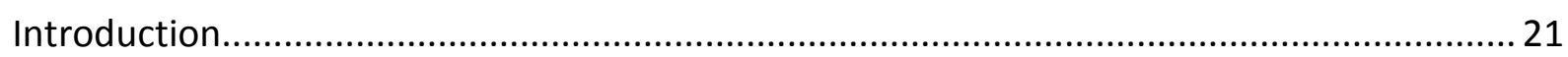

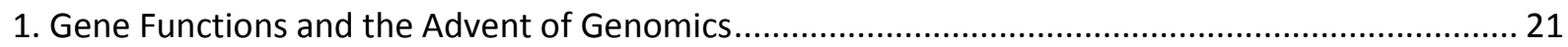

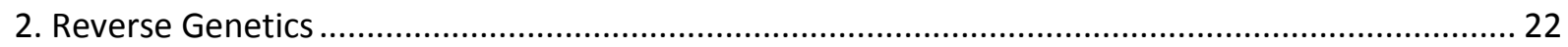

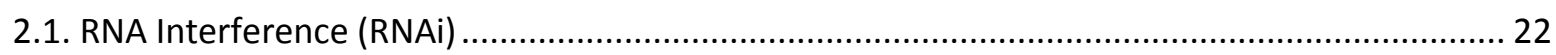

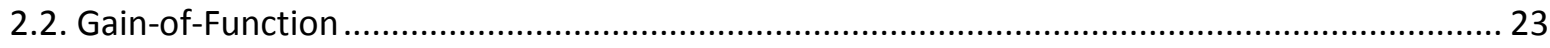

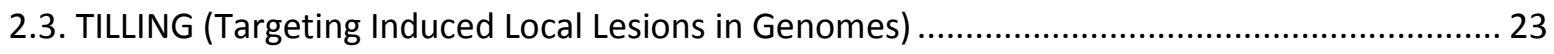

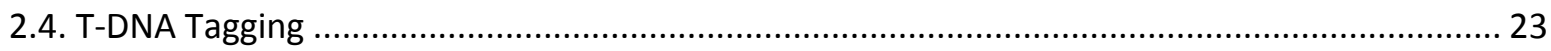

2.5. CRISPR/CAS (Clustered Regularly Interspaced Short Palindromic Repeats)............................. 23

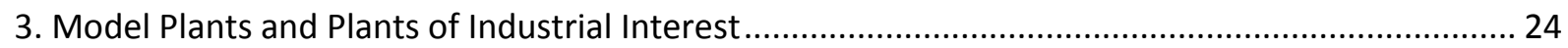

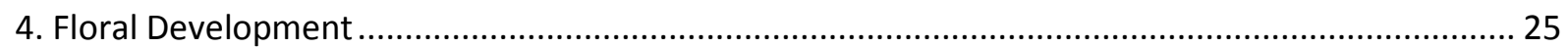

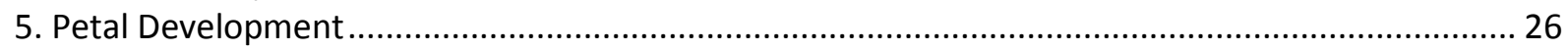

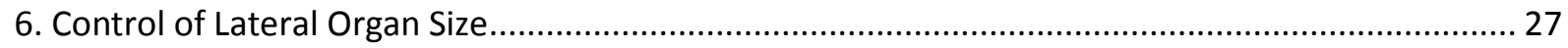

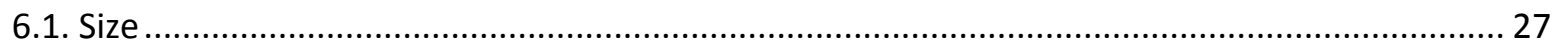

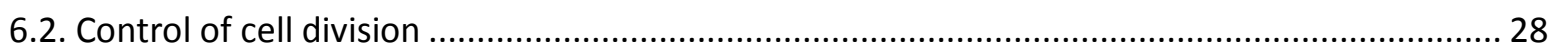

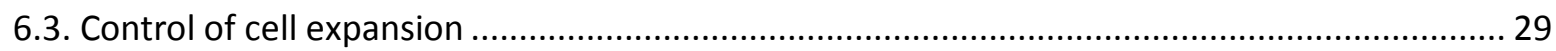

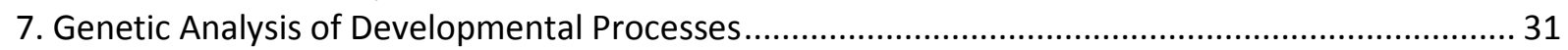

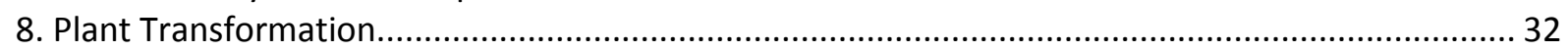

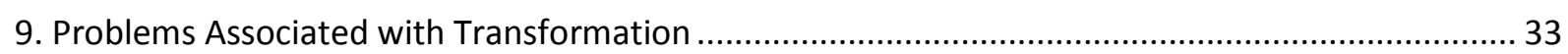

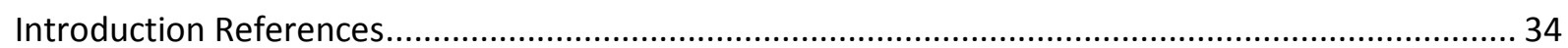

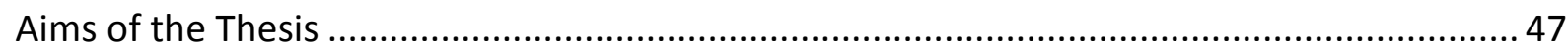

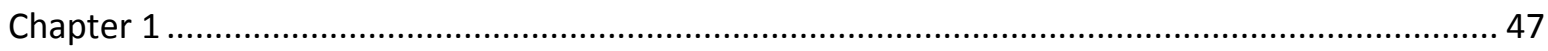

Chapter 2

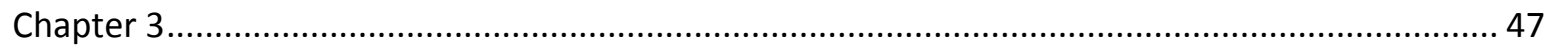

Chapter 1: Using 23S rDNA to identify contaminations of Escherichia coli in Agrobacterium

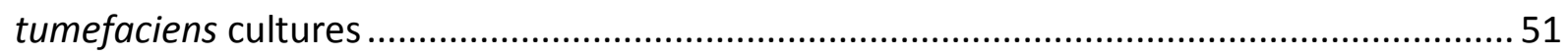

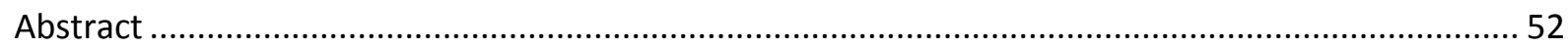

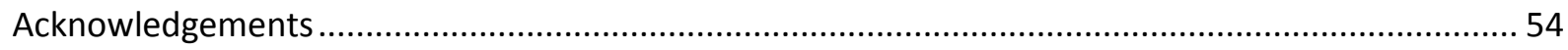

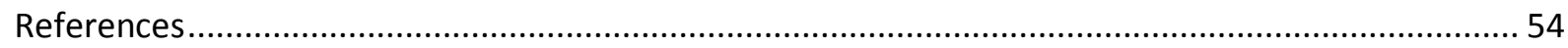

Chapter 2: Quantitative levels of Deficiens and Globosa during late petal development show

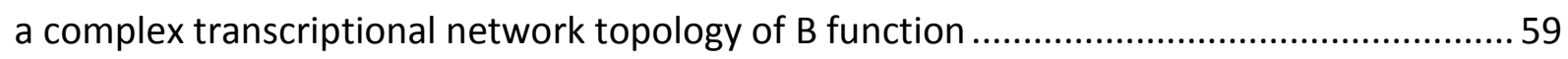

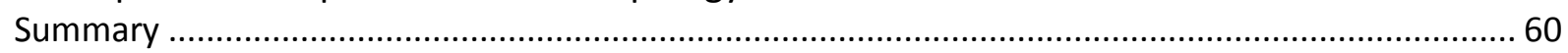

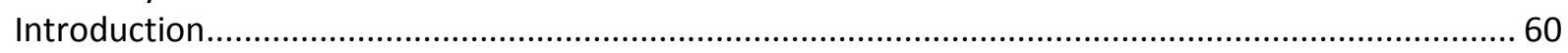

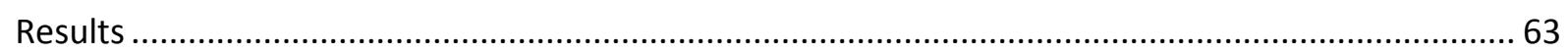

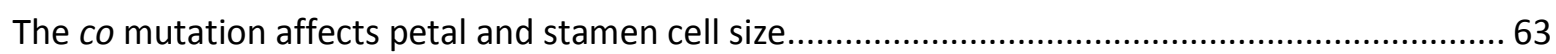

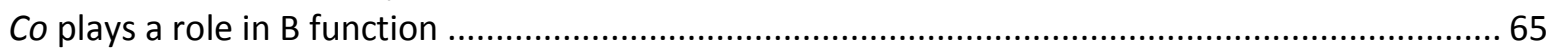

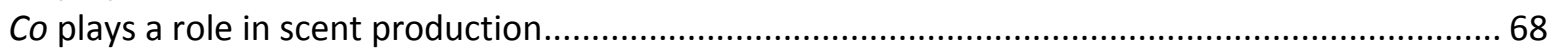

$C o$ is involved in $D E F$ transcriptional control and plays a role in $\mathrm{B}$ function ...................................68

Quantitative analysis of transcriptional regulatory network in late petal development ..................69

Reciprocal $D E F$ and $G L O$ transcript levels change during development......................................... 70

Effect of the $c o$ mutation and $B$ function manipulation on downstream processes.......................... 72

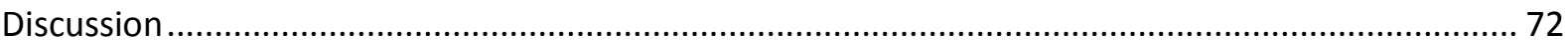




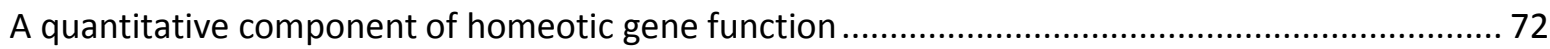

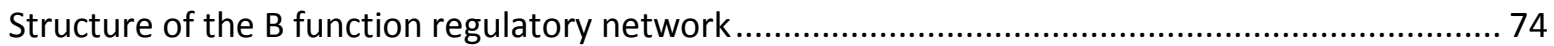

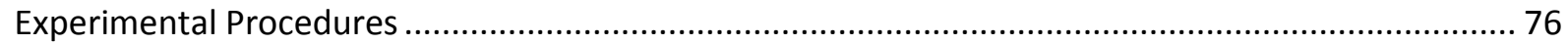

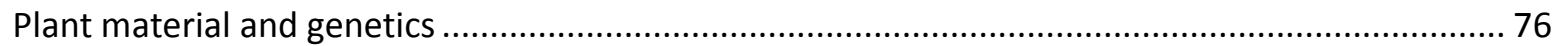

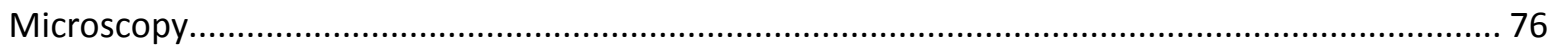

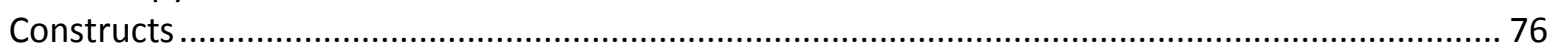

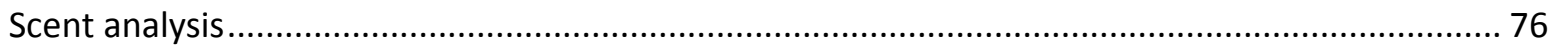

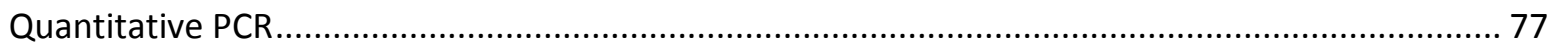

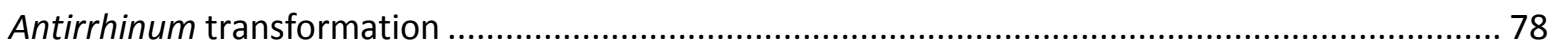

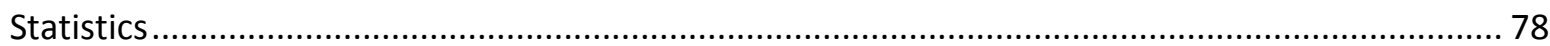

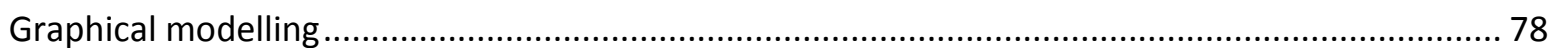

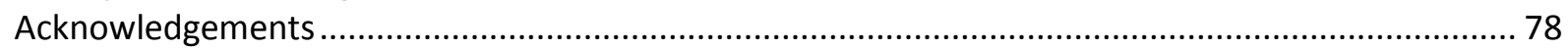

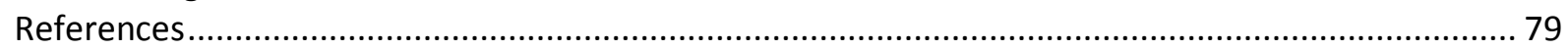

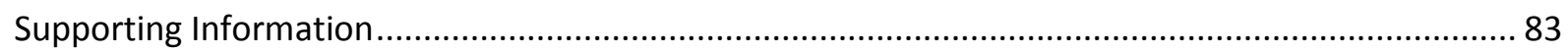

Appendix S1. Detailed Antirrhinum majus transformation protocol............................................... 84

Chapter 3: Validation of Aintegumenta as a gene to modify floral size in ornamental plants 91

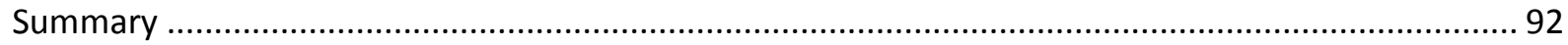

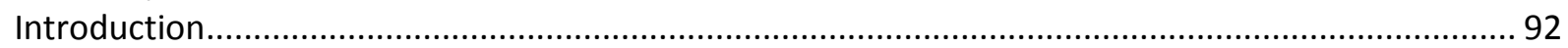

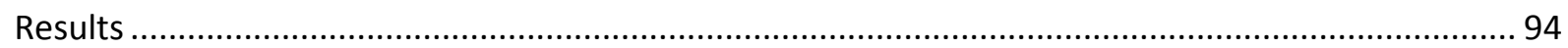

Cloning of an AINTEGUMENTA gene fragment from Petunia for functional analysis ...................... 94

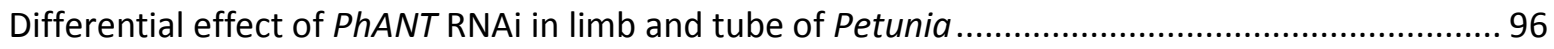

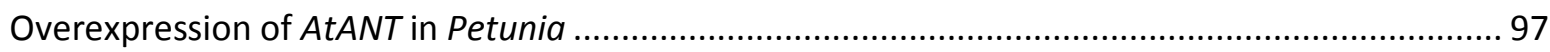

Changes in expression levels of ANT in Petunia expressing RNAi constructs and overexpressing

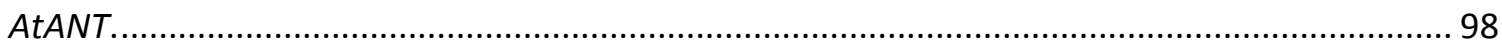

Effects of modified ANT expression levels on cell size and morphology in Petunia ........................ 99

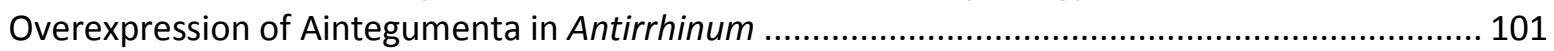

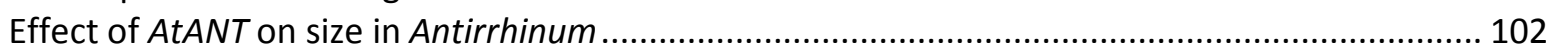

Differential effects of AtANT on endogenous ANT in Petunia and Antirrhinum ............................. 103

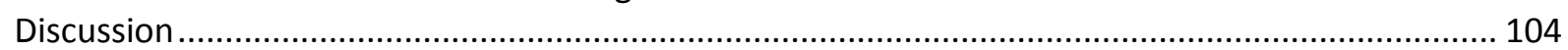

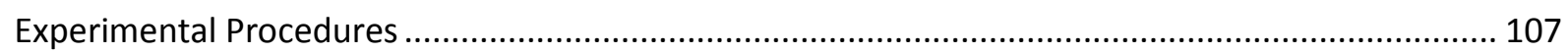

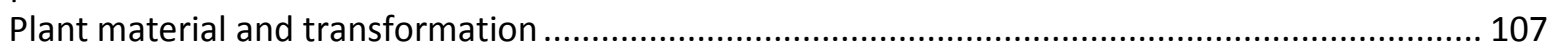

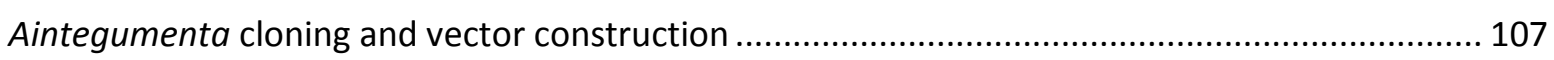

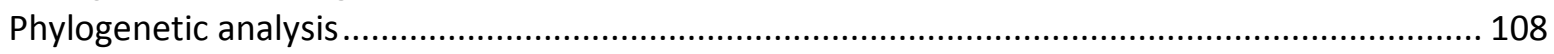

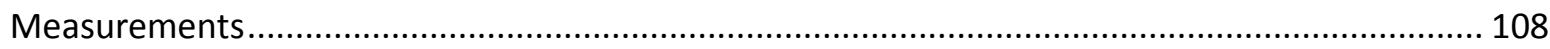

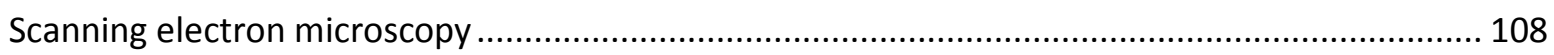

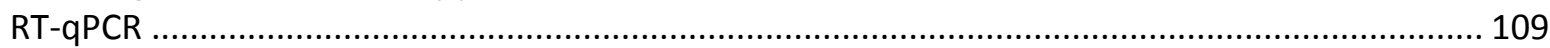

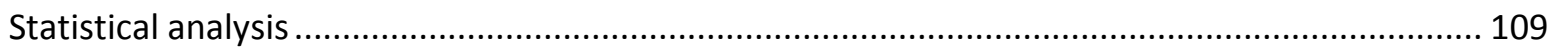

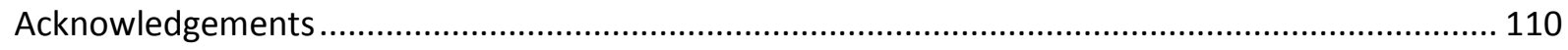

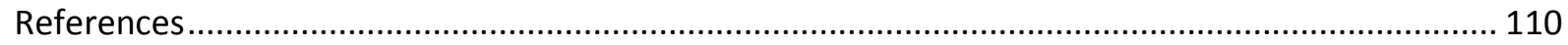

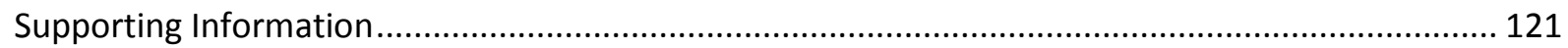

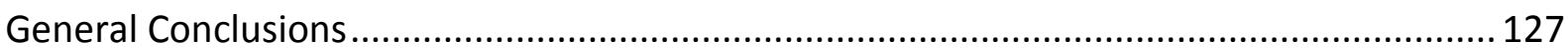

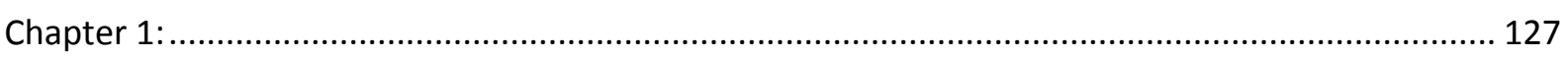

Chapter 2:

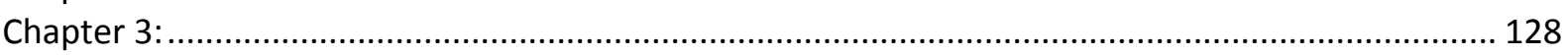

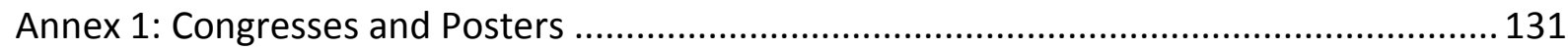




\section{List of Figures}

Introduction

Figure 1: $A B C D E$ Model of flower development

\section{Chapter 1}

Figure1: Amplification of 23S rDNA from bacterial samples.

\section{Chapter 2:}

Figure 1: Wild-type and co mutant flower from the side and longitudinal section 64

Figure 2: Scanning electron microscopy of cells from various organs of fully developed

flowers of wild-type and co mutant flowers

Figure 3: Phenotypes and lines of wild-type, co mutant, def fic and co def $f^{\text {nic }}$ double mutant.... 66

Figure 4: Scanning electron microscopy of floral organs of def $f^{\text {nic }}$ mutant and co def fic double mutant

Figure 5: Relative expression of DEFICIENS, GLOBOSA and MIXTA in second-whorl organs compared with wild-type

Figure 6: Box plot of expression values for GLO versus DEF in closed and open flowers.......... 71

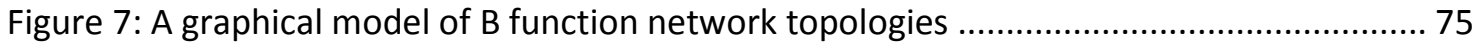

Figure S1: Segregation of colour genes in compacta genetic background ................................. 83

Figure S2: Volatile profiles of wild-type, $c 0$, def $^{\text {fic }}$ and co def fic double mutant......................... 83

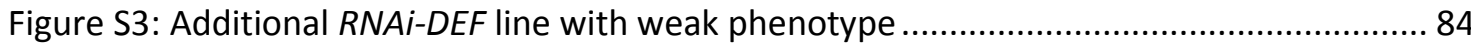

\section{Chapter 3:}

Figure 1: Phylogenetic tree of APETALA2 related predicted protein 96

Figure 2: Phenotype of Petunia flowers with silencing of PhANT gene or overexpression of AtANT.

Figure 3: Expression of AtANT and PhANT in flowers of transgenic lines................................. 99

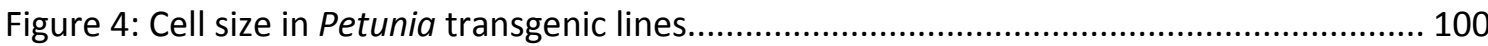

Figure 5: Expression of AtANT in transgenic Antirrhinum and phenotypes of

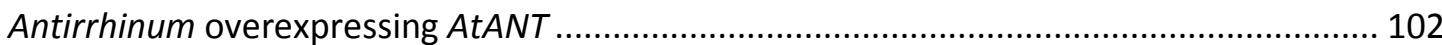

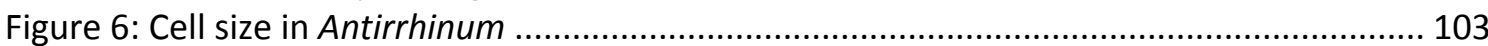

Figure 7: Level of endogenous AINTEGUMENTA in limb and tube in non-transgenic and transgenic plants

Figure S1: Multiple aligments of $A P 2$ and $A N T$ predicted protein

Figure S2: Petunia petal regions used to analyse effects of $A N T$ expression on cell division and expansion 


\section{List of Tables}

\section{Chapter 2:}

Table 1: Comparison of vegetative parameters between wild-type and co mutant.....

Table 2: Comparison of floral parameter for wild-type, the co mutant, the def $f^{\text {nic }}$ single mutant and co def ${ }^{\text {nic }}$ double mutant. 64

Table 3: Cell area of petal, stamen and style in wild-type and the co mutant 65

Table 4: Cell area of stamen and style in def $f^{\text {nic }}$ single mutant and co def $f^{\text {nic }}$ double mutant...... 67

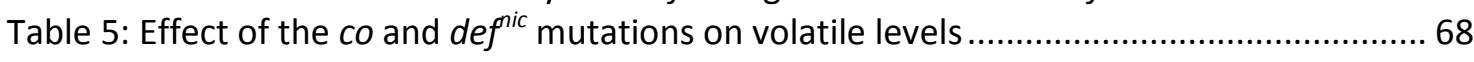

Table 6: Expression of GLO compared to $D E F$ in various tissues ............................................... 71

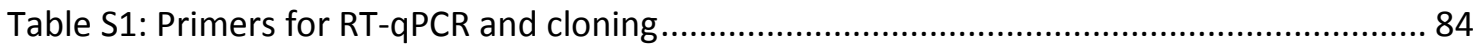

\section{Chapter 3:}

Table 1: Comparison of floral parameters between wild-type and transgenic lines................. 97

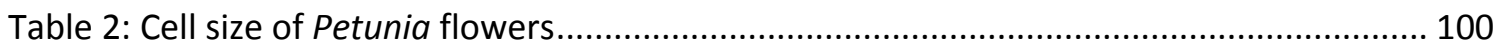

Table 3: Comparison of floral parameters between wild-type and transgenic lines.................. 102

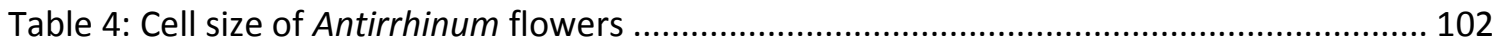

Table S1: Accession numbers of genes used for phylogenetics analysis ................................ 123

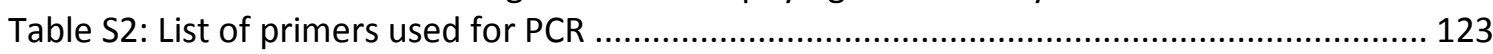

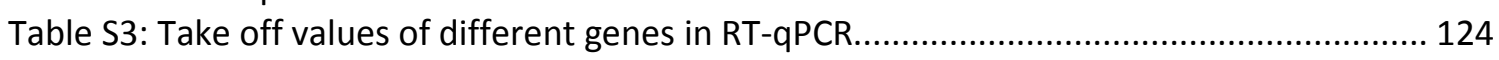


A mí famílía,

A los que están

A los que vendran Y a los que ya se han ido 



\section{Resumen}

El presente trabajo pretende explorar las técnicas de genética inversa para mejora de la planta ornamental. Se ha desarrollado un protocolo de transformación de Antirrhinum majus siéndonos de gran ayuda el desarrollo de una técnica para genotipar cepas de laboratorio de Agrobacterium tumefaciens y de Escherichia coli basado en los datos de fusionado de ADN de un fragmento de 235 ADN ribosomal, dado que la contaminación cruzada de stocks de Agrobacterium tumefaciens con Escherichia coli son difíciles de identificar por técnicas microbiológicas, dando lugar a resultados de falsos negativos en los experimentos de transformación.

Para la mejora de planta ornamental, nos hemos basado en el estudio de genes que afectan sobre todo al desarrollo floral en dos especies que son tradicionalmente utilizadas como plantas modelo, pero que además poseen un elevado interés económico, éstas son Antirrhinum majus y Petunia $\mathrm{x}$ hibrida.

Se analizaron los niveles de DEFICIENS y GLOBOSA en las etapas finales del desarrollo de pétalos en

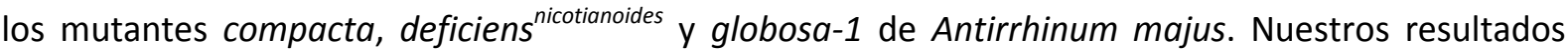
muestran que el nivel umbral de DEF o GLO para obtener tejido de pétalo es aproximadamente un 11\% del silvestre. Demostrándose que en las etapas finales del desarrollo de pétalo, la topología de la red transcripcional de la function $B$ no está basada en la autoregulación positiva y tiene componentes adicionales de mantenimiento de la transcripción.

Comprobamos el uso de AINTEGUMENTA como herramienta para modificar el tamaño floral en dos plantas diferentes, Petunia $x$ hybrida y Antirrhinum majus. La disminución de la expresión de PhANT muestra un efecto en el tamaño de las células, mientras que la sobreexpresión de AtANT en limbo y tubo de Petunia y en Antirrhinum causa un significante incremento en la expansion celular que podría explicar las diferencias en el tamaño de los órganos florales. El efecto diferencial de AtANT en el limbo y tubo de Petunia y Antirrhinum corresponde a diferencias fenotípicas observadas en la variación natural en el género correspondiente indicando una relación entre el espacio fenotípico de un género y el efecto de los niveles de $A N T$ modificados, validando ANT como un gen para modificar el tamaño floral. 


\section{Summary}

This present work aims to explore the technique of reverse genetics for the improvement of ornamental plants. For this purpose we have developed an Antirrhinum majus transformation protocol. The development of a genotyping assay for Agrobacterium tumefaciens and Escherichia coli lab strains based on DNA melting profiles of a $23 \mathrm{~S}$ rDNA fragment has been of great help in the process of elaborating the transformation assay, since cross contamination of Agrobacterium tumefaciens stocks with Escherichia coli are difficult to identify by microbiological techniques, leading to false negative results in transformation experiments.

For the improvement of ornamental plants, we concentrated on the study of genes that affect mostly the floral development in two species which are traditionally used as a model plants, but at the same time are of high economic interest, Antirrhinum majus, and Petunia $\mathrm{x}$ hybrida.

We investigated the levels of DEFICIENS and GLOBOSA at late stages of petal development in the Antirrhinum majus mutants compacta, deficiens ${ }^{\text {nicotianoides }}$ and globosa-1. We show that the threshold levels of DEF or GLO to obtain petal tissue are roughly $11 \%$ of wild-type. Our results demonstrate that at late stages of petal development, the B function transcriptional network topology is not based on positive autoregulation and has additional components of transcriptional maintenance.

We also tested the use of AINTEGUMENTA as a tool to modify floral size in our two model plants, Petunia $x$ hybrida and Antirrhinum majus. Downregulation of PhANT showed an effect on cell size while overexpression of AtANT in Petunia and Antirrhinum caused significant increases in cell expansion that could explain the differences in floral organ size. The differential effect of AtANT on limb and tube in Petunia and Antirrhinum correspond to phenotypic differences observed in natural variation in the corresponding genus indicating a relation between the phenotypic space of a genus and the effect of modified $A N T$ levels, validating $A N T$ as a gene to modify floral size. 
Introduction 



\section{Introduction}

\section{Gene Functions and the Advent of Genomics}

The development of the so called 'omics technologies' has had a clear impact on the attention given to the research related to biological processes in all areas. The beginning of such technologies is a result of the automation of genomic DNA sequencing.

Genomics is the science and techniques dedicated to the integrated study of the origin, evolution, operation and content of genomes. The analysis of genomes has undergone a boom in recent years, mainly thanks to advanced DNA sequencing technologies and advances in bioinformatics. These advances have resulted in the realization of huge projects to sequence entire genomes of various model organisms and several public servers, such as the NCBI (National Center for Biotechnology Information) that allow free access to the sequences of many organisms. The strong development of genomics has contributed to the progress in different fields of science, such as agriculture, thanks to the discovery of sequences of genes involved in traits of agronomic importance and through comparison of genomic sequences from different organisms.

An innovation introduced in the early nineties was the systematic sequencing of expressed sequence tags or ESTs (Adams et al., 1991).

The results of sequencing and annotation of genomes are deposited in databases. With the idea of unifying all this information in a meaningful way for researchers, the Gene Ontology (GO) project was born in 1998 (Ashburner et al., 2000). Initially this project involved the association of three model organism databases: the Drosophila genome database (FlyBase) (Anon, 1999), Mouse Genome Informatics database (MGI) (Blake et al., 2000) and the Saccharomyces Genome Database (SGD)(Ball et al., 2000). But nowadays the GO Consortium has grown to include many databases, such as several major genomes of animals, microorganisms and plants (Harris et al., 2004).

The Gene Ontology Consortium (Consortium, 2001) has created three extensive ontologies to describe molecular functions, biological processes, and cellular components, and providing a community database resource that supports the use of these ontologies:

- Biological process ontology: describes the sets of molecular events with a defined beginning and end, pertinent to the function of integrated living units such as cells, tissues, organs and organism. The biological process ontology may be inferred based on phylogenetic tools due to 
the fact that any protein has a specific biological function and a biological pathway requires the systematization of many proteins. Although it requires proof of concept by gain and/or loss of function of the genes involved.

- Molecular function ontology: refers to the molecular activity of a gene product. This can be inferred from BLAST (Altschul et al., 1990), a search algorithm used for comparing biological sequences and finding the similarity between them.

- Cellular component ontology: is defined as the part of a cell or its extracellular environment where a gene product is active. This ontology might be also inferred from BLAST.

\section{Reverse Genetics}

Traditionally, forward genetics tries to find out the sequence of a gene with known biological function starting from a mutant or an allele with a phenotype. In the last years, the widespread of molecular biology techniques has facilitated the massive sequencing of genes. This fact coupled with a significant cost reduction has enabled the completion of several genome projects. Therefore, nowadays a large number of sequences with an unknown function exist. A recent annotation of the Arabidopsis genome suggests that of the 27139 identified functional genes, 7592 (28\%) are predicted as protein of either hypothetical or unknown function (Brown et al., 2005).

By using reverse genetics it is possible to identify the biological function of these genes. The first step is generating individuals in which the sequence of the gene of interest has been altered, or changes in its expression levels lead to increased or decreased function. There are several techniques of reverse genetics that have been useful and described as follows.

\subsection{RNA Interference (RNAi)}

RNA interference is a loss-of-function technique, which is based on the biological process through specific mRNA degradation causing post-transcriptional gene silencing. Small RNA molecules are used as templates by a protein complex enabling it to recognize sequences of RNA, which are targeted for degradation. It is thought that RNA interference evolved as mechanism of defence against viruses and transposable elements (Waterhouse et al., 2001). This technology is based on a control system which modulates gene expression composition (Ketting et al., 1999; Tabara et al., 1999) or gene expression (Palatnik et al., 2003) by small RNA or micro RNAs. There have been many studies based on this technique and it is worth highlighting the researches with Caenorhabditis elegans (Fire et al., 1998) and Petunia hybrida (Napoli et al., 1990), as they were the first works which led to discover this biological pathway. 


\subsection{Gain-of-Function}

The gain-of-function method consists in introducing extra copies of a gene of interest in an individual. Experiments performed to obtain increased levels of gene expression are done in many cases with the constitutive $35 \mathrm{~S}$ promoter from Cauliflower Mosaic Virus (CaMV) (Benfey and Chua, 1990). This results in a mixture of overexpression and ectopic expression of the gene product. Its wide use is due to the fact that it derives from a potent virus with a wide host range both in angiosperms and gymnosperms, and a stable expression in many organs and at different developmental stages (Holtorf et al., 1995). The induced overexpression of a gene increases its activity and confers a new or enhanced activity of the corresponding protein. This kind of manipulation usually results in a dominant effect. Numerous studies have applied this technique in order to identify gene functions, including Drosophila (Rorth et al., 1998) and many plant species (Kondou et al., 2010).

\subsection{TILLING (Targeting Induced Local Lesions in Genomes)}

This technique is based on the generation of a directed chemical mutagenesis of a population of individuals (McCallum et al., 2000) by a chemical mutagen such as ethylmethanesulfonate or acridine orange. After that, the point mutations are recognized via DNA-screening techniques, which involve the formation of DNA heteroduplexes, cleavage by single stranded nucleases and size separation (Till et al., 2003). This reverse genetics method has been widely used in several species including zebrafish (Draper et al., 2004) and wheat (Slade et al., 2005).

\subsection{T-DNA Tagging}

T-DNA is a segment of the Ti plasmid from Agrobacterium that is transferred into the host plant and causes gene mutations. T-DNA tagging technique is based on this natural process and consists in replacing the tumor-promoting and opine-synthesis genes from the T-DNA by a selectable marker such us an antibiotic resistance gene or a fluorescent marker ( $g f p$ or gus gene). This method has been used to identify the biological function of genes in different organism such as Arabidopsis thaliana (Marks and Feldmann, 1989; Koncz et al., 1990), rice (An et al., 2003) or tobacco (Foster et al., 1999).

\subsection{CRISPR/CAS (Clustered Regularly Interspaced Short Palindromic Repeats)}

This technique is based on the defence mechanism in prokaryotes (Horvath and Barrangou, 2010), similar to RNAi in eukaryotes (Marraffini and Sontheimer, 2010). CRISPRs are short palindromic repeats in the prokaryotic genome, followed by short fragments of spacer DNA, which are integrated after a virus infection. Together with the CAS protein, they constitute the prokaryotic immune 
system allowing prokaryotes to recognize exogenous genetic material and cut it, thus preventing infection. The CRISR/CAS technology is being implemented for targeted genome engineering in higher plants such as crop plants (Belhaj et al., 2015). It is based on coexpression of Cas9 nuclease and an engineered single guide RNA that specifies a targeted nucleic acid sequence. Recent studies have shown its usefulness in humans and mice (Cong et al., 2013) and zebrafish (Hwang et al., 2013).

\section{Model Plants and Plants of Industrial Interest}

Model organisms are those that possess properties that facilitate growth and reproduction in laboratory conditions. They are usually robust organisms, with a short reproductive cycle and relatively small genomes. These model organisms are studied in biology to understand particular biological processes, which can be then extrapolated to other individuals. In molecular biology and plant genetics various model organisms are used, including Arabidopsis thaliana, Lotus japonicas or Picea abies.

Among the model plants there are some that also have a high agronomic and/or industrial interest. From the point of view of ornamental crops we could highlight species such as Antirrhinum majus and Petunia hybrida.

Arabidopsis thaliana as a single model plant is unable to represent the wide range of existing angiosperms. Antirrhinum majus is considered an alternative model angiosperm plant and the variety of species from Antirrhinum makes this plant of great interest for studying variation, inheritance and development (Schwarz-Sommer et al., 2003). Antirrhinum majus belongs to the Scrophulariaceae family, native to the Mediterranean region. It was first described as a model plant in the XXth century by Erwin Baur. A total of 500 mutants were described by Hans Stubbe (Stubbe, 1966) and this mutant collection is currently held in Gatersleben (Germany). Antirrhinum majus is a popular ornamental plant and one of the classic models for research in floral development (Carpenter and Coen, 1990). Antirrhinum flowers are zygomorphic, with only one plane of symmetry, and are composed of five sepals, five petals, four stamens and two fused carpels.

The ornamental garden Petunia (Petunia x hybrida Hort. ex Vilm., also presented as Petunia hybrida) is a hybrid between Petunia axilaris and Petunia integrifolia, that has also widely been used as a model system due to the availability of molecular genetics tools including a transformation protocol (Gerats and Vandenbussche, 2005). Petunia flowers present five sepals, five fused petals, five stamens and two carpels with zygomorphic symmetry (Rijpkema et al., 2006) 


\section{Floral Development}

Flower development requires the transformation of a vegetative meristem into a floral meristem in sexually mature plant. Organ identities are than established within the floral meristem that give rise to the several organs that compose the flower. Flower organs are organized in four concentric rings called whorls. From the outer to the inner these are: sepals, petals, stamens and carpel. The identity of the organs that constitute the flower is determined by three conserved genetic functions, which act in combination and are described by the $A B C$ model (Figure 1 ). It suggests that $A$ function genes control the identity of sepals, while a coexpression of A and B function genes controls the identity of petals, stamens result from the coexpression of $B$ and $C$ function genes, and carpels by the expression of C function genes (Haughn and Somerville, 1988). The existence of additional D and $E$ function genes was proposed later (Figure 1). The D function specifies the identity of ovules (Colombo et al., 1995) whereas E function would be necessary for the proper development of the four whorls (Ditta et al., 2004). Floral organ development begins with the activation of the so-called organ identity genes. In Antirrhinum majus these genes correspond to the MADS-box genes DEFICIENS and GLOBOSA, that determine the identity of the petals and stamens, and PLENA, that controls the stamen and carpel identity (Egea Gutierrez-Cortines and Davies, 2000). Petunia is a special case because there has been a complete gene duplication of B function genes involved in petal and stamen identity (Bombarely et al., n.d.). The four B function genes in Petunia are: Petunia hybrida TOMATO MADS-BOX GENE6 (PhTM6), and Petunia hybrida DEFICIENS (PhDEF), paralogs of APETALA3 (AP3) and DEFICIENS, and Petunia hybrida GLOBOSA1 (PhGLO1) and Petunia hybrida GLOBOSA2 (PhGLO2), paralogs of PISTILLATA (PI) and GLOBOSA (GLO) (Rijpkema et al., 2007), being PhGLO loss of function alleles those that as single mutants have stronger phenotypes in petal development (Vandenbussche et al., 2004). Petal morphogenesis occurs in several stages with an initial stage of cell division followed by a further stage in which growth occurs by cell expansion. That growth mode is common in Arabidopsis, Antirrhinum, Gerbera and Petunia indicating that it is a general growth characteristic of that organ (Egea-Cortines and Weiss, 2013).

A serial of processes are triggered during later stages of floral development that lead to the formation of mature flowers which are able to be pollinated and thereby ensure the continuity of the species. These processes include petal expansion, stamen filament elongation, anther dehiscence and gynoecium maturation. Arabidopsis studies revealed that jasmonate plays an important role during late stage in flower development (Brioudes et al., 2009). Mutations in DEFECTIVE IN ANTHER DEHISCENCE 1(DAD1) or DELAYED DEHISCENCE 1 (DDE1), two genes involved in the first steps of the synthesis of jasmonic acid, cause defects in anther dehiscence, pollen maturation and floral aperture 


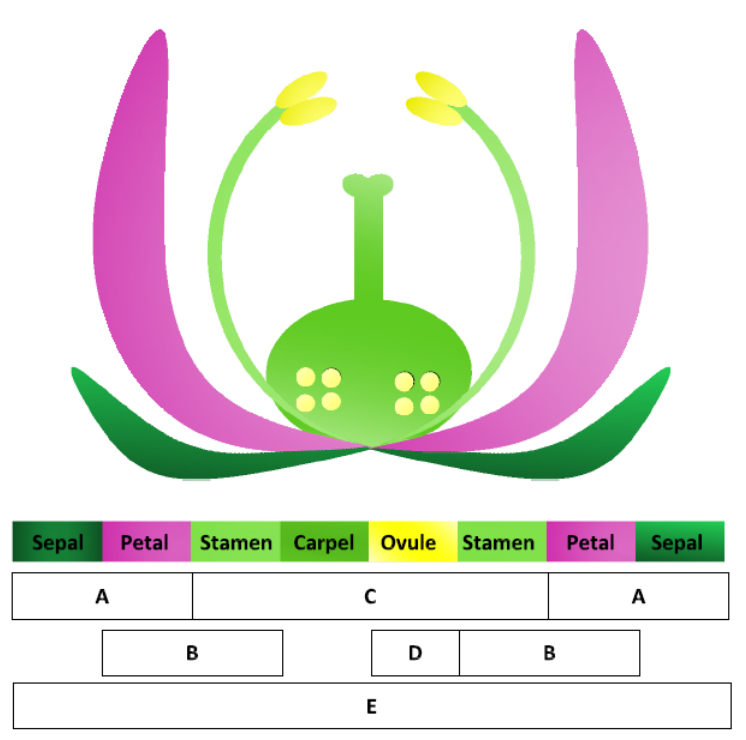

Figure 1: $A B C D E$ model of flower development

in Arabidopsis (Sanders, 2000; Ishiguro, 2001). This phytohormone is induced by the transcription factors AUXIN RESPONSE FACTOR 6 and 8 (ARF6 and ARF8) which trigger the expression of MYB21 and MYB24 provoking petal and stamen maturation (Reeves et al., 2012). The TRANSPORT INHIBITOR RESPONSE 1/AUXIN SIGNALING F-BOX (TIR1/AFB) family of F-box protein is an auxin receptors and studies with tir1 afb2 afb3 triple and tir1 afb1 afb2 afb3 quadruple mutants show that auxins are involved in anther dehiscence and pollen maturation (Cecchetti et al., 2008).

Once anthesis is achieved, floral organs start emitting scent. The emission of floral scent occurs from different floral organs including petals, stamens and pistils (Pichersky et al., 1994). It is believed that emission of floral scent is controlled by the type of organ, but direct proof is lacking. Scent emission makes a sudden debut as the profile specific of a species appears as such once flowers open (Weiss et. al personal communication). Amongst the volatiles produced by Antirrhinum are methylbenzoate, ocimene and myrcene (Wright et al., 2005).

\section{Petal Development}

The B function genes described in Arabidopsis thaliana are APETALA 3 (AP3) (Jack et al., 1992) and PISTILLATA (PI), whereas in Antirrhinum majus there are the orthologs DEFICIENS (DEF) (Sommer et al., 1990) and GLOBOSA (GLO) (Trobner et al., 1992), belonging to the MADS-box gene family of transcription factors.

DEFICIENS is a homeotic gene involved in the control of floral development, concretely in petal and stamen development; hence mutations of this gene lead to sepaloid petals and carpelloid stamens. Three morphoalleles are known in Antirrhinum which differ morphologically in the extend of 
modification of the different organs (Sommer et al., 1991). deficiens ${ }^{\text {chlorantha }}\left(\right.$ def $f^{\text {chl}}$ ) has flowers of reduced size, petals with sepaloid features and reduced male fertility due to feminized stamens. Flowers of the mutant deficiens ${ }^{\text {nicotianoides }}\left(\right.$ def $^{\text {nic }}$ ) have greenish sepal-like petals, and badly developed stamens, and deficiens ${ }^{\text {globifera }}\left(\right.$ def $^{\text {gli }}$ ) reveals the strongest phenotype (Baur, 1924; Hertwig, 1926). The $d e f^{g l i}$ allele has two whorls of sepals and one whorl of carpels, being the fourth whorl suppressed.

GLOBOSA is, as well as DEFICIENS, a homeotic gene and since their mutants show a similar phenotype it is thought that both genes have an equivalent function in floral morphogenesis. Similar to def $f^{g l i}$, the mutant glo-1 is a null allele that presents petals hardly distinguishable from the first whorl of organs (Tröbner et al., 1992).

MIXTA is a Myb-related transcription factor involved in the control of conical epidermal cell shape of Antirrhinum majus (Noda et al., 1994). This gene is also expressed in petals, affecting the formation of trichomes (Martin et al., 2002).

The gene AINTEGUMENTA (ANT) is an APETALA2 transcription factor, originally identified in a screen for female sterile plants, and is required for ovule initiation in Arabidopsis (Klucher et al., 1996; Elliott et al., 1996). Later works have shown that the overexpression of ANT in Arabidopsis causes increases in organ size while its loss of function results in decreased size because this gene regulates both cell division and cell expansion during the organogenesis (Krizek, 1999; Mizukami and Fischer, 2000). $A R G O S$ is an auxin-induced gene that has also been related with organ size control. It acts upstream of $A N T$ as an increase in organ size induced by overexpression of $A R G O S$ is revoked by the loss of function of $A N T$ (Hu et al., 2003). Therefore, $A N T$ is a gene downstream of auxin signalling.

\section{Control of Lateral Organ Size}

\subsection{Size}

There are many evidences showing that lateral floral organs grow as a result of an initial increase in cell number, followed by cell expansion. This is true in Arabidopsis leaves or Arabidopsis, Petunia and Gerbera petals (Laitinen et al., 2005; Reale et al., 2002; Kazama et al., 2010; Anastasiou et al., 2007). The organs appear to have a specific time, during which they have to reach a certain number of cells before proceeding to cellular expansion. The transition from cell division to cellular expansion in Arabidopsis leaves starts at the distal part and ends at the pedicel (Andriankaja et al., 2012). This transition happens very quickly and is highly coordinated. 


\subsection{Control of cell division}

It is important to make a distinction between cellular growth and cellular expansion, because proliferating cells need to grow before dividing. This growth is an increase in the cytoplasmic mass. In contrast, the cellular expansion is based on an increase in cellular volume by vacuolation (SugimotoShirasu and Roberts, 2003).

The triggering of cell proliferation in Arabidopsis includes a cascade of genes downstream of the phytohormone auxin. This cascade starts with ARGOS (Hu et al., 2006). Sense or antisense constructs in transgenic plants cause elongation or reduction of lateral organs. ARGOS upregulates AINTEGUMENTA (ANT), a gene that affects the period of cell proliferation (Mizukami and Fischer, 2000). Another gene promoting cell division is GROWTH REGULATION FACTOR 5 from Arabidopsis (AtGRF5), a putative transcription factor, whose overexpression results in the induction and/or maintenance of cell proliferation activity in leaf priomordia. Similar effects has ANGUSTIFOLIA3/GRFINTERACTING FACTOR1 (AN3/GIF1), a homologue of the human transcriptional coactivator SYNOVIAL SARCOMA TRANSLOCATION (SYT), that interacts with AtGRF (Horiguchi et al., 2005). Inducing cell division in an organ is regulated by JAGGED (JAG), a putative $\mathrm{C}_{2} \mathrm{H}_{2}$ zinc-finger transcription factor, and NUBBIN (NUB), a gene closely related to $J A G$, and acting in a redundant way in growing areas of lateral organs in Arabidopsis. However, another mechanism to promote cell division is controlled by the gene $K L U H(K L U)$ from Arabidopsis, a P450 cytochrome. Loss-of-function mutants of klu show a premature stop in cell division and smaller organs, whereas overexpression of $K L U$ produces larger organs with more cells. (Anastasiou et al., 2007; Kazama et al., 2010). Gene products that limit cell division usually are not uniformly distributed over organs or organ parts, for example stopping of cell division in leaves starts at the tip and involves TCP class II genes as CINCINNATA (CIN) of Antirrhinum, whose loss of function leads to prolonged proliferation in the leaf margin (Nath et al., 2003). The double mutant of Arabidopsis PEAPOD 1 and 2 shows an increment in the internal division of the leaf margin, which gives bell shaped leaves (White, 2006).

The miR396 miRNA antagonizes the expression pattern of transcription factor GRF and preferably is accumulated in the distal parts of the leaf by the attenuation of cell division (Rodriguez et al., 2010). The dominant mutant GRANDIFLORA (GRAF) of Antirrhinum shows an increment in cell division especially in stamens and style, indicating that GRAF limits cell division in an organ specific manner (Delgado-Benarroch, et al., 2009). Finally the FORMOSA (FO) gene of Antirrhinum specifically regulates flower size by inhibiting cell division and this inhibition is due to a downregulation of AmANT (Delgado-Benarroch, et al., 2009). A more general action upon size by restricting cell proliferation is conferred by the gene DA1 (DA means 'large' in Chinese) in Arabidopsis. This gene 
encodes an ubiquitin receptor and affects seed and organ size in parallel with BIG BROTHER (BB) and its allelic gene Enhancer of $D A 1$ (EOD1). The expression of $D A 1$ is induced by the growth regulator abscisic acid $(A B A)$, establishing a connection between $A B A$ and limiting the proliferative growth during organogenesis (Li et al., 2008).

Although we might conclude that the control of cell proliferation seems to be well preserved, this is not translated into a uniform pattern through a specific organ.

\subsection{Control of cell expansion}

The genetic control of cell expansion can also be divided into promoting and limiting factors. A promoting factor is the level of ploidy. Although the exact mechanism is not known yet, defects in the separation of chromatin based on double mutations that affect topoisomerase $\mathrm{VI}$ (topo $\mathrm{VI}$ ) restricts the endoreduplication to two cycles and decreases cell growth (Sugimoto-Shirasu et al., 2002).

The expansin superfamily is a group of genes involved in cell wall loosening through their effect on synthesis or on cellulose deposition. The decreased expression of the expansin gene PhEXP1 $\alpha$ of Petunia hybrida causes smaller cells and reduces the size of the petals (Zenoni et al., 2004). Members of two families of genes that stimulate both proliferation and cell enlargement have been found, which indicates a common regulatory mechanism for these two processes. The gene family of Arabidopsis GRF, which comprises nine members, includes the stimulator of cell division AtGRF5, while AtGRF1, 2 and 3 affect the expansion, as shown by decreased cell size in leaf tissue and cotyledons of the triple mutant (Kim et al., 2003). Similarly, while ARGOS promotes cell proliferation, overexpression of ARGOSLIKE (ARL), a gene suggested to partially mediate brassinosteroid signalling and promoting cell expansion during organ growth, produces larger organs due to larger cells (Hu et al., 2006). These examples show that a particular gene or a gene family can promote both cell division and cell expansion. In addition, action on cell division or cell expansion of a particular gene can be organ type specific or organ region specific. The mutant Grandiflora (Graf) from Antirrhinum produces larger cells in petals and increases cell division in stamens and styles, providing one of the few links between genes that control the size of the organ and organ identity (Delgado-Benarroch, et al., 2009). The FORMOSA (FO) gene of Antirrhinum is a specific regulator of floral size in an organ region specific way, either as an inhibitor of cell division in the whole flower or as activator of cell expansion in conical cells of petals and the style (Delgado-Benarroch, et al., 2009). The COMPACTA $\ddot{A} H N L I C H$ gene of Antirrhinum shows a promotion of cell expansion specific to an organ region. Mutations in this gene affect cell expansion in the proximal and distal regions of the petal, which 
leads to a petal size reduction. This suggests a differential regulation between petal lobe regions (Delgado-Benarroch, et al., 2009).

A limitation of cell expansion is also generated by BIGPETAL, a gene producing two mRNAs by alternative splicing, BPEup and BPEp. The first transcript appears in the whole plant while the second is preferably in petals. Lack of BPEp leads to bigger petals due to an increment in cell size (Szecsi et al., 2006). Accumulation of BPEP mRNA is under the control of the identity of floral organs, providing a link between transcription pathways that regulate organ identity and are involved in growth resulting in a distinction between organ form and organ size. In accordance with this interpretation, a reduction in cell expansion in specific floral organs of the Antirrhinum mutant formosa coincides with a positive regulation of AmBPE (Delgado-Benarroch, et al., 2009). The phytohormone jasmonate is required for controlling the expression of BPEP, thus BPEP is downstream of jasmonate in the signalling cascade during petal growth (Brioudes et al., 2009). Summarizing, recent work in Arabidopsis proposes a cascade of events involved in the morphogenesis of the side organs where the meristem identity is regulated by a signal from cytokinins. That signal decays during the formation of lateral primordia, increasing auxin signal. This is replaced by a gibberellin signal that leads to processes controlled by methyl jasmonate (Reeves et al., 2012; Nagpal et al., 2005; RubioSomoza and Weigel, 2013). These routes appear to be coordinated by at least three miRNAs (RubioSomoza and Weigel, 2013). The miR167 controls ARF6/ARF8 genes involved in auxin signalling (Wu et al., 2006). The miR159 is regulated by gibberellins (Achard et al., 2004). The loss of function in miR159a and b, two micro RNAs that target MYB33 and MYB65, show developmental defects (Allen et al., 2007). The miR319a is required for proper development of the petal and it targets TCP4, a member of the TCP transcription factor family which is called so because of the first characterized members (TEOSINTE BRANCHED 1 (TB1), CYCLOIDEA (CYC) and PROLIFERATING CELL FACTORS 1 and 2 (PCFs) (Cubas et al., 1999), for degradation (Nag et al., 2009).

Finally the AtE2Ff gene, an atypical member of the E2F transcription factors family, among others, affects cell size by controlling cell cycle transitions in an organ-specific manner. In the e2ff-1 mutant, hypocotyls are larger than wild-type, while overexpression leads to a reduction of hypocotyls due to changes in cell expansion. Since several genes involved in cell wall biosynthesis are direct targets of AtEF2f, it has been suggested that this gene may limit cell growth through direct suppression of cell wall biosynthesis (Fru et al., 2004) 


\section{Genetic Analysis of Developmental Processes}

Mutant plants are described as plants that have at least one variation in their DNA respect to the wild-type line, and show a phenotype for a given character. This variation may lead to a complete lack of gene functioning. The mutations can be classified into:

Conditional mutation: mutation that depend on the environmental conditions.

- Deleterious mutation: affects reproduction capacity of the individual.

- Lethal mutation: causes unviable organisms at a certain stage.

- Morphological mutation: affects the morphology of the individual.

- Loss of function mutation: reduces the function of a gene, and in most cases show recessive segregations.

- Gain of function mutation: on rare occasions a mutation can lead to overexpression of a gene and/or ectopic expression. These alleles tend to show dominant segregation. .

The analysis of mutant plants begins with phenotypic studies and segregation analysis in F2 populations resulting from crosses between the mutant and the wild-type.

Relating a mutant phenotype to a specific genotype includes methods belonging to forward and reverse genetics (see section 2 for methods in reverse genetics) such as site-directed mutagenesis, gene silencing by RNA interference or gain-of-function, with the purpose to cause null or amorph (total loss-of-function gene), hypomorphic (partial loss-of-function gene), neomorphic (causes a dominant gain of gene function that is different from the normal function) or hypermorphic (gain-offunction) phenotype. Once the gene related to a specific mutant phenotype has been identified, its relationship to other non-allelic genes that might interfere with the observed phenotype, as well as the order of gene function within a functional pathway needs to be investigated. Epistatic gene interactions occur if a gene (epistatic) inhibits the expression of another gene (hypostatic) from a different locus. Several types of epistasis exist, including single-recessive epistasis, if a recessive allele blocks the expression of another gene, single-dominant epistasis, if the dominant allele prevents the expression of the hypostatic gene, double-recessive epistasis, produced by the double action of recessive alleles over any other allele, double-dominant epistasis, a case of gene redundancy, when the presence of at least a dominant allele masks the expression of another gene, and double dominant recessive, if the dominant allele of a locus and the recessive of another one respectively suppresses the action of the other alleles. 
It has to be considered that, when two or more redundant genes encode the same protein, loss-offunction mutants do not show the desired reduction of gene expression. One of the reasons why genetic redundancy could be maintained by selection may be due to pleiotropic actions of the involved genes (Vavouri et al., 2008).

In order to know in depth the interactions between genes and the order of gene function, double mutants are generated including those with loss- or gain-of-function of the target genes. There have been many studies using this technique over the years in yeast (Game and Cox, 1972), mice (Murphy et al., 2003), rice (Lin et al., 2000), tomato (Kachanovsky et al., 2012) and human (Papaleo et al., 2014).

\section{Plant Transformation}

The ability to regenerate plants in cell culture, coupled with the unique characteristics of the natural process of tumorigenesis induced by Agrobacterium species, laid the groundwork for the development of a whole methodology aimed at obtaining transgenic plants, in which the works done by the groups of Jeff Schell (Max-Planck Institute, Colonia) and Van Montagu (Universidad de Gante) have been decisive (Schell et al., 1979; Hernalsteens et al., 1980; Herrera-Estrella et al., 1983). Ti plasmid attenuation by eliminating oncogenic T-DNA genes, and the replacement of these by the gene transfer, led to the development of binary vectors of suitable size which are used in this natural transformation system. The system also requires a promoter recognizable by DNA polymerase; it is common to use a constitutive promoter such as CaMV 35 S promoter, in which characterization the Nam-Hai Chua group played a fundamental role (Benfey and Chua, 1990). Isolation of tissue-specific promoters which allow expression of the transgene in the appropriate time and place has become an important and economically interesting task, as the future of transgenic plants lies in utilizing promoters that show an activity in the situation and the tissue that the breeder needs.

Transferring genes by Agrobacterium bacteria is routinely performed in vegetables such as tomato, melon, cucumber and watermelon as well as in other important crop species such as corn, soybean, cotton and sunflower. Species of interest such as cereals or legumes however are difficult to transform through this system, although the problem appears to lie in the process of plant regeneration rather than in the transformation process. That is why alternative strategies have been developed to introduce DNA directly into the cells, either through microinjection using microprojectiles coated with the DNA for DNA transfer or by direct transformation of tissues in transient expression assays (Xiong et al., 2013; Davies et al., 2013; Wefers et al., 2013). 
It is worthwhile commenting on the leading role that reverse genetics has had in plant genetics from the mid-80s onward, since the existence of many enzymes and well characterized proteins enabled the isolation of the corresponding cDNA and the development of loss and gain of function experiments by antisense expression, co-suppression and ectopic expression. This led to the identification of genes whose potential for agriculture was unknown a priori. To this the development of the RNA interference technique, a new powerful molecular tool that allows to silence genes at the post-transcriptional level and identify functions associated with these genes, must also be mentioned. The RNA interference strategy is based on the degradation of messenger RNA by introducing a small homologous double chain RNA (siRNA) to the cellular messenger RNA of interest, causing the degradation of a sequence in a specific manner. Craig C. Mello and Andrew Fire received the Nobel Prize in Physiology or Medicine in 2006 for their discovery of siRNA (Grishok et al., 2001).

Genetic transformation of plants and the cultivation of genetically modified varieties of tomato, corn, soybeans, cotton, rice, oilseed rape, sugar beet and alfalfa also has attracted excessive controversy. The scientific achievements, including herbicide resistance obtained by transfer of genes whose products detoxify the herbicide or block the receptor on which it acts, must be mention in this section. In the field of plant pathology, the initial interest was captured by transgenic crops expressing the protein Bti from Bacillus thurigiensis var. israeliensis whose toxicity and accumulation in the digestive tract of the insects causes death, and therefore the resistance of plants. More recently plant resistance to certain viruses has been achieved. The process by which transgenic plants expressing viral capsid proteins achieve immunity is still not well understood (Mason et al., 1996).

Some other characters worth of mentioning in this section are those related to the quality of agricultural products. The molecular characterization of genes involved in fruit ripening process has led to the production of transgenic varieties called 'long life', especially in tomato. Here transgenesis prevents degradation of the fruit wall through strategies provoking antisense expression which can inhibit the biosynthesis of pectins and polygalacturonic acid, main components of the cell wall, or enzymes of the ethylene biosynthetic pathway, a hormone triggering the maturation process.

\section{Problems Associated with Transformation}

Handling of different microbial strains in the laboratory can turn into a problem when different bacteria become contaminated with each other. In most cases, contamination of bacterial strains is the result of sharing plasticware, pipettes and solutions. Furthermore, although different bacterial 
genera can be grown on specific media, simplicity has led to a generalized use of common growth media as long as they do not interfere with bacterial properties. Two types of bacterial genera are routinely used in plant biology laboratories, Escherichia coli used for general cloning and Agrobacterium tumefaciens to obtain transgenic plants. But one obvious problem is that if Agrobacterium strains are contaminated with E. coli, then some of the processed colonies will not transform plants giving as result a very low or null transformation efficiency.

\section{Introduction References}

Achard, P., Herr, A., Baulcombe, D.C. and Harberd, N.P. (2004) Modulation of floral development by a gibberellin-regulated microRNA. Development, 131, 3357-65.

Adams, M.D., Kelley, J.M., Gocayne, J.D., et al. (1991) Complementary DNA sequencing: expressed sequence tags and human genome project. Sci. , 252 , 1651-1656. Available at: http://www.sciencemag.org/ content/252/5013/1651.abstract.

Aida, M., Beis, D., Heidstra, R., et al. (2004) The PLETHORA genes mediate patterning of the Arabidopsis root stem cell niche. Cell, 119, 109-120.

Allen, R.S., Li, J., Stahle, M.I., Dubroué, A., Gubler, F. and Millar, A.A. (2007) Genetic analysis reveals functional redundancy and the major target genes of the Arabidopsis miR159 family. Proc. Natl. Acad. Sci. U. S. A., 104, 16371-6.

Alon, U. (2007) Network motifs: theory and experimental approaches. Nat Rev Genet, 8, 450-461.

Altschul, S.F., Gish, W., Miller, W., Myers, E.W. and Lipman, D.J. (1990) Basic local alignment search tool. J. Mol. Biol., 215, 403-410.

An, S., Park, S., Jeong, D.-H., et al. (2003) Generation and Analysis of End Sequence Database for T-DNA Tagging Lines in Rice. Plant Physiol. , 133 , 2040-2047. Available at: http://www.plantphysiol.org/content/ 133/4/2040.abstract.

Anastasiou, E., Kenz, S., Gerstung, M., Maclean, D., Timmer, J., Fleck, C. and Lenhard, M. (2007) Control of Plant Organ Size by KLUH/CYP78A5-Dependent Intercellular Signaling. Dev. Cell, 13, 843-856.

Andriankaja, M., Dhondt, S., Bodt, S. De, et al. (2012) Exit from proliferation during leaf development in Arabidopsis thaliana: a not-so-gradual process. Dev. Cell, 22, 64-78.

Anon (1999) The FlyBase database of the Drosophila Genome Projects and community literature. Nucleic Acids Res., 27, 85-88.

Ashburner, M., Ball, C.A., Blake, J.A., et al. (2000) Gene ontology: tool for the unification of biology. The Gene Ontology Consortium. Nat. Genet., 25, 25-9.

Ball, C.A., Dolinski, K., Dwight, S.S., et al. (2000) Integrating functional genomic information into the Saccharomyces Genome Database. Nucleic Acids Res. , 28 , 77-80. Available at: http:// nar.oxfordjournals.org/content/28/1/77.abstract.

Baumann, K., Perez-Rodriguez, M., Bradley, D., Venail, J., Bailey, P., Jin, H.L., Koes, R., Roberts, K. and Martin, C. (2007) Control of cell and petal morphogenesis by R2R3 MYB transcription factors. Development, 134, 1691-1701. 
Baur, E. (1924) Untersuchungen iiber das Wesen, die Entstehung und die Vererbung yon Rassenunterschieden bei Antirrhinum magus. Bibl. Genet. IV.

Bayo-Canha, A., Delgado-Benarroch, L., Weiss, J. and Egea-Cortines, M. (2007) Artificial decrease of leaf area affects inflorescence quality but not floral size in Antirrhinum majus. Sci. Hortic. (Amsterdam)., 113, 383386.

Belhaj, K., Chaparro-Garcia, A., Kamoun, S., Patron, N.J. and Nekrasov, V. (2015) Editing plant genomes with CRISPR/Cas9. Curr. Opin. Biotechnol., 32, 76-84.

Benfey, P.N. and Chua, N.-H. (1990) The cauliflower mosaic virus 35S promoter: combinatorial regulation of transcription in plants. Science (80-. )., 250, 959.

Blake, J.A., Eppig, J.T., Richardson, J.E., Davisson, M.T. and the Mouse Genome Database Group (2000) The Mouse Genome Database (MGD): expanding genetic and genomic resources for the laboratory mouse. Nucleic Acids Res. , 28 , 108-111. Available at: http://nar.oxfordjournals.org/content/28/1/108.abstract.

Bombarely, A., Moser, M., Amrad, A., Bapaume, L. and Barry, C.S. Whole genome sequences of the wild parents of the garden petunia give insights into the evolution of Solanaceae genomes.

Bradley, D., Carpenter, R., Sommer, H., Hartley, N. and Coen, E. (1993) Complementary floral homeotic phenotypes result from opposite orientations of a transposon at the plena locus of Antirrhinum. Cell, 72, 85-95.

Brioudes, F., Joly, C., Szécsi, J., Varaud, E., Leroux, J., Bellvert, F., Bertrand, C., Bendahmane, M. and Szecsi, J. (2009) Jasmonate controls late development stages of petal growth in Arabidopsis thaliana. Plant J.

Brown, D.M., Zeef, L.A.H., Ellis, J., Goodacre, R. and Turner, S.R. (2005) Identification of Novel Genes in Arabidopsis Involved in Secondary Cell Wall Formation Using Expression Profiling and Reverse Genetics. Plant Cell , 17 , 2281-2295. Available at: http://www.plantcell.org/content/17/8/2281.abstract.

Carpenter, R. and Coen, E.S. (1990) Floral homeotic mutations produced by transposon-mutagenesis in Antirrhinum majus. Genes Dev., 4, 1483.

Castresana, J. (2000) Selection of conserved blocks from multiple alignments for their use in phylogenetic analysis. Mol. Biol. Evol., 17, 540-552.

Causier, B., Cook, H. and Davies, B. (2003) An Antirrhinum ternary complex factor specifically interacts with Cfunction and SEPALLATA-like MADS-box factors. Plant Mol. Biol., 52, 1051-1062.

Causier, B., Schwarz-Sommer, Z. and Davies, B. (2010) Floral organ identity: 20 years of ABCs. Semin Cell Dev Biol, 21, 73-79.

Cecchetti, V., Altamura, M.M., Falasca, G., Costantino, P. and Cardarelli, M. (2008) Auxin Regulates Arabidopsis Anther Dehiscence, Pollen Maturation, and Filament Elongation. Plant Cell , 20 , 1760-1774. Available at: http://www.plantcell.org/content/20/7/1760.abstract.

Chevenet, F., Brun, C., Bañuls, A.-L., Jacq, B. and Christen, R. (2006) TreeDyn: towards dynamic graphics and annotations for analyses of trees. BMC Bioinformatics, 7, 439.

Coen, E.S. and Meyerowitz, E.M. (1991) The War of the Whorls - Genetic Interactions Controlling Flower Development. Nature, 353, 31-37.

Colombo, L., Franken, J., Koetje, E., Went, J. van, Dons, H.J., Angenent, G.C. and Tunen, A.J. van (1995) The petunia MADS box gene FBP11 determines ovule identity. Plant Cell, 7, 1859-1868. Available at: http://www.ncbi.nlm.nih.gov/pmc/articles/PMC161044/. 
Cong, L., Ran, F.A., Cox, D., et al. (2013) Multiplex Genome Engineering Using CRISPR/Cas Systems. Sci. , 339 , 819-823. Available at: http://www.sciencemag.org/content/339/6121/819.abstract.

Consortium, T.G.O. (2001) Creating the Gene Ontology Resource: Design and Implementation. Genome Res., 11, 1425-1433. Available at: http://genome.cshlp.org/content/11/8/1425.abstract.

Cubas, P., Lauter, N., Doebley, J. and Coen, E. (1999) The TCP domain: a motif found in proteins regulating plant growth and development. Plant J., 18, 215-222.

Davies, B., Davies, G., Preece, C., Puliyadi, R., Szumska, D. and Bhattacharya, S. (2013) Site specific mutation of the Zic2 locus by microinjection of TALEN mRNA in mouse $C D 1, C 3 H$ and $C 57 B L / 6 \mathrm{~J}$ oocytes. PLoS One, 8, e60216. Available at: http://dx.doi.org/10.1371/journal.pone.0060216 [Accessed October 7, 2015].

Delgado-Benarroch, L., Causier, B., Weiss, J. and Egea-Cortines, M. (2009) FORMOSA controls cell division and expansion during floral development in Antirrhinum majus. Planta, 229, 1219-1229.

Delgado-Benarroch, L., Weiss, J. and Egea-Cortines, M. (2009) Floral organ size control: interplay between organ identity, developmental compartments and compensation mechanisms. Plant Signal. Behav., 9, 14.

Delgado-Benarroch, L., Weiss, J. and Egea-Cortines, M. (2010) Sizing up the flower. In M. Yaish and J. Colasanti, eds. The Flowering Process and its Control in Plants: Gene Expression and Hormone Interaction.

Delgado-Benarroch, L., Weiss, J. and Egea-Cortines, M. (2009) The mutants compacta ähnlich, Nitida and Grandiflora define developmental compartments and a compensation mechanism in floral development in Antirrhinum majus. J. Plant Res., 122, 559-69.

Dereeper, A., Audic, S., Claverie, J.-M. and Blanc, G. (2010) BLAST-EXPLORER helps you building datasets for phylogenetic analysis. BMC Evol. Biol., 10, 8.

Dereeper, A., Guignon, V., Blanc, G., et al. (2008) Phylogeny.fr: robust phylogenetic analysis for the nonspecialist. Nucleic Acids Res., 36, W465-9.

Disch, S., Anastasiou, E., Sharma, V.K., Laux, T., Fletcher, J.C. and Lenhard, M. (2006) The E3 ubiquitin ligase BIG BROTHER controls Arabidopsis organ size in a dosage-dependent manner. Curr. Biol., 16, 272-279.

Ditta, G., Pinyopich, A., Robles, P., Pelaz, S. and Yanofsky, M.F. (2004) The SEP4 Gene of Arabidopsis thaliana Functions in Floral Organ and Meristem Identity. Curr. Biol., 14, 1935-1940. Available at: http://www.sciencedirect.com/science/article/pii/S0960982204008152.

Dona, D.H., Dunwell, J. and Gibbings, J. (2010) Characterization of Aintegumenta-like Gene in Coconut (Cocos nucifera L) and Its Expression During Embryogenesis. Vitr. Cell. Dev. Biol., 46, S123-S124.

Dornelas, M.C., Patreze, C.M., Angenent, G.C. and Immink, R.G.H. (2011) MADS: the missing link between identity and growth? Trends Plant Sci., 16, 89-97.

Draper, B.W., McCallum, C.M., Stout, J.L., Slade, A.J. and Moens, C.B. (2004) A high-throughput method for identifying N-ethyl-N-nitrosourea (ENU)-induced point mutations in zebrafish. Methods Cell Biol., 77, 91112.

Dubois, A., Raymond, O., Maene, M., Baudino, S., Langlade, N.B., Boltz, V., Vergne, P. and Bendahmane, M. (2010) Tinkering with the C-Function: A Molecular Frame for the Selection of Double Flowers in Cultivated Roses. PLoS One, 5.

Edgar, R.C. (2004) MUSCLE: multiple sequence alignment with high accuracy and high throughput. Nucleic Acids Res., 32, 1792-1797. 
Egea Gutierrez-Cortines, M. and Davies, B. (2000) Beyond the ABCs: ternary complex formation in the control of floral organ identity. Trends Plant Sci., 5, 473-478.

Egea Gutierrez-Cortines, M., Davies, B. and Gutierrez-Cortines, M.E. (2000) Beyond the ABCs: ternary complex formation in the control of floral organ identity. Trends Plant Sci., 5, 473-478.

Egea-Cortines, M., Saedler, H. and Sommer, H. (1999) Ternary complex formation between the MADS-box proteins SQUAMOSA, DEFICIENS and GLOBOSA is involved in the control of floral architecture in Antirrhinum majus. EMBO J., 18, 5370-5379.

Egea-Cortines, M. and Weiss, J. (2013) Control of plant organ size. eLS. Wiley.

Elliott, R.C., Betzner, A.S., Huttner, E., Oakes, M.P., Tucker, W.Q.J., Gerentes, D., Perez, P. and Smyth, D.R. (1996) AINTEGUMENTA, an APETALA2-like gene of Arabidopsis with pleiotropic roles in ovule development and floral organ growth. Plant Cell, 8, 155-168.

Feng, X., Wilson, Y., Bowers, J., Kennaway, R., Bangham, A., Hannah, A., Coen, E. and Hudson, A. (2009) Evolution of Allometry in Antirrhinum. Plant Cell, 21, 2999-3007.

Ferjani, A., Horiguchi, G., Yano, S. and Tsukaya, H. (2007) Analysis of leaf development in fugu mutants of Arabidopsis reveals three compensation modes that modulate cell expansion in determinate organs. Plant Physiol., 144, 988-999.

Ferrario, S., Immink, R.G.H., Shchennikova, A., Busscher-Lange, J. and Angenent, G.C. (2003) The MADS box gene FBP2 is required for SEPALLATA function in petunia. Plant Cell, 15, 914-925.

Fire, A., Xu, S., Montgomery, M.K., Kostas, S.A., Driver, S.E. and Mello, C.C. (1998) Potent and specific genetic interference by double-stranded RNA in Caenorhabditis elegans. Nature, 391, 806-811. Available at: http://dx.doi.org/10.1038/35888.

Foster, E., Hattori, J., Labbé, H., Ouellet, T., Fobert, P.R., James, L.E., Iyer, V.N. and Miki, B.L. (1999) A tobacco cryptic constitutive promoter, tCUP, revealed by T-DNA tagging. Plant Mol. Biol., 41, 45-55. Available at: http://europepmc.org/abstract/MED/10561067.

Fru, C., Ramirez-Parra, E., Lo, M.A., Lopez-Matas, M.A., Frundt, C., Gutierrez, C., López-Matas, M.A. and Fründt, C. (2004) Role of an atypical E2F transcription factor in the control of arabidopsis cell growth and differentiation. Plant Cell, 16, 2350-2363.

Gaj, T., Gersbach, C.A. and Barbas, C.F. (2013) ZFN, TALEN, and CRISPR/Cas-based methods for genome engineering. Trends Biotechnol., 31, 397-405.

Galimba, K.D., Tolkin, T.R., Sullivan, A.M., Melzer, R., Theissen, G. and Stilio, V.S. Di (2012) Loss of deeply conserved C-class floral homeotic gene function and $\mathrm{C}$ - and E-class protein interaction in a doubleflowered ranunculid mutant. Proc. Natl. Acad. Sci. U. S. A., 109, E2267-E2275.

Galinha, C., Hofhuis, H., Luijten, M., Willemsen, V., Blilou, I., Heidstra, R. and Scheres, B. (2007) PLETHORA proteins as dose-dependent master regulators of Arabidopsis root development. Nature, 449, 10531057.

Galliot, C., Hoballah, M.E., Kuhlemeier, C. and Stuurman, J. (2006) Genetics of flower size and nectar volume in Petunia pollination syndromes. Planta, 225, 203-212.

Galliot, C., Stuurman, J. and Kuhlemeier, C. (2006) The genetic dissection of floral pollination syndromes. Curr. Opin. Plant Biol., 9, 78-82.

Game, J.C. and Cox, B.S. (1972) Epistatic interactions between four rad loci in yeast. Mutat. Res. Mol. Mech. 
Mutagen., 16, 353-362. Available at: http://www.sciencedirect.com/science/article/pii/ 0027510772 902035 [Accessed October 14, 2015].

Gawenda, I., Schroder-Lorenz, A. and Debener, T. (2012) Markers for ornamental traits in Phalaenopsis orchids: population structure, linkage disequilibrium and association mapping. Mol. Breed., 30, 305-316.

Gerats, T. and Vandenbussche, M. (2005) A model system for comparative research: Petunia. Trends Plant Sci., 10, 251-6. Available at: http://www.ncbi.nlm.nih.gov/pubmed/15882658 [Accessed November 5, 2014].

Grishok, A., Pasquinelli, A.E., Conte, D., et al. (2001) Genes and mechanisms related to RNA interference regulate expression of the small temporal RNAs that control C. elegans developmental timing. Cell, 106, 23-34.

Guindon, S. and Gascuel, O. (2003) A Simple, Fast, and Accurate Algorithm to Estimate Large Phylogenies by Maximum Likelihood. Syst. Biol., 52, 696-704.

Harris, M.A., Clark, J., Ireland, A., et al. (2004) The Gene Ontology (GO) database and informatics resource. Nucleic Acids Res., 32, D258-61. Available at: http://nar.oxfordjournals.org/cgi/content/long/32/ suppl_1/D258 [Accessed February 23, 2015].

Hartmann, H.T. and Kester, D.E. (1975) Plant propagation: principles and practices. 3rd edition.

Haughn, G.W. and Somerville, C.R. (1988) Genetic control of morphogenesis in Arabidopsis. Dev. Genet., 9, 7389. Available at: http://dx.doi.org/10.1002/dvg.1020090202.

Helliwell, C. and Waterhouse, P. (2003) Constructs and methods for high-throughput gene silencing in plants. Methods, 30, 289-295.

Hermann, K. and Kuhlemeier, C. (2011) The genetic architecture of natural variation in flower morphology. Curr. Opin. Plant Biol., 14, 60-5.

Hernalsteens, J.-P., Vliet, F. Van, Beuckeleer, M. De, Depicker, A., Engler, G., Lemmers, M., Holsters, M., Montagu, M. Van and Schell, J. (1980) The Agrobacterium tumefaciens Ti plasmid as a host vector system for introducing foreign DNA in plant cells.

Herrera-Estrella, L., Depicker, A., Montagu, M. Van and Schell, J. (1983) Expression of chimaeric genes transferred into plant cells using a Ti-plasmid-derived vector. Nature, 303, 209-213.

Hertwig, P. (1926) Ein neuer Fall von multiplem Allelomorphismus bei Antirrhinum. Mol. Gen. Genet. MGG, 41, 42-47.

Holtorf, S., Apel, K. and Bohlmann, H. (1995) Comparison of different constitutive and inducible promoters for the overexpression of transgenes in Arabidopsis thaliana. Plant Mol. Biol., 29, 637-646. Available at: http://dx.doi.org/10.1007/BF00041155.

Honma, T. and Goto, K. (2001) Complexes of MADS-box proteins are sufficient to convert leaves into floral organs. Nature, 409, 525-529.

Horiguchi, G., Gonzalez, N., Beemster, G.T.S., Inze, D. and Tsukaya, H. (2009) Impact of segmental chromosomal duplications on leaf size in the grandifolia-D mutants of Arabidopsis thaliana. Plant J., 60, 122-133.

Horiguchi, G., Kim, G.-T.T. and Tsukaya, H. (2005) The transcription factor AtGRF5 and the transcription coactivator AN3 regulate cell proliferation in leaf primordia of Arabidopsis thaliana. Plant J., 43, 68-78.

Horiguchi, G. and Tsukaya, H. (2006) A mechanism that monitors the number of leaf cells and its role in the determination of cell size and leaf size. Plant Cell Physiol., 47, S118-S118. 
Horsch, R.B., Fry, J.E., Hoffmann, N.L., Eichholtz, D., Rogers, S.G. and Fraley, R.T. (1985) A Simple and GeneralMethod for Transferring Genes into Plants. Science (80-. )., 227, 1229-1231.

Horvath, P. and Barrangou, R. (2010) CRISPR/Cas, the Immune System of Bacteria and Archaea. Sci. , 327 , $167-$ 170. Available at: http://www.sciencemag.org/content/327/5962/167.abstract.

Hu, Y., Poh, H.M. and Chua, N.-H. (2006) The Arabidopsis ARGOS-LIKE gene regulates cell expansion during organ growth. Plant J., 47, 1-9.

Hu, Y.X., Xie, O., Chua, N.H. and Xie, Q. (2003) The Arabidopsis auxin-inducible gene ARGOS controls lateral organ size. Plant Cell, 15, 1951-1961.

Hwang, W.Y., Fu, Y., Reyon, D., Maeder, M.L., Tsai, S.Q., Sander, J.D., Peterson, R.T., Yeh, J.-R.J. and Joung, J.K. (2013) Efficient genome editing in zebrafish using a CRISPR-Cas system. Nat Biotech, 31, $227-229$. Available at: http://dx.doi.org/10.1038/nbt.2501.

Ishiguro, S. (2001) The DEFECTIVE IN ANTHER DEHISCENCE1 Gene Encodes a Novel Phospholipase A1 Catalyzing the Initial Step of Jasmonic Acid Biosynthesis, Which Synchronizes Pollen Maturation, Anther Dehiscence, and Flower Opening in Arabidopsis. PLANT CELL ONLINE, 13, 2191-2209.

Jack, T., Brockman, L.L. and Meyerowitz, E.M. (1992) The homeotic gene APETALA3 of Arabidopsis thaliana encodes a MADS box and is expressed in petals and stamens. Cell, 68, 683-697.

Jaglo-Ottosen, K.R., Gilmour, S.J., Zarka, D.G., Schabenberger, O. and Thomashow, M.F. (1998) Arabidopsis CBF1 overexpression induces COR genes and enhances freezing tolerance. Science (80-. )., 280, 104-106.

Kachanovsky, D.E., Filler, S., Isaacson, T. and Hirschberg, J. (2012) Epistasis in tomato color mutations involves regulation of phytoene synthase 1 expression by cis-carotenoids. Proc. Natl. Acad. Sci. , 109 , 1902119026. Available at: http://www.pnas.org/content/109/46/19021.abstract.

Kater, M.M., Franken, J., Aelst, A. van and Angenent, G.C. (2000) Suppression of cell expansion by ectopic expression of the Arabidopsis SUPERMAN gene in transgenic petunia and tobacco. Plant J., 23, 407-413.

Kazama, T., Ichihashi, Y., Murata, S. and Tsukaya, H. (2010) The Mechanism of Cell Cycle Arrest Front Progression Explained by a KLUH/CYP78A5-dependent Mobile Growth Factor in Developing Leaves of Arabidopsis thaliana. Plant Cell Physiol., 51, 1046-1054.

Keck, E., McSteen, P., Carpenter, R. and Coen, E. (2003) Separation of genetic functions controlling organ identity in flowers. EMBO J., 22, 1058-1066.

Ketting, R.F., Haverkamp, T.H.., Luenen, H.G.A.. van and Plasterk, R.H.. (1999) mut-7 of C. elegans, Required for Transposon Silencing and RNA Interference, Is a Homolog of Werner Syndrome Helicase and RNaseD. Cell, 99, 133-141. Available at: http://www.sciencedirect.com/science/article/pii/S0092867400816451 [Accessed March 7, 2015].

Kim, J.H., Choi, D.S. and Kende, H. (2003) The AtGRF family of putative transcription factors is involved in leaf and cotyledon growth in Arabidopsis. Plant J., 36, 94-104.

Kim, S., Soltis, P.S., Wall, K. and Soltis, D.E. (2006) Phylogeny and domain evolution in the APETALA2-like gene family. Mol. Biol. Evol., 23, 107-120.

Klucher, K.M., Chow, H., Reiser, L. and Fischer, R.L. (1996) The AINTEGUMENTA gene of Arabidopsis required for ovule and female gametophyte development is related to the floral homeotic gene APETALA2. Plant Cell, 8, 137-153.

Koncz, C., Mayerhofer, R., Koncz-Kalman, Z., Nawrath, C., Reiss, B., Redei, G.P. and Schell, J. (1990) Isolation of a 
gene encoding a novel chloroplast protein by T-DNA tagging in Arabidopsis thaliana. EMBO J., 9, 13371346. Available at: http://www.ncbi.nlm.nih.gov/pmc/articles/PMC551817/.

Kondou, Y., Higuchi, M. and Matsui, M. (2010) High-Throughput Characterization of Plant Gene Functions by Using Gain-of-Function Technology. Annu. Rev. Plant Biol., 61, 373-393. Available at: http://dx.doi.org/ 10.1146/annurev-arplant-042809-112143.

Krizek, B. a and Eaddy, M. (2011) AINTEGUMENTA-LIKE6 regulates cellular differentiation in flowers. Plant Mol Biol, 78, 199-209.

Krizek, B.A. (1999) Ectopic expression of AINTEGUMENTA in Arabidopsis plants results in increased growth of floral organs. Dev. Genet., 25, 224-236. Available at: http://dx.doi.org/10.1002/(SICI)15206408 (1999)25:3<224::AID-DVG5>3.3.CO;2-P.

Krizek, B.A. and Anderson, J.T. (2013) Control of flower size. J. Exp. Bot., 64, 1427-1437.

Laitinen, R.A.E., Immanen, J., Auvinen, P., et al. (2005) Analysis of the floral transcriptome uncovers new regulators of organ determination and gene families related to flower organ differentiation in Gerbera hybrida (Asteraceae). Genome Res., 15, 475-486.

Larkin, M.A., Blackshields, G., Brown, N.P., et al. (2007) Clustal W and Clustal X version 2.0. Bioinformatics, 23, 2947-8.

Li, Y., Zheng, L., Corke, F., Smith, C. and Bevan, M.W. (2008) Control of final seed and organ size by the DA1 gene family in Arabidopsis thaliana. Genes Dev, 22, 1331-1336.

Lin, H.X., Yamamoto, T., Sasaki, T. and Yano, M. (2000) Characterization and detection of epistatic interactions of 3 QTLs, Hd1, Hd2, and Hd3, controlling heading date in rice using nearly isogenic lines. Theor. Appl. Genet., 101, 1021-1028. Available at: http://dx.doi.org/10.1007/s001220051576.

Liu, Q., Kasuga, M., Sakuma, Y., Abe, H., Miura, S., Yamaguchi-Shinozaki, K. and Shinozaki, K. (1998) Two transcription factors, DREB1 and DREB2, with an EREBP/AP2 DNA binding domain separate two cellular signal transduction pathways in drought- and low-temperature-responsive gene expression, respectively, in Arabidopsis. Plant Cell, 10, 1391-1406.

Maes, T., Steene, N. Van de, Zethof, J., Karimi, M., D’Hauw, M., Mares, G., Montagu, M. Van and Gerats, T. (2001) Petunia Ap2-like genes and their role in flower and seed development. Plant Cell, 13, 229-244.

Mallona, I., Weiss, J. and Egea-Cortines, M. (2011) pcrEfficiency: a Web tool for PCR amplification efficiency prediction. BMC Bioinformatics, 12, 404.

Manchado-Rojo, M., Delgado-Benarroch, L., Roca, M.J., Weiss, J. and Egea-Cortines, M. (2012) Quantitative levels of Deficiens and Globosa during late petal development show a complex transcriptional network topology of B function. Plant J., 72, 294-307.

Marks, M.D. and Feldmann, K.A. (1989) Trichome Development in Arabidopsis thaliana. I. T-DNA Tagging of the GLABROUS1 Gene. Plant Cell , 1 , 1043-1050. Available at: http://www.plantcell.org/content/ 1/11/1043.abstract.

Marraffini, L.A. and Sontheimer, E.J. (2010) CRISPR interference: RNA-directed adaptive immunity in bacteria and archaea. Nat. Rev. Genet., 11, 181-190. Available at: http://www.ncbi.nlm.nih.gov/pmc/ articles/PMC2928866/.

Martin, C., Bhatt, K., Baumann, K., Jin, H., Zachgo, S., Roberts, K., Schwarz-Sommer, Z., Glover, B. and PerezRodrigues, M. (2002) The mechanics of cell fate determination in petals. Philos. Trans. R. Soc. London $B$ 
Biol. Sci., 357, 809-813. Available at: http://rstb.royalsocietypublishing.org/content/357/1422/ 809.abstract.

Mason, H.S., Ball, J.M., Shi, J.J., Jiang, X., Estes, M.K. and Arntzen, C.J. (1996) Expression of Norwalk virus capsid protein in transgenic tobacco and potato and its oral immunogenicity in mice. Proc. Natl. Acad. Sci. , 93 , 5335-5340. Available at: http://www.pnas.org/content/93/11/5335.abstract.

McCallum, C.M., Comai, L., Greene, E.A. and Henikoff, S. (2000) Targeting Induced LocalLesions IN Genomes (TILLING) for Plant Functional Genomics. Plant Physiol. , 123 , 439-442. Available at: http://www.plantphysiol.org/content/123/2/439.short.

Mizukami, Y. and Fischer, R.L. (2000) Plant organ size control: AINTEGUMENTA regulates growth and cell numbers during organogenesis. Proc. Natl. Acad. Sci., 97, 942-947. Available at: http://www.pnas.org/ cgi/doi/10.1073/pnas.97.2.942 [Accessed October 28, 2014].

Murphy, D.L., Uhl, G.R., Holmes, A., Ren-Patterson, R., Hall, F.S., Sora, I., Detera-Wadleigh, S. and Lesch, K.-P. (2003) Experimental gene interaction studies with SERT mutant mice as models for human polygenic and epistatic traits and disorders. Genes, Brain Behav., 2, 350-364. Available at: http://dx.doi.org/10.1046/ j.1601-1848.2003.00049.x.

Nag, A., King, S. and Jack, T. (2009) miR319a targeting of TCP4 is critical for petal growth and development in Arabidopsis. Proc. Natl. Acad. Sci. U. S. A., 106, 22534-9.

Nagpal, P., Ellis, C.M., Weber, H., et al. (2005) Auxin response factors ARF6 and ARF8 promote jasmonic acid production and flower maturation. Development, 132, 4107-4118.

Napoli, C., Lemieux, C. and Jorgensen, R. (1990) Introduction of a Chimeric Chalcone Synthase Gene into Petunia Results in Reversible Co-Suppression of Homologous Genes in trans. Plant Cell , 2 , $279-289$. Available at: http://www.plantcell.org/content/2/4/279.abstract.

Nath, U., Crawford, B.C.W., Carpenter, R. and Coen, E. (2003) Genetic control of surface curvature. Science (80-. )., 299, 1404-1407.

Neufeld, T.P., la Cruz, A.F.A. de, Johnston, L.A. and Edgar, B.A. (1998) Coordination of Growth and Cell Division in the Drosophila Wing. Cell, 93, 1183-1193.

Noda, K., Glover, B.J., Linstead, P. and Martin, C. (1994) Flower colour intensity depends on specialized cell shape controlled by a Myb-related transcription factor. Nature, 369, 661-664. Available at: http://dx.doi.org/10.1038/369661a0.

Palatnik, J.F., Allen, E., Wu, X., Schommer, C., Schwab, R., Carrington, J.C. and Weigel, D. (2003) Control of leaf morphogenesis by microRNAs. Nature, 425, 257-263. Available at: http://dx.doi.org/10.1038/ nature01958.

Papaleo, F., Burdick, M.C., Callicott, J.H. and Weinberger, D.R. (2014) Epistatic interaction between COMT and DTNBP1 modulates prefrontal function in mice and in humans. Mol Psychiatry, 19, 311-316. Available at: http://dx.doi.org/10.1038/mp.2013.133.

Perrière, G. and Gouy, M. (1996) WWW-Query: An on-line retrieval system for biological sequence banks. Biochimie, 78, 364-369.

Pfaffl, M.W., Horgan, G.W. and Dempfle, L. (2002) Relative expression software tool (REST(C)) for group-wise comparison and statistical analysis of relative expression results in real-time PCR. Nucl. Acids Res., 30, e36-. 
Pichersky, E., Raguso, R.A., Lewinsohn, E., Croteau, R. and Eran Pichersky, Robert A. Raguso, E.L. and R.C. (1994) Floral Scent Production in Clarkia (Onagraceae) .1. Localization and Developmental Modulation of Monoterpene Emission and Linalool Synthase Activity. Plant Physiol., 106, 1533-1540.

Prasad, K., Grigg, S.P., Barkoulas, M., et al. (2011) Arabidopsis PLETHORA Transcription Factors Control Phyllotaxis. Curr. Biol., 21, 1123-1128.

Reale, L., Porceddu, A., Lanfaloni, L., Moretti, C., Zenoni, S., Pezzotti, M., Romano, B. and Ferranti, F. (2002) Patterns of cell division and expansion in developing petals of Petunia hybrida. Sex. Plant Reprod., 15, 123-132.

Reeves, P.H., Ellis, C.M., Ploense, S.E., et al. (2012) A regulatory network for coordinated flower maturation. M. F. Yanofsky, ed. PLoS Genet., 8, e1002506.

Rieu, I., Bots, M., Mariani, C. and Weterings, K.A.P. (2005) Isolation and expression analysis of a tobacco AINTEGUMENTA ortholog (NtANTL). Plant Cell Physiol., 46, 803-805.

Rijpkema, A., Gerats, T. and Vandenbussche, M. (2006) Genetics of Floral Development in Petunia. In B. T.-A. in B. Research, ed. Developmental Genetics of the Flower. Academic Press, pp. 237-278. Available at: http://www.sciencedirect.com/science/article/pii/S0065229606440064.

Rijpkema, A.S., Gerats, T. and Vandenbussche, M. (2007) Evolutionary complexity of MADS complexes. Curr. Opin. Plant Biol., 10, 32-38.

Rodriguez, R.E., Mecchia, M.A., Debernardi, J.M., Schommer, C., Weigel, D. and Palatnik, J.F. (2010) Control of cell proliferation in Arabidopsis thaliana by microRNA miR396. Development, 137, 103-12.

Rorth, P., Szabo, K., Bailey, A., et al. (1998) Systematic gain-of-function genetics in Drosophila. Development, 125, 1049-1057. Available at: http://dev.biologists.org/content/125/6/1049.abstract.

Rubio-Somoza, I. and Weigel, D. (2013) Coordination of Flower Maturation by a Regulatory Circuit of Three MicroRNAs L.-J. Qu, ed. PLoS Genet., 9, e1003374.

Sanders, P.M. (2000) The Arabidopsis DELAYED DEHISCENCE1 Gene Encodes an Enzyme in the Jasmonic Acid Synthesis Pathway. PLANT CELL ONLINE, 12, 1041-1062.

Schell, J., Montagu, M. Van, Beuckeleer, M. De, et al. (1979) Interactions and DNA transfer between Agrobacterium tumefaciens, the Ti-plasmid and the plant host. Proc. R. Soc. London B Biol. Sci., 204, 251266.

Schwarz-Sommer, Z., Davies, B. and Hudson, A. (2003) An everlasting pioneer: the story of Antirrhinum research. Nat Rev Genet, 4, 655-664. Available at: http://dx.doi.org/10.1038/nrg1127.

Shigyo, M., Hasebe, M. and Ito, M. (2006) Molecular evolution of the AP2 subfamily. Gene, 366, $256-265$.

Shigyo, M. and Ito, M. (2004) Analysis of gymnosperm two-AP2-domain-containing genes. Dev. Genes Evol., 214, 105-114.

Slade, A.J., Fuerstenberg, S.I., Loeffler, D., Steine, M.N. and Facciotti, D. (2005) A reverse genetic, nontransgenic approach to wheat crop improvement by TILLING. Nat. Biotechnol., 23, 75-81.

Sommer, H., Beltrán, J.P., Huijser, P., Pape, H., Lönnig, W.E., Saedler, H. and Schwarz-Sommer, Z. (1990) Deficiens, a homeotic gene involved in the control of flower morphogenesis in Antirrhinum majus: the protein shows homology to transcription factors. EMBO J., 9, 605-613. Available at: http://www.ncbi.nlm.nih.gov/pmc/articles/PMC551713/. 
Sommer, H., Nacken, W., Beltran, P., Huijser, P., Pape, H., Hansen, R., Flor, P., Saedler, H. and Schwarz-Sommer, Z. (1991) Properties of deficiens, a homeotic gene involved in the control of flower morphogenesis in Antirrhinum majus. Dev. , 113 , 169-175. Available at: http://dev.biologists.org/content/113/ Supplement_1/169.abstract.

Stubbe, H. (1966) Genetik und Zytologie von Antirrhinum L. sect. Antirrhinum Veb Gustav.,.

Stuurman, J., Hoballah, M.E., Broger, L., Moore, J., Basten, C. and Kuhlemeier, C. (2004) Dissection of floral pollination syndromes in petunia. Genetics, 168, 1585-1599.

Sugimoto-Shirasu, K. and Roberts, K. (2003) "Big it up": endoreduplication and cell-size control in plants. Curr. Opin. Plant Biol., 6, 544-553.

Sugimoto-Shirasu, K., Stacey, N.J., Corsar, J., Roberts, K. and McCann, M.C. (2002) DNA topoisomerase VI is essential for endoreduplication in Arabidopsis. Curr. Biol., 12, 1782-6.

Szecsi, J., Joly, C., Bordji, K., Varaud, E., Cock, J.M., Dumas, C., Bendahmane, M. and Szécsi, J. (2006) BIGPETALp, a $b H L H$ transcription factor is involved in the control of Arabidopsis petal size. EMBO J., 25, 3912-3920.

Tabara, H., Sarkissian, M., Kelly, W.G., Fleenor, J., Grishok, A., Timmons, L., Fire, A. and Mello, C.C. (1999) The rde-1 Gene, RNA Interference, and Transposon Silencing in C. elegans. Cell, 99, 123-132. Available at: http://www.sciencedirect.com/science/article/pii/S009286740081644X [Accessed March 7, 2015].

Till, B., Colbert, T., Tompa, R., et al. (2003) High-Throughput TILLING for Functional Genomics. In E. Grotewold, ed. Plant Functional Genomics SE - 13. Methods in Molecular Biology ${ }^{\mathrm{TM}}$. Humana Press, pp. 205-220. Available at: http://dx.doi.org/10.1385/1-59259-413-1\%3A205.

Till, B.J., Reynolds, S.H., Greene, E.A., et al. (2003) Large-scale discovery of induced point mutations with highthroughput TILLING. Genome Res., 13, 524-530.

Trobner, W., Ramirez, L., Motte, P., Hue, I., Huijser, P., Lonnig, W.E., Saedler, H., Sommer, H. and SchwarzSommer, Z. (1992) GLOBOSA: a homeotic gene which interacts with DEFICIENS in the control of Antirrhinum floral organogenesis. EMBO J., 11, 4693-4704.

Tröbner, W., Ramirez, L., Motte, P., Hue, I., Huijser, P., Lönnig, W.E., Saedler, H., Sommer, H. and SchwarzSommer, Z. (1992) GLOBOSA: a homeotic gene which interacts with DEFICIENS in the control of Antirrhinum floral organogenesis. EMBO J., 11, 4693-4704. Available at: http://www.ncbi.nlm.nih.gov/ pmc/articles/PMC556944/.

Truernit, E. and Haseloff, J. (2008) Arabidopsis thaliana outer ovule integument morphogenesis: ectopic expression of KNAT1 reveals a compensation mechanism. BMC Plant Biol, 8, 35.

Vandenbussche, M., Zethof, J., Royaert, S., Weterings, K. and Gerats, T. (2004) The Duplicated B-Class Heterodimer Model : Whorl-Specific Effects and Complex Genetic Interactions in Petunia hybrida Flower Development. , 16, 741-754.

Vavouri, T., Semple, J.I. and Lehner, B. (2008) Widespread conservation of genetic redundancy during a billion years of eukaryotic evolution. Trends Genet., 24, 485-488.

Venail, J., Dell'Olivo, A. and Kuhlemeier, C. (2010) Speciation genes in the genus Petunia. Philos. Trans. R. Soc. B-Biological Sci., 365, 461-468.

Waterhouse, P.M., Wang, M.-B. and Lough, T. (2001) Gene silencing as an adaptive defence against viruses. Nature, 411, 834-842. Available at: http://dx.doi.org/10.1038/35081168.

Wefers, B., Meyer, M., Ortiz, O., Hrabé de Angelis, M., Hansen, J., Wurst, W. and Kühn, R. (2013) Direct 
production of mouse disease models by embryo microinjection of TALENs and oligodeoxynucleotides. Proc. Natl. Acad. Sci. , 110 , 3782-3787. Available at: http://www.pnas.org/content/110/10/ 3782.abstract.

Weiss, J., Burgos, L. and Egea Gutierrez-Cortines, M. (2005) Biotechnology applications in crops. In R. Dris, ed. Crops: Growth, quality and biotechnology. Helsinki: WFL Publisher, pp. 1068-1086.

Weiss, J., Cano-Vicente, E. and Egea-Cortines, M. (2006) From the wild to the market: evolution of floral size and architecture in ornamentals. In T. da S. JA, ed. Floriculture, Ornamental and Plant Biotechnology: Advances and Topical Issues. London: Global Science Books.

Weiss, J., Delgado-Benarroch, L. and Egea-cortines, M. (2005) Genetic control of floral size and proportions. Int. J. Dev. Biol., 49, 513-525.

Weiss, J. and Egea-Cortines, M. (2009) Transcriptomic analysis of cold response in tomato fruits identifies dehydrin as marker to study cold acclimation. J. Appl. Genet., 50, 311-319.

Weiss, J., Mallona, I., Gomez-di-Marco, P., Fernández-Valera, J.M. and Egea-Cortines, M. (2012) Genotyping Antirrhinum commercial varieties using miniature inverted-repeat transposable elements (MITEs). Sci. Hortic. (Amsterdam)., 144, 161-167.

White, D.W.R. (2006) PEAPOD regulates lamina size and curvature in Arabidopsis. Proc. Natl. Acad. Sci. U. S. A., $103,13238-43$

Wright, G.A., Lutmerding, A., Dudareva, N. and Smith, B.H. (2005) Intensity and the ratios of compounds in the scent of snapdragon flowers affect scent discrimination by honeybees (Apis mellifera). J. Comp. Physiol. a-Neuroethology Sens. Neural Behav. Physiol., 191, 105-114.

Wu, M.-F., Tian, Q. and Reed, J.W. (2006) Arabidopsis microRNA167 controls patterns of ARF6 and ARF8 expression, and regulates both female and male reproduction. Development, 133, 4211-8.

Wurschum, T., Gross-Hardt, R. and Laux, T. (2006) APETALA2 regulates the stem cell niche in the Arabidopsis shoot meristem. Plant Cell, 18, 295-307.

Xiong, Y., Jung, J., Zeng, Q., Gallo, M. and Altpeter, F. (2013) Comparison of procedures for DNA coating of micro-carriers in the transient and stable biolistic transformation of sugarcane. Plant Cell, Tissue Organ Cult., 112, 95-99. Available at: http://dx.doi.org/10.1007/s11240-012-0208-8.

Yanofsky, M.F., Ma, H., Bowman, J.L., Drews, G.N., Feldmann, K.A. and Meyerowitz, E.M. (1990) The protein encoded by the Arabidopsis homeotic gene agamous resembles transcription factors. Nature, 346, 35-39.

Zenoni, S., Fasoli, M., Tornielli, G.B., et al. (2011) Overexpression of PhEXPA1 increases cell size, modifies cell wall polymer composition and affects the timing of axillary meristem development in Petunia hybrida. New Phytol, 191, 662-677.

Zenoni, S., Reale, L., Tornielli, G.B., et al. (2004) Downregulation of the Petunia hybrida alpha-expansin gene PhEXP1 reduces the amount of crystalline cellulose in cell walls and leads to phenotypic changes in petal limbs. Plant Cell, 16, 295-308. 
Aims of the Thesis 



\section{Aims of the Thesis}

\section{Chapter 1}

The aim of this chapter was to develop a screening method based on DNA melting profiles for the detection of Escherichia coli contamination in Agrobacterium tumefaciens cultures as prerequisite for efficient plant genetic transformation.

\section{Chapter 2}

The goal of this chapter was to establish a stable protocol of Antirrhinum majus transformation previous to determine the quantitative requirements for floral organ identity genes during late flower development.

\section{Chapter 3}

The protocol of stable plant transformation developed in Chapter 2 was used in order to evaluate the possibility to modify floral organ size in model/ornamental species by variation of AINTEGUMENTA gene expression, a gene known to affect floral organ size in Arabidopsis. 

Chapter 1 



\title{
Chapter 1: Using 235 rDNA to identify contaminations of Escherichia coli in Agrobacterium tumefaciens cultures
}

\author{
Manchado-Rojo, María ${ }^{a, b}$, Weiss, Julia ${ }^{a, b}$ and Egea-Cortines, Marcos ${ }^{a, b *}$ \\ a Departamento de Ciencia y Tecnología Agraria, Universidad Politécnica de Cartagena, 30203 \\ Cartagena, Spain

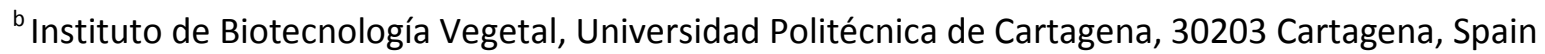

*Corresponding Author: marcos.egea@upct.es (Marcos Egea-Cortines)

Telf: +34968325705

Fax: +34968325433

Abbreviations used: qPCR, quantitative PCR; VIGS, virus-induced gene silencing; SDS, sodium dodecyl sulphate; LB: Luria Bertani broth

Manchado-Rojo, M., Weiss, J., \& Egea-Cortines, M. (2008). Using 23s rDNA to identify contaminations of Escherichia coli in Agrobacterium tumefaciens cultures. Analytical Biochemistry, 372(2), $253-4$. doi:10.1016/j.ab.2007.09.011 


\begin{abstract}
Cross contamination of Agrobacterium tumefaciens stocks with Escherichia coli are difficult to identify by microbiological techniques, leading to false negative results in transformation experiments. We have developed a genotyping assay for $A$. tumefaciens and $E$. coli lab strains based on amplification of 23 S rDNA by PCR. Agrobacterium strains LBA 4404, C58 and EHA105 and E. coli strains DB3.1, DH5 $\alpha$ and XL1-Blue can be identified separating the corresponding PCR amplicons in $2.5 \%$ agarose gels. However, in crossed contaminations, interpretation of results is improved using melting point analysis on a quantitative PCR machine.
\end{abstract}

Handling of different microbial strains in laboratory practice can turn into a problem when different bacteria become contaminated with each other. In most cases, contamination of bacterial strains is the result of sharing plasticware, pipettes and solutions. Furthermore, although different bacterial genera can be grown on specific media, simplicity has led to a generalized use of common growth media as long as they do not interfere with bacterial properties. Two types of bacterial genera are routinely used in plant biology laboratories, Escherichia coli used for general cloning and Agrobacterium tumefaciens to obtain transgenic plants.

Recent advances in cloning strategies based on recombination cloning coupled with virus-induced gene silencing (VIGS) [1] allow research projects where hundreds to thousands of genes can be tested for loss of function. The standard procedure is the construction of cDNA libraries and development of recombinant libraries in vectors suitable for VIGS. These recombinant libraries are then transferred to Agrobacterium that is used to obtain transiently transformed plants expressing the cDNA cloned as double stranded RNA that causes post transcriptional gene silencing. This technology has been shown to work in different plants like Papaver [2], potato [3] or Petunia [4].

But one obvious problem is that if Agrobacterium strains are contaminated with E. coli, then some of the colonies processed will not transform plants giving as a result a false negative. Although $E$. coli and Agrobacterium can be differentiated by microbiological techniques, it is much faster to establish a genotyping protocol based on PCR that will allow the identification of E.coli contaminations in those cases where there is doubt of the purity of the Agrobacterium strain. In this study we report the development of a genotyping assay to distinguish between E. coli and Agrobacterium.

We grew on LB medium to complete saturation the E. coli strains DH5 $\alpha$, and DB3.1 from Invitrogen and XL1-Blue from Stratagene at 37으 while the Agrobacterium strains LBA 4404, C58 and EHA105 
were grown at $28^{\circ} \mathrm{C}$. Extraction of bacterial genomic DNA was performed starting from $1.5 \mathrm{~mL}$ of saturated culture. Samples were centrifuged and the bacterial pellets were resuspended in $1 \mathrm{~mL}$ of TE buffer (10 mM Tris HCL, 1mM EDTA, pH 8.0) and lysed with $200 \mu \mathrm{g}$ of lysozyme and 1\% SDS. Protein was digested with $500 \mu \mathrm{g}$ of proteinase $\mathrm{K}$ incubating at $65 \circ \mathrm{C}$ for one hour. Genomic DNA was purified from the samples by standard phenol:chloroform extraction and precipitation [5]. The resulting pellets were resuspended in $100 \mu \mathrm{L}$ of TE buffer. Amongst the possible genome regions valuable for genotyping, the intergenic transcribed spacer (ITS) has been found useful in plants [6], the $23 \mathrm{~S}$ rDNA and the 16S-23S rDNA spacer in bacteria [7], or 5.8S-ITS region to identify yeast contamination in food samples [8]. We used specific primers that amplify the bacterial 23S rDNA (23S-forward ACCAGGATTTTGGCTTAGAAG and 23S-reverse CACTTACCCCGACAAGGAAT) [7] in a standard PCR experiment performed with Taq polymerase from Promega. The cycling conditions consisted in thirty cycles of 30 seconds at $94^{\circ} \mathrm{C}, 30$ seconds at $62^{\circ} \mathrm{C}$ and 30 seconds at $72^{\circ} \mathrm{C}$. Reaction products were separated using $2.5 \%$ agarose gels containing ethydium bromide, and visualized with a UV transilluminator. Amplification products from Agrobacterium and E. coli could be visually differentiated on the gel, showing PCR fragments of 780 and $850 \mathrm{bp}$ respectively (Fig.1A). This suggests that direct analysis of PCR products is feasible. However, we found that in complex mixtures of bacterial strains i.e when there is contamination of Agrobacterium with E. coli, it would be better to have a more powerful assay since the size differences between amplicons make results difficult to interpret on agarose gels (data not shown). We solved this problem by performing a RT-qPCR on a CR-Corbett Research-quantitative PCR using TaKara Sybr Green quantitative PCR amplification kit. The PCR conditions were an initial denaturation of 5 minutes at $95^{\circ} \mathrm{C}$ followed by forty cycles with a scheme of $95^{\circ} \mathrm{C} 30$ seconds, $62^{\circ} \mathrm{C} 30$ seconds, $72^{\circ} \mathrm{C} 30$ seconds, a read at $83^{\circ} \mathrm{C}$ for 15 seconds and finally a melting point analysis starting at $60^{\circ} \mathrm{C}$ and reaching $94{ }^{\circ} \mathrm{C}$ with reads every $0.5 \circ \mathrm{C}$ for 15 seconds. The melting point of the $23 S$ rDNA region of Agrobacterium and E. coli differed by $1.6 \circ \mathrm{C}$ (87.9 and 89.5 respectively), giving clear-cut results that allow the genotyping of Agrobacterium and E. coli (Fig 1.B). 


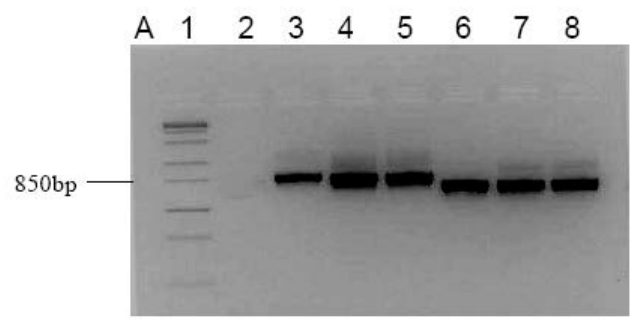

B

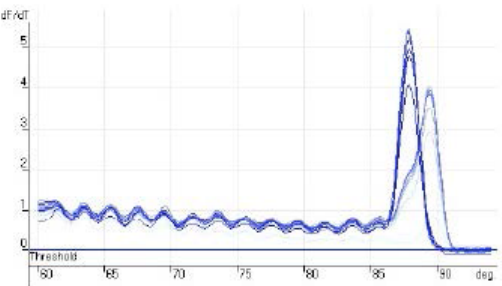

Figure 1: (A) Amplification of 23S rDNA from bacterial samples by PCR. Lane 1 molecular weight; Lane 2 negative control; Lane 3 E. coli DB3.1; Lane 4 E. coli DH5 $\alpha$; Lane 5 XL1-Blue; Lane 6 A tumefaciens LBA4404; Lane 7 C58; Lane 8 EHA105. Molecular weight markers were ZipRuler ladder-1 from Fermentas with molecular weights of 10000, 5000, 3000, 2000, 1200, 850, 500, 300 and 100 bp. (B) Melting curve of samples of $A$. tumefaciens and E. coli. The peak at 89.5 degrees corresponds to duplicated samples of DB3.1, DH5 $\alpha$ and XL1-Blue, while the peak at 87.9 corresponds to LBA4404, C58 and EHA105 A. tumefaciens strains.

In summary, we developed a PCR assay to genotype Agrobacterium and E. coli that helps overcome situations of cross contamination between these types of bacteria. The protocol presented should be useful to test clones that do not appear to transform plants, and this lack of transformation capacity could be the result of contaminated bacterial stocks. Our approach has the additional advantage of being based on codominant PCR markers that should be more useful than Agrobacterium or E. coli specific PCR makers.

\section{Acknowledgements}

This work was financed by the Fundación Séneca de la Región de Murcia and BIOCARM.

\section{References}

1. Burch-Smith, T. M., Anderson, J. C., Martin, G. B., and Dinesh-Kumar, S. P. (2004) Plant Journal 39, 734746.

2. Hileman, L. C., Drea, S., de Martino, G., Litt, A., and Irish, V. F. (2005) Plant Journal 44, 334-341.

3. Brigneti, G., Martin-Hernandez, A. M., Jin, H., Chen, J., Baulcombe, D. C., Baker, B., and Jones, J. D. (2004) Plant J 39, 264-72.

4. Chen, J. C., Jiang, C. Z., Gookin, T. E., Hunter, D. A., Clark, D. G., and Reid, M. S. (2004) Plant Molecular Biology 55, 521-530.

5. Sambrook, J., Fritsch, E. F., and Maniatis, T. (1989) Molecular cloning: a laboratory manual, Cold Spring Harbour Laboratory Press, New York.

6. Kress, W. J., Wurdack, K. J., Zimmer, E. A., Weigt, L. A., and Janzen, D. H. (2005) Proceedings of the National Academy of Sciences of the United States of America 102, 8369-8374. 
7. Hong, B. X., Jiang, L. F., Hu, Y. S., Fang, D. Y., and Guo, H. Y. (2004) Journal of Microbiological Methods 58, 403-411.

8. Ros-Chumillas, M., Egea-Cortines, M., Lopez-Gomez, A., and Weiss, J. (2007) Food Control 18, 33-39. 

Chapter 2 



\section{Chapter 2: Quantitative levels of Deficiens and Globosa during late petal development show a complex transcriptional network topology of B function}

María Manchado-Rojo, Luciana Delgado-Benarroch ${ }^{1}$, María José Roca², Julia Weiss and Marcos EgeaCortines*

Genetics, ETSIA, Instituto de Biotecnología Vegetal, Universidad Politécnica de Cartagena, Paseo Alfonso XIII 48, 30203 Cartagena, Spain.

1 Present Address: Instituto de Botánica del Nordeste (IBONE-CONICET), Facultad de Ciencias Agrarias, Universidad Nacional del Nordeste. Sargento Cabral 2131 CC 209, (3400) Corrientes, Argentina.

${ }^{2}$ Servicio de Apoyo a la Investigación Tecnológica, Universidad Politécnica de Cartagena, Plaza del Hospital s/n, 30202 Cartagena, Spain

* Corresponding Author: Genetics, ETSIA, Universidad Politécnica de Cartagena, Paseo Alfonso XIII 48, 30203 Cartagena, Spain.

Telephone: 34868071077; Fax: 34968325433; e-mail: marcos.egea@upct.es

Keywords: Antirrhinum majus, B function, autoregulatory loop, network topology, floral size, floral scent.

Manchado-Rojo, M., Delgado-Benarroch, L., Roca, M. J., Weiss, J., \& Egea-Cortines, M. (2012). Quantitative levels of Deficiens and Globosa during late petal development show a complex transcriptional network topology of B function. Plant Journal, 72(2), 294-307. 


\section{Summary}

The transcriptional network topology of B function in Antirrhinum, required for petal and stamen development, is thought to rely on initial activation of transcription of DEFICIENS (DEF) and GLOBOSA $(G L O)$, followed by a positive autoregulatory loop maintaining gene expression levels. Here, we show that the mutant compacta $(c o)$, whose vegetative growth and petal size are affected, plays a role in B function. Late events in petal morphogenesis such as development of conical cell area and scent emissions were reduced in co and $\operatorname{def}^{\text {nicotianoides }}\left(\operatorname{def}^{\text {nic }}\right)$, and absent in co def ${ }^{\text {nic }}$ double mutants, suggesting a role for $C O$ in petal identity. Expression of $D E F$ was down-regulated in co but surprisingly GLO was not affected. We investigated the levels of DEF and GLO at late stages of petal development in the $c o, d e f^{n i c}$ and glo-1 mutants, and established a reliable transformation protocol that yielded RNAi-DEF lines. We show that the threshold levels of $D E F$ or GLO required to obtain petal tissue are approximately $11 \%$ of wild-type. The relationship between $D E F$ and $G L O$ transcripts is not equal or constant and changes during development. Furthermore, down-regulation of DEF or GLO does not cause parallel down-regulation of the partner. Our results demonstrate that, at late stages of petal development, the B function transcriptional network topology is not based on positive autoregulation, and has additional components of transcriptional maintenance. Our results suggest changes in network topology that may allow changes in protein complexes that would explain the fact that not all petal traits appear early in development.

\section{Introduction}

Seminal work in Antirrhinum majus and Arabidopsis thaliana allowed formulation of a combinatorial model based on gene functions explaining what later was found to be a general scheme of floral organ development in angiosperms (Schwarz-Sommer et al., 1990; Coen and Meyerowitz, 1991; Egea Gutierrez-Cortines and Davies, 2000; Causier et al., 2010). The so-called ABC model has been tested and interpreted in various forms in several plant species. B function genes are involved in petal and stamen morphogenesis, and two genes, DEFICIENS and GLOBOSA, perform this task in Antirrhinum (Sommer et al., 1990; Trobner et al., 1992).

Petal development involves several subsets of genes activated by the B function. Amongst the features of a fully mature petal are the distinct colours displayed, resulting from pigment synthesis and down-regulation of chlorophyll production, proper size and shape, and release of scent. Petal development is not a linear process. The phenylpropanoid synthesis pathway involved in petal pigmentation does not show simple activation, but instead follows a pattern of early and late gene expression (Martin and Gerats, 1993). This is true in Antirrhinum and Petunia, indicating that some 
fine regulatory aspects of petal development may be conserved in evolution (Almeida et al., 1989; Martin et al., 1991; Weiss et al., 1993). Petal growth also displays bi-phasic behaviour in Petunia, Gerbera and Arabidopsis, with petal development promoted by cell division and later stages promoted by cell expansion (Reale et al., 2002; Anastasiou and Lenhard, 2007; Laitinen et al., 2007). In Antirrhinum, petal growth is somewhat more complex, as cell division occurs in early stages and regions where cell division occur are also detected late in development (Perez-Rodriguez et al., 2005; Delgado-Benarroch et al., 2009a).

At later stages, petal epidermal cells become conical as a result of expression of the MIXTA gene (Noda et al., 1994). This process is conserved among species, and both conical cell development and the angle of petal reflection are controlled partly by MIXTA in Antirrhinum and Petunia (Baumann et al., 2007). Conical cell formation in Antirrhinum continues until late stages of petal development, well after anthesis and before petal abscission (Goodwin et al., 2003). MIXTA and MIXTA-LIKE genes have a conserved function in conical cell development during evolution (Di Stilio et al., 2009). MIXTA expression is known to be controlled by B function genes, as plants expressing unstable alleles of def have been shown to display conical cells in reverting sectors (Carpenter and Coen, 1990). The level of expression of MIXTA and MIXTA-LIKE-1 depend on the quantitative levels of DEF and GLO in Antirrhinum (Perez-Rodriguez et al., 2005). Conical cells have several biological functions related to pollinator attraction, including scent production (Kolosova et al., 2001; Whitney et al., 2009a,b, 2011). The complex floral scent profile of most plants is the result of unique blends of compounds, whose production is due to activation of several biochemical pathways (Vainstein et al., 2001). The Antirrhinum scent profile includes methyl benzoate, a product of the phenylpropanoid synthesis pathway, and terpenoids such as myrcene and ocimene (Dudareva et al., 2000, 2003).

Activation of floral homeotic genes in Arabidopsis requires two partially redundant paralogs, APETALA1 (AP1) and CAULIFLOWER (Kempin et al., 1995; Ferrandiz et al., 2000). Negative regulation of the genes AGAMOUS-LIKE24 (AGL24) and SHORT VEGETATIVE PHASE (SVP) by AP1 is required to activate SEPALLATA (SEP) (Kaufmann et al., 2010b). The SEP1-4 family is important to activate B function in Petunia, tomato and Arabidopsis (Angenent et al., 1993; Pnueli et al., 1994; Pelaz et al., 2000; Vandenbussche et al., 2003). The resulting B function activity is maintained by a positive autoregulatory loop that has been described in Antirrhinum, Petunia and Arabidopsis (SchwarzSommer et al., 1992; Halfter et al., 1994; Zachgo et al., 1995; Honma and Goto, 2000; Vandenbussche et al., 2004). The B function gene products form heterodimers (Davies et al., 1996b; Winter et al., 2002; Wang et al., 2010) that can bind their own promoters and activate transcription. Plants expressing hypomorphic alleles of def display progressively smaller petals that become more 
sepalloid with the strength of the alleles (Schwarz-Sommer et al., 1992; Zachgo et al., 1995; Bey et al., 2004). Petal growth as a whole is affected in B function homeotic mutants. Plants expressing null $d_{e f} f^{g l o b i f e r a}\left(d e f^{g l i}\right)$ and glo-1 alleles display second-whorl organs that are indistinguishable from firstwhorl sepals (Trobner et al., 1992), and sepals are much shorter than petals in Antirrhinum majus (Delgado-Benarroch et al., 2009a). As a result of the studies described above and others performed in Arabidopsis (Szecsi et al., 2006; Kaufmann et al., 2009), there is a general agreement that floral organ size requires proper function of the floral organ identity genes (Yu et al., 2004; Dornelas et al., 2011).

Although positive autoregulatory loops occur as network motifs in many biological pathways (Heintzen et al., 1997; Varghese and Cohen, 2007; Fujiwara et al., 2009), they are inherently slow to respond to variation of gene expression (Kalir et al., 2005; Alon, 2007), which may result in decreased flexibility (Ma et al., 2006). Given the importance of the B function in terms of petal and stamen identity, it is possible that $B$ function transcriptional maintenance includes gene activation, positive autoregulatory loop control and some parallel or ancillary components that add robustness to the system. Indeed, the obligate heterodimerization of canonical B function gene products adds robustness to the system at the post-transcriptional level (Espinosa-Soto et al., 2004; Lenser et al., 2009; Kaufmannet al., 2010a; Geuten et al., 2011). Further robustness is probably achieved as a result of larger MADS box complexes, which may aid in stabilization of the protein-DNA binding complexes (Egea-Cortine e al., 1999; Theissen and Saedler, 2001; Melzer and Theissen, 2009; Kaufmann et al., 2010a). Despite these protein stabilization processes, decreases in B function gene expression cause clear homeotic changes in Antirrhinum, Petunia (Vandenbussche et al., 2004; Rijpkema et al., 2006) and Arabidopsis (Irish and Yamamoto, 1995), demonstrating the importance of sustained transcriptional activity of the B function.

Although the initial steps of petal development are understood in some detail, late stages of development are thought to be a follow-up, but, to the best of our knowledge, no quantitative analysis of B function transcription at late stages of petal development has been performed to support this hypothesis.

Here we report genetic characterization of the mutant compacta, a classic Antirrhinum majus mutant (Kuckuck and Schick, 1930) in which leaf shape and floral size are affected. We uncover a genetic interaction of co with def that implicates $C O$ in activation of DEF expression. We measured scent production in the co and def $f^{\text {nic }}$ mutants, and found that production of methyl benzoate, ocimene and myrcene was reduced in co and def $f^{\text {nic }}$ mutants and was completely absent in co def ${ }^{\text {nic }}$ double 
mutants, demonstrating a role for $c o$ in B function. In order to establish the threshold of B function, we developed a highly reliable transformation protocol and obtained RNAi-DEF lines. We performed quantitative expression analysis of DEF, GLO and MIXTA in co def $f^{\text {nic }}$ double mutants, glo-1 and RNAi$D E F$ lines. We identified the thresholds of DEF and GLO associated with different levels of petal identity, and surprisingly found that the levels of DEF and GLO transcripts changed at later stages of development, which was unexpected from a network topology based exclusively on positive autoregulation. We propose a model of B function transcriptional control that accommodates the data presented and may explain petal development as a multistep process.

\section{Results}

\section{The co mutation affects petal and stamen cell size}

The mutant compacta had been described as a recessive mutant (Stubbe, 1966), and segregation analysis of a cross of co with the laboratory wild-type line 165E confirmed this result (SchwarzSommer et al., 2010). As previously described, we found that the co mutation affected vegetative growth, including decreased internode elongation and smaller leaves that were altered both in width and length (Table 1). Leaf number until the first flower was not different from wild-type, indicating that the co mutation does not affect floral transition.

Table 1: Comparison of vegetative parameters between wild-type and the co mutant

\begin{tabular}{|c|c|c|c|c|c|c|c|c|c|c|c|c|}
\hline Genot. & \multicolumn{3}{|c|}{ Internode $(\mathbf{m m})$} & \multicolumn{2}{c|}{ Leaf $\mathbf{1}(\mathbf{m m})$} & \multicolumn{2}{c|}{ Leaf $\mathbf{2}(\mathrm{mm})$} & \multicolumn{3}{c|}{ Leaf $\mathbf{3}$ (mm) } & \multicolumn{2}{c|}{ Leaf number } \\
\hline & 1 & 2 & 3 & Length & Width & Length & Width & Length & Width & Decusate & Spiral & Total \\
\hline co & $10.4 \pm 3.4$ & $16.8 \pm 7.4$ & $21 \pm 4.9$ & $16.1 \pm 2.2$ & $11.2 \pm 1.2$ & $259 \pm 1.5$ & $15.6 \pm 10$ & $35.5 \pm 59$ & $16 \pm 2.4$ & $8.8 \pm 1.2$ & $5.2 \pm 4.1$ & $14 \pm 4.0$ \\
\hline Wt & $189 \pm 1.9$ & $27.2 \pm 3.2$ & $31.8 \pm 43$ & $24.1 \pm 2.1$ & $13.4 \pm 0.8$ & $39 \pm 2.9$ & $19.4 \pm 1.6$ & $46.1 \pm 49$ & $189 \pm 2.9$ & $8.1 \pm 1.3$ & $3.7 \pm 2.7$ & $118 \pm 1.8$ \\
\hline$\%$ & $-45.16^{* * *}$ & $-38.41^{* * *}$ & $-33.89 * * *$ & $-33.22^{* * *}$ & $-16.39 * * *$ & $-33.57 * * *$ & $-19.36 * * *$ & $-23.01^{* * *}$ & $-15.48^{*}$ & 8.64 & 40.54 & 15.71 \\
\hline
\end{tabular}

Values of internode size and leaves are means \pm standard deviation $(n=15)$. Percentages refer to wild-type siblings in the $F_{2}$ segregating population. Asterisks indicate significant differences between the co mutant and wild-type: ${ }^{*} P<0.05 ; * * P<0.01 ; * * * P<0.001$.

The flowers of co plants may be easily distinguished from those of wild-type because stamens protrude outside the tube (Figure 1a). Furthermore, they were significantly smaller than those of wild-type (Figure 1b, 1c and Table 2) for all floral parameters analyzed, except for the adaxial stamens, which retained wild-type size (Figure 1d). In many cases, under greenhouse conditions, the adaxial protruding stamens tended to show dehiscence and dehydration before the flowers were fully open. Furthermore, the abaxial stamens appeared more separate than in wild-type, forming a characteristic $V$ shape (Figure 1d). Hand self-pollinated co flowers were fully fertile. Flower colour was not affected in co mutants, which displayed colour segregation of the nivea, delila and pallida recurrens loci (Figure S1) present in the 165E and Sippe50 wild-type background 


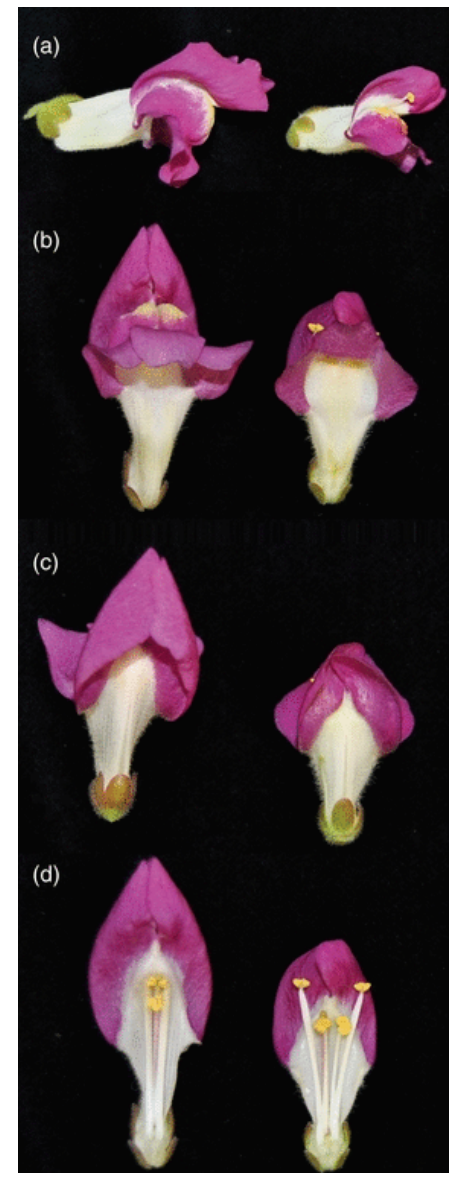

Figure 1. Wild-type (left) and co mutant flowers (right) from the side, and longitudinal sections.

Table 2. Comparison of floral parameters for wild-type, the co mutant, the $d e f^{\text {nic }}$ single mutant and the co def $f^{\text {nic }}$ double mutant

\begin{tabular}{|c|c|c|c|c|c|c|c|c|c|c|}
\hline Genotype & $\begin{array}{c}\text { Tube } \\
\text { length } \\
(\mathrm{mm})\end{array}$ & $\begin{array}{c}\text { Lower } \\
\text { length } \\
(\mathrm{mm})\end{array}$ & $\begin{array}{c}\text { Petal } \\
\text { height } \\
(\mathrm{mm})\end{array}$ & $\begin{array}{c}\text { Sepal } \\
\text { length } \\
(\mathrm{mm})\end{array}$ & $\begin{array}{c}\text { Tube } \\
\text { width } \\
(\mathrm{mm})\end{array}$ & $\begin{array}{c}\text { Upper } \\
\text { (total) } \\
\text { length } \\
(\mathrm{mm})\end{array}$ & $\begin{array}{c}\text { Lower petal } \\
\text { expansion } \\
(\mathrm{mm})\end{array}$ & $\begin{array}{c}\text { Upper petal } \\
\text { expansion } \\
(\mathrm{mm})\end{array}$ & $\begin{array}{c}\text { Stamen } \\
\text { lemgth } \\
(\mathrm{mm})\end{array}$ & $\begin{array}{c}\text { Gynoecium } \\
\text { length }(\mathrm{mm})\end{array}$ \\
\hline $\mathrm{Wt}$ & $17.9 \pm 0.7$ & $30.8 \pm 2.7$ & $26.4 \pm 2.7$ & $7.9 \pm 0.8$ & $12.1 \pm 0.8$ & $39.5 \pm 0.9$ & $26.2 \pm 1.6$ & $29.9 \pm 2.0$ & $25.6 \pm 0.9$ & $22 \pm 0.7$ \\
\hline $\mathrm{co}$ & $15.3 \pm 0.8$ & $23.5 \pm 1.3$ & $17.1 \pm 2.3$ & $6.6 \pm 0.5$ & $10.4 \pm 0.7$ & $28.3 \pm 1.4$ & $19.2 \pm 2.7$ & $16.4 \pm 2.3$ & $26 \pm 1.8$ & $20.1 \pm 1.0$ \\
\hline def $^{\text {nic }}$ & $8.7 \pm 4.9$ & $20.5 \pm 2.0$ & $11.2 \pm 1.9$ & $6.4 \pm 0.6$ & $7.1 \pm 0.5$ & $20.8 \pm 2.3$ & $15.8 \pm 2.9$ & $11.7 \pm 2.3$ & $16.6 \pm 1.3$ & $19.3 \pm 2.3$ \\
\hline co def fic & $5.3 \pm 0.5$ & $11.4 \pm 1.7$ & $8.1 \pm 1.0$ & $7.2 \pm 0.8$ & $5.7 \pm 0.5$ & $12.0 \pm 1.9$ & $7.6 \pm 1.5$ & $8.1 \pm 0.8$ & $14.8 \pm 0.6$ & $16.9 \pm 0.9$ \\
\hline \% deffic vs co def fic & $-38.38^{*}$ & $-44.64^{* * *}$ & $-27.93^{* * *}$ & 12.80 & $-19.26^{* * *}$ & $-42.25^{* * *}$ & $-51.82^{* * *}$ & $-30.37^{* *}$ & $-10.62^{* *}$ & $-12.17^{*}$ \\
\hline \%co vs $\mathrm{Wt}$ & $-15.07^{* * *}$ & $-23.64^{* * *}$ & $-35.01^{* * *}$ & $-16.48^{* * *}$ & $-14.03^{* * *}$ & $-28.37^{* * *}$ & $-26.93^{* * *}$ & $-45.09^{* * *}$ & 1.40 & $-8.68^{* * *}$ \\
\hline
\end{tabular}

Total number of measurements for each parameter $=10$. Values are means \pm standard deviation. Asterisks indicate significant differences using the wild-type or $d e f^{\text {nic }}$ single mutant as: ${ }^{*} P<0.05 ; * * P<0.01 ; * * * P<0.001$.

We investigated the effects of the co mutation on cell division and expansion in the various floral organs. Sexual organs in the co mutant showed independent cellular phenotypes, as cells in stamens were significantly smaller than in wild-type, whereas cell size in styles was not affected (Figure 2 and Table 3). With regard to petals, flat cells proximal to the tube did not show significant differences with respect to wild-type flowers. However, in the distal part of the petal, conical cells were $43 \%$ smaller than in wild-type, and flat cells showed a decrease in area of 33\%. Altogether, the observed petal phenotypes may be explained by a decrease in cellular size in the petals (Figure 2 and Table 3 ). 

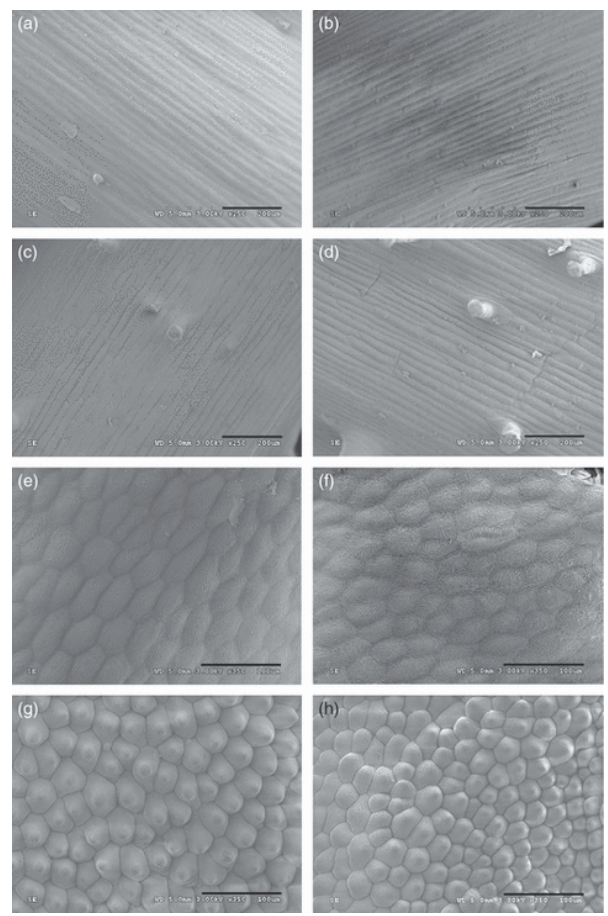

Figure 2. Scanning electron microscopy of cells from various organs of fully developed flowers of wild-type (left) and co mutant flowers (right). (a, b) Third-whorl styles, (c, d) fourth-whorl gynoecium, (e, f) dorsal petal, proximal to the tube, and (g, h) dorsal petal, distal part. Scale bars $=100 \mu \mathrm{m}$.

Table 3. Cell area of petal, stamen and style in wild-type and the co mutant

\begin{tabular}{|c|c|c|c|c|}
\hline \multirow{2}{*}{ Genotype } & $\begin{array}{c}\text { Stamen } \\
\left(\mu \mathrm{m}^{2}\right)\end{array}$ & $\begin{array}{c}\text { Style } \\
\left(\mu \mathrm{m}^{2}\right)\end{array}$ & \multicolumn{2}{|c|}{ Petal $\left(\mu \mathrm{m}^{2}\right)$} \\
\cline { 3 - 5 } & $2948.4 \pm 103.9$ & $2123.1 \pm 85.1$ & $756.9 \pm 29.0$ & $1609.66 \pm 52.19$ \\
\hline Co & $3568.1 \pm 76.4$ & $2221.9 \pm 70.5$ & $1346.5 \pm 43.3$ & $2101.24 \pm 55.83$ \\
\hline Wild-type & $-17.37^{*}$ & -4.45 & $-43.78^{*}$ & $-23.39 *$ \\
\hline$\%$ & &
\end{tabular}

Total number of cells measured for each organ/mutant $=50$. Values are means \pm standard error. Asterisks indicate significant differences between the co mutant and wild-type: ${ }^{*} P<0.05$.

\section{Co plays a role in B function}

As petal and stamen cell size were significantly reduced in the co mutant, we investigated a possible interaction with organ identity. We crossed co with the weak allele def ${ }^{\text {nic }}$. This allele affects secondand third-whorl organ identity, with sepaloid petals that are smaller than wild-type petals but still develop colour and conical cells (Schwarz-Sommer et al., 1992). We constructed an $F_{2}$ population of $c o \times d e f^{\text {nic }}$, obtaining a Mendelian segregation of 47 wild-type, $17 c o, 19 d e f^{\text {nic }}$ and seven plants with a stronger phenotype $\left(\chi^{2}=0.8642\right.$, d.f. $\left.=3, P=0.8341\right)$. The plants with floral phenotypes differing from co or def ${ }^{\text {nic }}$ single mutants were considered co def ${ }^{\text {nic }}$ double mutants. The phenotype resembled $d e f^{\text {nic }}$ but was more extreme, in some cases showing second-whorl sepalloid organs resembling those of $d e f^{g l i}$ null mutants (Figure 3a-c). We selfed co mutant siblings of the putative double mutants and obtained a segregation of 3:1 for plants displaying an enhanced def $f^{\text {nic }}$ phenotype, thus confirming that the effect of the co mutation is an enhancement of $d e f^{\text {nic }}$. The $C O$ gene is not allelic to $D E F$ based 
on the $F_{1}$ phenotypes that were wild-type and the fact that these genes map to linkage groups 6 and 8, respectively (Schwarz-Sommer et al., 2010).

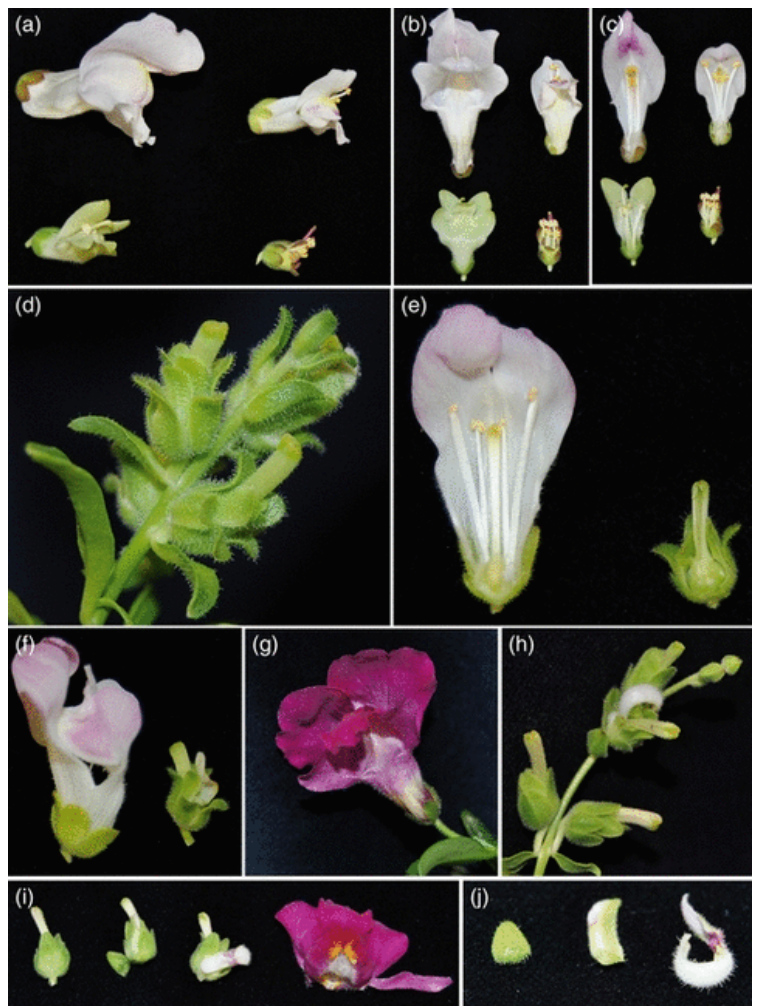

Figure 3. Phenotypes and lines. (a-c) Top left, wild-type; top right, the co mutant; bottom left, def $f^{\text {nic }}$; bottom right, co def ${ }^{\text {nic }}$ double mutant. (d) RNAi-DEF transgenic line showing extreme phenotypes similar to the classic $d e f^{g l i}$ null allele. (e) Section of wild-type (left) and the RNAi$D E F$ strong phenotype line (right). (f) Wild-type (left) and partially reverting RNAi-DEF flower with chimeric second-whorl organ (right). (g) RNAi-DEF flower with wild-type appearance. (h) glo-1 mutant showing a revertant second-whorl organ. (i) Comparison of glo-1 flowers, showing two without reversion, one with a partial petaloid structure in the second whorl, and a petal with wild-type appearance from the RNAi-DEF line. (j) Close-up of increasingly wild-type second-whorl organs from glo-1 flowers.

We compared organ size in co mutants and co def $f^{\text {nic }}$ double mutants, and found that all measured parameters were significantly smaller except first-whorl sepals (Table 2), indicating a synergistic effect of the co and $d e f^{\text {nic }}$ mutations. The most prominent decreases in size in the second whorl corresponded to the tube length and lateral expansion of the abaxial petals, which showed mean reductions $>60 \%(P<0.001)$. Furthermore, co def ${ }^{\text {nic }}$ double mutants completely lacked the typical Antirrhinum petal palate. Modest but significant reductions in size were found in the third whorl, which showed partial carpelloid structures, although stamens were formed in all flowers analyzed.

We examined cellular morphologies and sizes in petals of $d e f^{\text {nic }}$. As previously described, def $f^{\text {nic }}$ mutants showed a range of cells reminiscent of wild-type sepal and petal cell types. We observed typical puzzle cells seen in sepals, with a gradient towards the distal portion of the petal that started with flat oval-shaped cells that increased gradually in size until true conical cells formed at the edges of the petaloid organs (Figure 4). Both the size of the conical cells and the overall surface of the petal 
were greatly reduced compared to wild-type petals or co. In contrast, we did not find conical cells in co def $f^{\text {nic }}$ double mutant flowers, which displayed both puzzle cells and flat cells. Differences in cell morphology between the co mutant and the co def ${ }^{\text {nic }}$ double mutant were pronounced enough not to permit legitimate comparison of cell sizes. The lack of conical cells in co def ${ }^{\text {nic }}$ double mutants strongly suggests that co itself plays a role, not only in determination of cell size, but also in late petal development. Cells in the third whorl of co def ${ }^{\text {nic }}$ double mutants showed a decrease in size beyond that found for def ${ }^{\text {nic }}$ single mutants. The fourth-whorl style cells in wild-type and co were not significantly different (Table 3). However, the co def ${ }^{\text {nic }}$ double mutant had larger cells than def single mutants despite the fact that this organ is smaller (Table 4). This suggests that co may interact with other genes involved in carpel and stamen development such as PLENA and FARINELLI (Bradley et al., 1993; Davies et al., 1999).
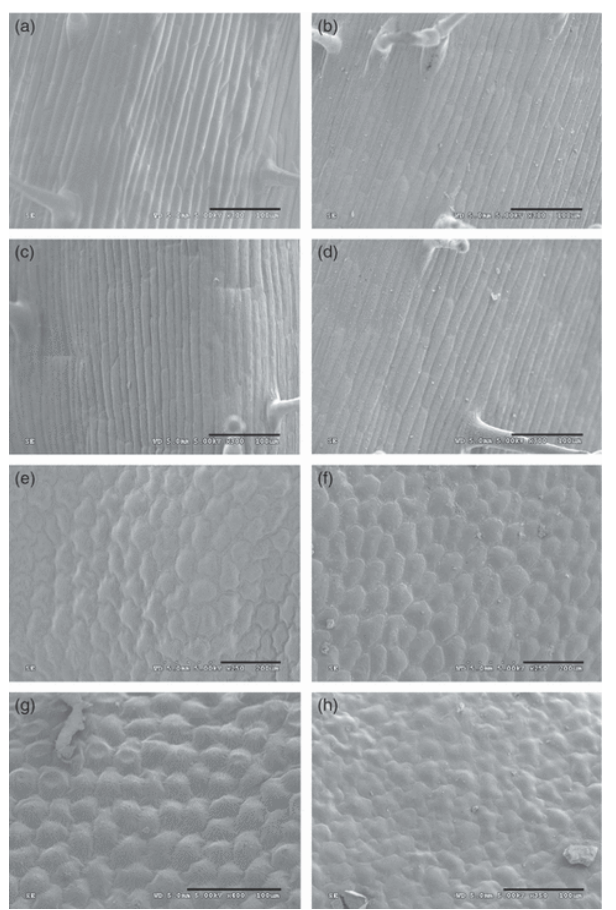

Figure 4. Scanning electron microscopy of floral organs of $d e f^{\text {nic }}$ mutant (left) and co def $f^{\text {fic }}$ double mutant (right). (a, b) Third-whorl organs, (c, d) gynoecia, (e, f) dorsal petal proximal region of flat cells, and ( $g$, h) dorsal petal distal region of conical cells. Scale bars $=100 \mu \mathrm{m}$.

Table 4. Cell area of stamen and style in the $d e f^{\text {nic }}$ single mutant and the co def $f^{\text {nic }}$ double mutant

\begin{tabular}{|c|c|c|}
\hline & Stamen filament $\left(\mu \mathrm{m}^{2}\right)$ & Style $\left(\mu \mathrm{m}^{2}\right)$ \\
\hline Wild-type & $3568.09 \pm 154.43$ & $2221.99 \pm 70.49$ \\
\hline$d e f^{\text {nic }}$ & $2213.4 \pm 96.5$ & $1466.9 \pm 76.2$ \\
\hline co def nic & $1940.5 \pm 76.6$ & $1842.2 \pm 70.3$ \\
\hline$\%$ co vs $w t$ & $-17.37 * * *$ & -4.45 \\
\hline$\% d e f^{\text {nic }}$ vs. co def $f^{\text {nic }}$ & $-12.33 *$ & $+25.58 * * *$ \\
\hline
\end{tabular}

Total number of cells measured for each organ/mutant $=50$. Values are means \pm standard error. Asterisks indicate significant differences using the wild-type or def $f^{\text {pic }}$ single mutant as: ${ }^{*} P<0.05 ; * * * P<0.001$. 


\section{Co plays a role in scent production}

We measured the production of three major scent compounds (myrcene, ocimene and methyl benzoate) in fully developed flowers of a segregating population of $c o$ and $d e f^{n i c}, 24 \mathrm{~h}$ after anthesis (Table 5 and Figure S2). We observed emission of the three compounds in wild-type flowers. However, we did not find myrcene in any of the co samples analyzed, and the levels of emission of ocimene and methyl benzoate were similar to those of wild-type. In $d e f^{\text {nic }}$ flowers, we found levels similar to wild-type for myrcene, whereas ocimene and methyl benzoate were drastically reduced. The phenotype of the co def $f^{n i c}$ double mutant was extreme concerning scent emission, as we were not able to detect myrcene, ocimene or methyl benzoate in any of the samples analyzed.

Table 5. Effect of the co and def $f^{\text {nic }}$ mutations on volatile levels

\begin{tabular}{|c|c|c|c|}
\hline Genotype & Myrcene & Ocimene & Methyl benzoate \\
\hline Wild-type & 40.2 & 251.2 & 137.2 \\
\hline co & ND & 156.6 & 165.4 \\
\hline$d e f^{\text {nic }}$ & 34.4 & 9.7 & 29.6 \\
\hline co $d e f^{\text {nic }}$ & ND & ND & ND \\
\hline
\end{tabular}

Quantities refer to mean emissions of three samples $\left(\mathrm{ng} \mathrm{g}^{-1}\right.$ tissue $\mathrm{h}^{-1}$ ). ND indicates that we could not detect the compound in any sample.

\section{Co is involved in DEF transcriptional control and plays a role in B function}

As the co mutant showed a number of phenotypes that may be described as B function-related, we investigated the effect of the co mutation on the B function transcriptional network by quantitative gene expression analysis. We found that $D E F$ gene expression was significantly down-regulated in co mutants to $11.6 \%$ of the value found in wild-type ( $P=0.04$; Figure $5 a)$, similar to the down-regulation in $\operatorname{def}^{\text {nic }}(P=0.653)$ versus wild-type. Surprisingly, the levels of $G L O$ expression were higher in co than in wild-type, but not significantly $(P=0.23)$. This finding is contrary to what would be expected from a positive autoregulatory loop scheme (Schwarz-Sommer et al., 1992), which suggests simultaneous down-regulation of GLO as observed in $\operatorname{def}^{n i c}(P=0.029)$. These unexpected results indicate that $C O$ is involved in the activation or maintenance of DEF expression, whereas GLO is not directly affected. In the co def ${ }^{\text {nic }}$ double mutant, both DEF and GLO expression were down-regulated compared to wild-type. Furthermore, the high levels of GLO in the co mutant may be partly responsible for the better petal development observed compared to $d e f^{\text {nic }}$, but the results for the double mutant indicate that $C O$ also plays a downstream role, beyond the uncovered effect on $D E F$ expression, and may be considered a B function gene itself, supporting the previous data on cell types and scent emission. 

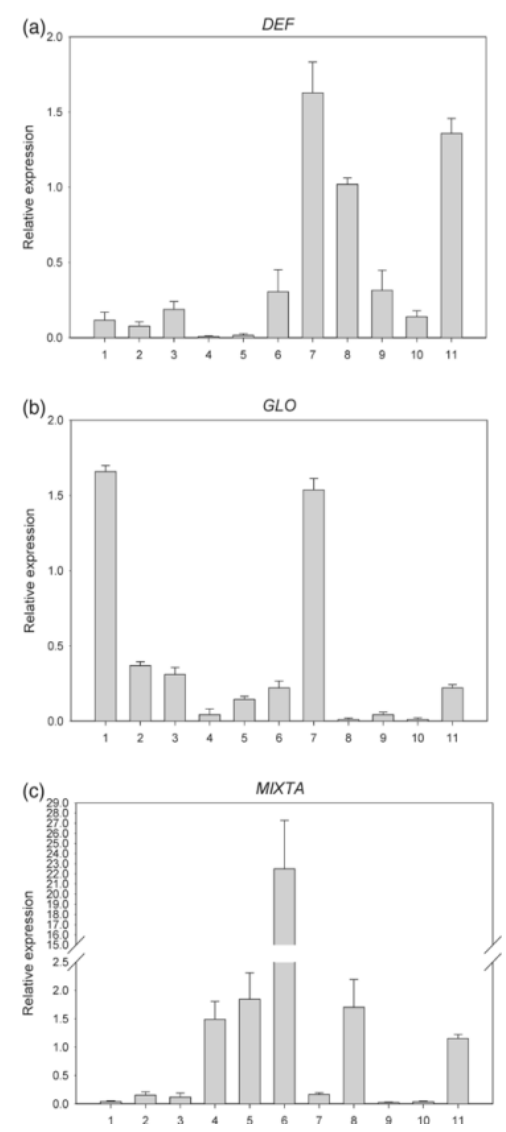

Figure 5. Relative expression of (a) DEFICIENS, (b) GLOBOSA and (c) MIXTA in second-whorl organs compared to wild-type petals. An arbitrary level of 1 was assigned to the wild-type: 1 , the co mutant; 2, def $f^{\text {nic }}$; 3 , co def ${ }^{\text {nic }}$ double mutant; 4, RNAi-DEF sepal; 5, RNAi-DEF petal/sepal; 6, RNAi-DEF petal; 7, RNAi-DEF petal (normal flower); 8, RNAi-DEF tube; 9, glo-1 sepal; 10, glo-1 revertant; 11, glo-1 petal.

\section{Quantitative analysis of transcriptional regulatory network in late petal development}

In order to obtain a comprehensive picture of gene expression levels of $D E F$ and $G L O$, and identify the quantitative thresholds supporting different degrees of petal development, we used a mixture of genetic backgrounds. We developed an improved protocol to transform Antirrhinum majus (see Experimental procedures and Appendix S1), and obtained two independent transgenic lines harbouring an RNAi-DEF construct that were positive for kanamycin resistance and showed a range of phenotypes from weak to null def alleles (Figures $3 d$ and S3). Flowers of the strongest line showed two whorls of sepals and a third whorl of carpels, typical of a def ${ }^{g l i}$ allele (Figure 3e). In a direct comparison, they could not be distinguished from flowers expressing $d e f^{g l i}$ or glo-1 null alleles. The strongest line showed progressive acropetal loss of the extreme phenotype, displaying flowers with second-whorl sepal/petal chimeric organs (Figure 3f), and eventually reverted completely to produce apparent wild-type flowers (Figure 3g).

We gathered second-whorl organs from the aforementioned single and double mutants and the strong RNAi-DEF line. In order to obtain additional samples from revertant tissue, we established a greenhouse plot of plants expressing the glo-1 unstable allele for several years, and obtained 
revertant flowers with second-whorl chimeric organs (Figure $3 \mathrm{~h}-\mathrm{j}$ ) during the spring under southern Spain growing conditions.

We analyzed the levels of $D E F$ and GLO expression in the second-whorl organs of the transgenic line displaying the strongest phenotype by quantitative RT-qPCR, and found that expression was reduced to $2 \%$ of wild-type, as expected for organs that were completely transformed into sepals (Figure 5). The smallest second-whorl chimeric organs recovered (sepal/petal) displayed levels of DEF expression at a level that was $14 \%$ of that of the wild-type $(P=0.029)$ (Figure 5a). Furthermore, the two independent RNAi lines displayed an interesting feature in that the first flowers showed a def phenotype that was lost later on, indicating that an acropetal gradient could overcome the RNAidependent decrease in gene expression. Independent transgenic experiments with other genes indicate that this was a feature of the RNAi-DEF construct but is not a general feature of Antirrhinum stably transformed lines (Manchado-Rojo, M., unpublished observations). RNAi-DEF flowers with a wild-type appearance had DEF and GLO expression levels similar to wild-type. The glo-1 allele shows instability, and we compared it against the RNAi-DEF plants and the series of co and def ${ }^{\text {nic }}$ mutants. The results obtained show that the levels of DEF in glo-1 were between 11 and $31 \%$ of wild-type in sepal and sepal/petal organs, with $22 \%$ in revertant petals and wild-type levels of expression in nearwild-type looking petals. In contrast, GLO levels did not fully recover the wild-type expression levels, showing levels that were always significantly lower than in wild-type petals.

Our data shows that thresholds of $11-15 \%$ of wild-type levels of expression of DEF or GLO are associated with development of recognizable petal tissue.

\section{Reciprocal DEF and GLO transcript levels change during development}

Although the currently supported hypothesis of B function is based on a positive autoregulatory loop of two B function gene products, a direct comparison of mRNA levels for DEF versus GLO has not been reported, and examination of the levels of $D E F$ and GLO in the tissues analyzed indicated that important differences may exist in the reciprocal levels of expression. Thus we used the data obtained to perform a nested calculation allowing direct comparison of DEF versus GLO in each sample. We used a large sample for quantitative RT-qPCR: 20 biological samples with three technical replicates comprising ten wild-type flowers at developmental stage 13-14, i.e. approximately $1 \mathrm{~cm}$ long and still closed (Vincent and Coen, 2004), and ten wild-type fully open flowers 1 day after anthesis. The reason for this was that sampling of revertant and transgenic tissue necessarily has to be performed when development is complete and the phenotypes are distinguishable, but we wished to identify possible ontogenic changes in reciprocal levels of $D E F$ and GLO gene expression. A 
simple inspection of the data from closed flowers showed that, contrary to what was expected, transcriptional levels of $D E F$ and GLO were not equal. GLO gene expression in petals was significantly lower than that of $D E F$ in four of ten samples. Combining all samples indicated a level for GLO transcripts of 0.806 relative to $\operatorname{DEF}(P=0.013)$, with most values below 1.0 (Figure 6 and Table 6). Surprisingly this unequal relationship for GLO versus DEF expression levels resulted in significantly higher expression of $G L O$ in petals when flowers were open $(1.847 ; P=0.000)$. We compared two samples of gene expression data that had equal variances (Fligner-Killeen test, $P=0.5541$ ), and found that, as expected from the data inspection, the relationships between DEF and GLO expression in closed and open flowers are significantly different $(t$-test, $P=5.765 \mathrm{e}-06)$. The data show that, from middle to late stages of development, the relationship between DEF and GLO transcription varies significantly, with a marked up-regulation of GLO compared to DEF.

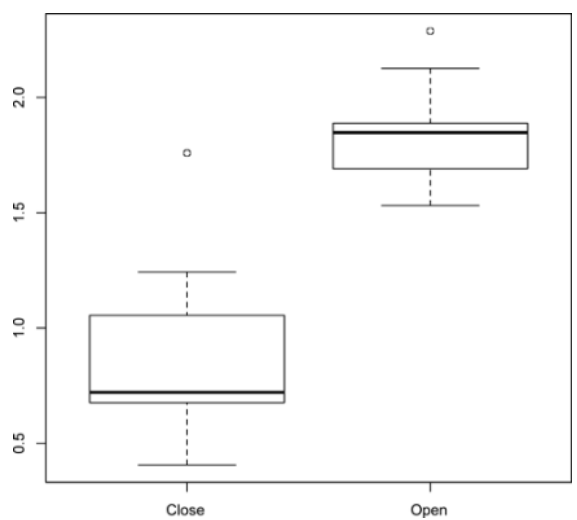

Figure 6. Box plot of expression values for GLO versus DEF in closed and open flowers. The $y$ axis refers to $G L O$ expression values compared to $D E F$ having an arbitrary value of 1 .

Table 6. Expression of GLO compared to $D E F$ in various tissues

\begin{tabular}{lcc}
\hline Organ & $\begin{array}{c}\text { Related GLO } \\
\text { expression }\end{array}$ & p values \\
\hline WT close & 0.806 & 0.013 \\
WT open & 1.847 & 0.000 \\
$C O$ & 13.375 & 0.001 \\
$D E F^{\text {nic }}$ & 20.128 & 0.0020 \\
CO DEF & 6.824 & 0.0010 \\
pH12-DEF petal (small) & 6.465 & 0.003 \\
pH12-DEF petal-sepal & 98.632 & 0.001 \\
pH12-DEF sepal & 60.537 & 0.0000 \\
pH12-DEF tube & 8.05 & 0.234 \\
pH12-DEF (normal flower) & 12.36 & 0.0010 \\
Glo-1 sepal & 0.093 & 0.001 \\
Glo-1 rev & 0.617 & 0.491 \\
Glo-1 petal & 1.057 & 0.695 \\
\hline
\end{tabular}

An arbitrary value of 1 was assigned to each tissue for the level of $D E F$.

In glo-1 revertant petals, DEF and GLO expression levels were close to 1 . However, DEF and GLO levels were dissimilar in the rest of the samples analyzed (Table 6). In perfectly formed petals of 
RNAi-DEF plants, GLO expression was at least 11 -fold higher than DEF. These large differences between $D E F$ and GLO expression were also found in co petals, indicating that disparity in gene expression between $D E F$ and GLO may be tolerated and still give rise to petal tissue. In the rest of the samples with strong homeotic alterations, differences between DEF and GLO ranged between five fold in co def ${ }^{\text {nic }}$ double mutants to close to 100 -fold in the strongest homeotically transformed organs, i.e. sepal/petal organs of RNAi-DEF or second-whorl sepals of glo-1. Our results show that, in wild-type flowers, DEF and GLO expression is not matched, and the large differences between the two genes in terms of gene expression in the array of tissues analyzed cannot be completely reconciled if we assume a positive autoregulatory loop as the sole form of B function transcriptional maintenance.

\section{Effect of the co mutation and B function manipulation on downstream processes}

As MIXTA is a well-defined downstream target of B function, and the co mutation affected the area of conical cells, we measured MIXTA gene expression and found that levels of MIXTA in the co mutant were as low as $4.1 \%$ of the wild-type (Figure 5 ). These low levels were also found in secondwhorl sepals of glo-1, glo-1 revertant sepal/petal tissues and RNAi-DEF normal flowers. However, the other RNAi-DEF tissues showed higher levels of MIXTA expression, indicating that, although the levels of $D E F$ and GLO were significantly lower than in wild-type, there may be other factors involved requiring further analysis.

\section{Discussion}

\section{A quantitative component of homeotic gene function}

As the $A B C$ model is based on spatial restriction of gene expression, much information has been generated to explain the discrete gene expression patterns. Many mutants identified show homeotic changes caused by lack of expression of the $A B C$ genes. Less well characterized are the quantitative requirements for floral organ identity genes. The original hypothesis developed in Antirrhinum postulates that DEF and GLO transcription occurs in an initial step, and self-maintained gene expression levels take over the initial activation to run the developmental program until organ development is complete.

Our data shows that levels of DEF or GLO mRNA of $11 \%$ or above can support development of recognizable petal tissue. However, these levels do not sustain full organ size. The fact that the palate is completely absent in many def ${ }^{\text {nic }}$ flowers and all co def $f^{\text {nic }}$ double mutants indicates that different regions of the petal also require different thresholds of B function for development or have 
different levels of expression of B function along the petal area. The effects on late developmental stages are even more pronounced, as the finding of MIXTA expression levels of $4 \%$ of the wild-type in the co mutant or $16 \%$ in RNAi-DEF revertant petal confirms previous work that established the quantitative importance of DEF expression for MIXTA expression (Perez-Rodriguez et al., 2005). Reduced expression of the $C$ function gene AGAMOUS $(A G)$ in Arabidopsis by RNAi plants and plants expressing several ag alleles analyzed have shown that threshold levels of $A G$ have different effects on organ identity and meristem determinacy (Sieburth et al., 1995;Causier et al., 2009; Das et al., 2009; Maier et al., 2009), indicating that not all downstream processes require the same levels of expression. Furthermore, quantitative changes in gene expression modify the spatial expression of AG in Arabidopsis (Cartolano et al., 2009), supporting the importance of quantitative gene expression levels for floral patterning and organ development.

The phenotypic effects of the co mutation on petal cell development clearly show a strong decrease in the area with conical cells, correlated with down-regulation of MIXTA. This decrease in the area comprising conical cells and the smaller size of the cells may explain the decrease in MIXTA expression. It may also explain a quantitative decrease in scent production, as benzoic acid carboxyl methyl transferase, which is involved in methyl benzoate production, is expressed in conical cells in Antirrhinum (Kolosova et al., 2001). An additional role of CO downstream of DEF is supported by the finding that $d e f^{\text {nic }}$ single mutants and co def ${ }^{\text {nic }}$ double mutants have similar levels of DEF and GLO, but the phenotypes analyzed are more extreme in the double mutant, suggesting that $C O$ is a $\mathrm{B}$ function gene that is involved in activation or maintenance of $D E F$, and activation of part of the scent transcriptional network at late stages of petal development.

Determining the degree of homeotic transformation or petal organ identity has not been an easy task. Studies in Arabidopsis using ectopic expression of PISTILLATA (PI) or its homolog from pea PsPI have used chimeric first-whorl organs comprising sepal and petal tissue as criteria to establish B function activity (Krizek and Meyerowitz, 1996; Berbel et al., 2005). Indeed, model organisms such as Petunia, in which B function genes are duplicated, allow a much more detailed analysis. For instance, petal defects in plants expressing mutant alleles of Phglo1 and Phglo2 show greener and broader midvein, conversion of conical cells to sepal-like epidermal cells, or lack of stamen fusion to the petal tube (Vandenbussche et al., 2004). Expression of the TM6 gene from Petunia under the control of a 35 S promoter can rescue Phdef phenotypic defects to some extent, but still petals show a broad green midvein (Rijpkema et al., 2006). Thus our approach of considering petal tissue as second-whorl organs that have recognizable regions resembling petals and are confirmed by scanning electron microscopy as having conical cells, fulfils a qualitative definition of the organ. 
Determining what a petal is in terms of identity does not address the functional aspects. Petals have at least two recognizable functions: physical protection of the sexual organs during flower development, and insect attraction. Clearly these two functions do not necessarily overlap or have similar importance in all plants. Our data suggest that levels of DEF and GLO transcription above a threshold are required to obtain wild-type petal size, good development of conical cells, and scent production. Our data do not allow us to determine whether the reduction in scent is a result of decreased MIXTA expression that leads to fewer conical cells in which scent is produced, or whether it is a direct effect of $C O$ or DEF and GLO. However, these possibilities are not mutually exclusive.

\section{Structure of the B function regulatory network}

A network topology based on a simple positive autoregulatory loop is not supported by the data obtained in the various tissues and genetic backgrounds described here. First, the co mutant has a strong effect on $D E F$ but not on GLO gene expression, indicating that $C O$ may be directly involved in $D E F$ activation. GLO expression levels were maintained despite a decreased level of DEF-GLO heterodimer and increased basal promoter activity, indicating that other factors maintain GLO expression in the absence of positive autoregulation. This basal promoter activity may be flowerspecific as GLO has well-defined expression patterns in petals and stamens (Trobner et al., 1992; Zachgo et al., 1995). In second-whorl organs with complete homeotic transformation, although the actual level of expression of DEF in glo-1 or GLO in RNAi-DEF is significantly down-regulated compared to wild-type, the levels of expression of GLO compared to DEF in RNAi-DEF and DEF versus GLO in glo-1 are significantly higher. This implies that the positive autoregulatory loop is only part of the $\mathrm{B}$ function maintenance, and a basal level of transcriptional activation is present for both $D E F$ and $G L O$, at least at late stages of development. A graphical model describing the current model of transcriptional network and a new one based on the data presented in this contribution are shown in Figure 7. Activation of $\mathrm{B}$ function consists of triggering DEF and GLO (Figure 7a), and such activation becomes independent at the middle and late stages of development (Figure 7b). Activation of DEF and GLO seem to be partly independent as CO only affects DEF (Figure 7c). Early experiments in tobacco showed a spatial difference in transcriptional activation of NtDEF and NtGLO. Ectopic expression of DEF and GLO causes ectopic expression of NtDEF in leaves and all floral organs, whereas NtGLO is ectopically expressed only in first-whorl organs (Davies et al., 1996a). This indicates that positive autoregulation comprises organ-specific components and may differ between $D E F$ and GLO. 


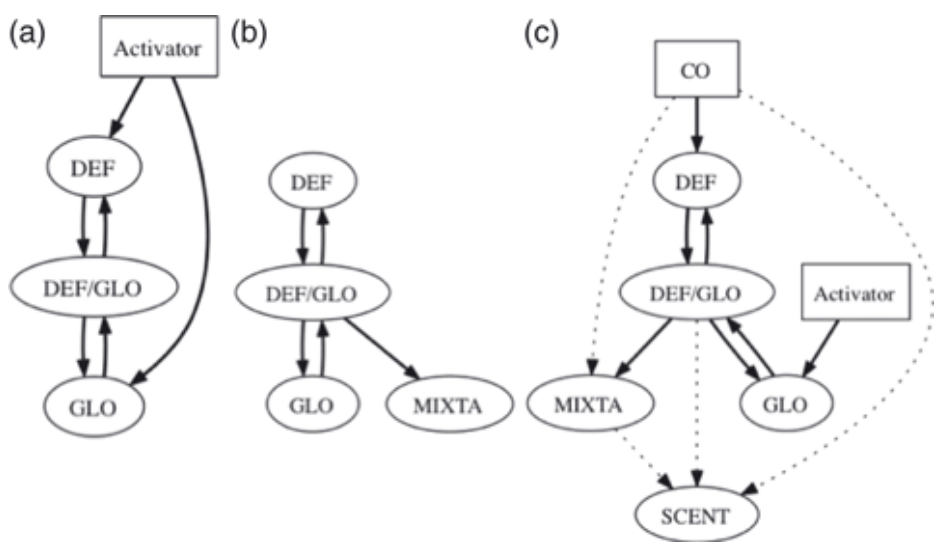

Figure 7. A graphical model of B function network topologies. Initial steps of B function activation during early petal development (a), middle to late stages of petal development (b), and a newly proposed network topology for late stages of development (c). Rectangles refer to a transcriptional activation function. Dotted lines refer to direct activation that is possible but the current data do not allow discrimination between direct and indirect activation.

We did not expect to observe differences in gene expression between $D E F$ and $G L O$, and even more unexpected was the existence of developmental differences such as those found in the balance of the two transcripts. This also shows that the transcriptional network topology of B function changes during petal development, and is not a fixed entity as originally thought. However, petal growth and anthocyanin production are biphasic. Petal growth comprises cell division in early stages and cell expansion at later stages in different plants (Martin and Gerats, 1993; Reale et al., 2002), whereas anthocyanin genes show early and late activation (Jackson et al., 1992;Weiss et al., 1993). Finally, scent production starts at anthesis. These obvious changes in the downstream targets of DEF and GLO cannot be explained by a simple model in which B function operates as a single-geared process. Our work has concentrated on transcriptional changes, but recent work has shown that translation rate constants play a dominant role in determining protein levels, and, combined with mRNA levels, account for $95 \%$ of the variance in protein quantities (Schwanhäusser et al., 2011). This suggests that, if linear levels of translation rates are maintained during petal development for $D E F$ and $G L O$, the changes in mRNA should translate into differing levels of protein.

Recent work has shown that quaternary complexes with diverse composition co-exist in Arabidopsis petals, indicating that there is an inherent flexibility in MADS-box tetramer formation (Smaczniak et al., 2012). The developmental changes in the ratio of DEF/GLO expression levels may have implications with regard to the type of target genes that plant MADS box complexes recognize during petal development, and may explain the gradual developmental processes that occur during petal morphogenesis that lasts more than 20 days in Antirrhinum. 


\section{Experimental Procedures}

\section{Plant material and genetics}

The compacta and deficiens nicotianoides mutants were obtained from the Gatersleben collection (IPK Gatersleben, Gatersleben, Germany). The laboratory lines Sippe50, 165E and the globosa unstable allele glo-1 (Trobner et al., 1992) was obtained from Dr Zsuzsanna Schwarz-Sommer (MaxPlanck-Institut für Pflanzenzüchtungsforschung, Köln, Germany). Plants were grown in the greenhouse as described previously (Bayo-Canha et al., 2007). Homozygote mutants were crossed to obtain $F_{2}$ plants as described previously (Egea-Cortines et al., 1999), and double mutants were identified by their phenotype (see Results) and the corresponding Mendelian segregation.

\section{Microscopy}

Fully developed flowers were harvested and analyzed as described previously (Delgado-Benarroch et al., 2009b).

\section{Constructs}

We cloned a fragment of $207 \mathrm{bp}$ encompassing the last 60 codons and $27 \mathrm{bp}$ of the $3^{\prime}$ UTR of the DEFICIENS cDNA from A. majus into the pHellsgate12 plasmid (Helliwell and Waterhouse, 2003), using the primers DEF-forward (5'-GATGCAAGGAGAGAGGATC-3') and DEF-reverse (5'CTATAACATATATCGATCATACCATTAATT-3') (Table S1). The hairpin construct of the pHellsgate12 vector was checked by PCR using an internal primer for the intron pH12-forward (5'GTTGGCAGCATCACCCGA-3') and pH12-reverse (5'-AAACTAGAAATTTACCTGCAC- ${ }^{\prime}$ ) and a primer for the $D E F$ gene in both directions.

\section{Scent analysis}

The volatile constituents in the flowers of the plants were separated and qualitatively identified by capillary gas chromatography/mass spectrometry (GC-MS).

For extraction of the volatile components, one cut flower per line was placed inside Falcon tubes for $24 \mathrm{~h}$ (DeltaLab,http://www.deltalab.es). The tubes contained a suspended Twister ${ }^{\mathrm{TM}}$ bar (Gerstel GmbH \& Co. KG, http://www.gerstel.de/), a magnetic stir bar of $10 \mathrm{~mm}$ length coated with $0.5 \mathrm{~mm}$ polydimethylsiloxane that had previously been conditioned. 
Scent profiles were resolved on a 6890 gas chromatograph coupled to a 5975 inert XL mass selective detector (Agilent Technologies,http://www.home.agilent.com) equipped with a thermal desorption unit, a cooled injector system (CIS 4) and a multi-purpose sampler (MPS2) (Gerstel GmbH \& Co. KG).

The GC separation was performed on an HP-5MS UI capillary column (Agilent Technologies), $30 \mathrm{~m}$, length $\times 0.25 \mathrm{~mm}$, internal diameter $\times 0.25 \mu \mathrm{m}($ film) in constant pressure mode. The oven temperature was sequentially increased from 50 to $70^{\circ} \mathrm{C}$ at 5 ㅇ per min, held for $1 \mathrm{~min}$, and thereafter increased to $240^{\circ} \mathrm{C}$ at $10^{\circ} \mathrm{C}$ per min, with a holding time of $15 \mathrm{~min}$. The inlet operated in solvent vent mode with a split ratio of 1:15. Chromatographic-grade helium was used as the carrier gas. We used $n$-pentadecane as an internal standard for qualitative analysis of the samples, adding $1 \mu l n$ pentadecane (standard for gas chromatography, Fluka, Sigma-Aldrich,http://www.sigmaaldrich.com) prepared to $20 \mathrm{ppm}$ in dichloromethane (Lab-Scan, http://www.labscan.ie/)).

The stir bar was thermally desorbed into the thermal desorption unit using the following desorption temperature program: initial temperature of $40^{\circ} \mathrm{C}$, ramping at $100^{\circ} \mathrm{C}$ per min until $150^{\circ} \mathrm{C}$, and a holding time of $5 \mathrm{~min}$. The transfer temperature was $300^{\circ} \mathrm{C}$, working in splitless desorption mode. The volatiles thermally desorbed were cryo-focused in the cooled injector system inlet at $-100^{\circ} \mathrm{C}$ using liquid nitrogen, with a carrier gas flow of $50 \mathrm{ml} \mathrm{min}^{-1}$. After cryo-focusing was completed, the volatiles were transferred into the capillary column by heating the CIS4 inlet at a rate of $10^{\circ} \mathrm{C} \mathrm{sec}$ to $150^{\circ} \mathrm{C}$ (holding time $3 \mathrm{~min}$ ).

Mass spectra were collected in the scan range $\mathrm{m} / \mathrm{z} 30-450$. The measurements were performed using an electron bombardment ion source with electron energy of $70 \mathrm{eV}$. The transfer line, source and quadrupole temperatures were set at 280,230 and $150^{\circ} \mathrm{C}$, respectively. The chromatograms and mass spectra were evaluated using ChemStation software (G1791CA, version D.03.00; Agilent Technologies). Chromatographic peak identification was performed by library matching using the Standard Reference Database 1A NIST 2005, version 2.0 (National Institute of Standards and Technology, http://www.nist.gov/rsd/nist1a.cfm).

\section{Quantitative PCR}

Total RNA was isolated from $100 \mathrm{mg}$ homogenized plant material using an RNeasy mini kit (Qiagen, http://www.qiagen.com/default.aspx), including DNase treatment. cDNA was synthesized from $1 \mu \mathrm{g}$ total RNA using a Maxima first strand cDNA synthesis kit (Fermentas, http://www.fermentas.com/ en/home). 
Quantitative RT-PCR reactions were performed using SYBR Premix ExTaq ${ }^{\mathrm{TM}}$ (Takara, http://www.takara-bio.com/) on a Rotor-Gene Q machine (Qiagen). The housekeeping gene ubiquitin protein ligase was used for relative quantification of gene expression. In order to minimize the variability, we used three biological replicates and two technical replicates for each sample. We obtained take-offs and efficiency values and computed differences in gene expression analysis as described previously and using the REST program (Pfafflet al., 2002; Delgado-Benarroch et al., 2009a; Mallona et al., 2010, 2011).

\section{Antirrhinum transformation}

We developed a new protocol to obtain stable transformants (Appendix S1). These transformants were further analyzed by PCR using primers for the NPTII gene. Two independent plants positive for NPTII that showed phenotypes that ranged from the classic null allele $\operatorname{def}^{g l i}$ to weak alleles such as def $f^{\text {nic }}$ were also used.

\section{Statistics}

Statistical analysis was performed using the $\mathrm{R}$ package (http://www.r-project.org/) and Excel (Microsoft, http://www.microsoft.com). Unless otherwise stated, we used the Kruskal-Wallis test because growth and cellular data were not normally distributed.

\section{Graphical modelling}

The graphic models describing the currently known and proposed transcriptional networks were programmed in the Dot graph specification language and visualized using Graphviz (http://www.graphviz.org).

\section{Acknowledgements}

This work was funded by the Ministerio de Ciencia e Innovación/Fondos Europeos de Desarrollo Regional, FEDER (project BFU-2010-15843). We would like to thank Dr Leandro Peña (Centro de Protección Vegetal y Biotecnología, Instituto Valenciano de Investigaciones Agrarias, Valencia, Spain) for suggesting the use of Agrobacterium tumefaciens strains for transformation. We are grateful to Dr Barry Causier (Institute of Integrative and Comparative Biology, Faculty of Biological Sciences University of Leeds, UK) and Fabiola Ruiz Ramón for comments on the manuscript. 


\section{References}

Almeida, J., Carpenter, R., Robbins, T.P., Martin, C. and Coen, E.S. (1989) Genetic interactions underlying flower color patterns in Antirrhinum majus. Genes Dev. 3, 1758-1767.

Alon, U. (2007) Network motifs: theory and experimental approaches. Nat. Rev. Genet. 8, 450-461.

Anastasiou, E. and Lenhard, M. (2007) Growing up to one's standard. Curr. Opin. Plant Biol. 10, 63-69.

Angenent, G.C., Franken, J., Busscher, M., Colombo, L. and van Tunen, A.J. (1993) Petal and stamen formation in Petunia is regulated by the homeotic gene fbp1. Plant J. 4, 101-112.

Baumann, K., Perez-Rodriguez, M., Bradley, D., Venail, J., Bailey, P., Jin, H.L., Koes, R., Roberts, K. and Martin, C. (2007) Control of cell and petal morphogenesis by R2R3 MYB transcription factors. Development, 134, 1691-1701.

Bayo-Canha, A., Delgado-Benarroch, L., Weiss, J. and Egea-Cortines, M. (2007) Artificial decrease of leaf area affects inflorescence quality but not floral size in Antirrhinum majus. Sci. Hortic. 113, 383-386.

Berbel, A., Navarro, C., Ferrandiz, C., Canas, L.A., Beltran, J.P. and Madueno, F. (2005) Functional conservation of PISTILLATA activity in a pea homolog lacking the PI motif. Plant Physiol. 139, 174-185.

Bey, M., Stuber, K., Fellenberg, K., Schwarz-Sommera, Z., Sommer, H., Saedler, H. and Zachgo, S. (2004) Characterization of Antirrhinum petal development and identification of target genes of the class $B$ MADS box gene DEFICIENS. Plant Cell, 16,3197-3215.

Bradley, D., Carpenter, R., Sommer, H., Hartley, N. and Coen, E. (1993) Complementary floral homeotic phenotypes result from opposite orientations of a transposon at the plena locus of Antirrhinum. Cell, 72, 85-95.

Carpenter, R. and Coen, E.S. (1990) Floral homeotic mutations produced by transposon mutagenesis in Antirrhinum majus. Genes Dev. 4, 1483-1493.

Cartolano, M., Efremova, N., Kuckenberg, M., Raman, S. and Schwarz-Sommer, Z. (2009) Enhanced AGAMOUS expression in the centre of the Arabidopsis flower causes ectopic expression over its outer expression boundaries. Planta, 230, 857-862.

Causier, B., Bradley, D., Cook, H. and Davies, B. (2009) Conserved intragenic elements were critical for the evolution of the floral C-function. Plant J. 58, 41-52.

Causier, B., Schwarz-Sommer, Z. and Davies, B. (2010) Floral organ identity: 20 years of ABCs. Semin. Cell Dev. Biol. 21, 73-79.

Coen, E.S. and Meyerowitz, E.M. (1991) The war of the whorls: genetic interactions controlling flower development. Nature, 353,31-37.

Das, P., Ito, T., Wellmer, F., Vernoux, T., Dedieu, A., Traas, J. and Meyerowitz, E.M. (2009) Floral stem cell termination involves the direct regulation of AGAMOUS by PERIANTHIA. Development, 136, 1605-1611.

Davies, B., DiRosa, A., Eneva, T., Saedler, H. and Sommer, H. (1996a) Alteration of tobacco floral organ identity by expression of combinations of Antirrhinum MADS-box genes. Plant J. 10, 663-677.

Davies, B., Egea-Cortines, M., de Andrade, S.E., Saedler, H. and Sommer, H. (1996b) Multiple interactions amongst floral homeotic MADS box proteins. EMBO J. 15, 4330-4343.

Davies, B., Motte, P., Keck, E., Saedler, H., Sommer, H. and Schwarz-Sommer, Z. (1999) PLENA and FARINELLI: redundancy and regulatory interactions between two Antirrhinum MADS-box factors controlling flower development. EMBO J. 18, 4023-4034.

Delgado-Benarroch, L., Causier, B., Weiss, J. and Egea-Cortines, M. (2009a) FORMOSA controls cell division and expansion during floral development in Antirrhinum majus. Planta, 229, 1219-1229.

Delgado-Benarroch, L., Weiss, J. and Egea-Cortines, M. (2009b) The mutants compacta ähnlich, Nitida and Grandiflora define developmental compartments and a compensation mechanism in floral development in Antirrhinum majus. J. Plant. Res. 122,559-569.

Di Stilio, V.S., Martin, C., Schulfer, A.F. and Connelly, C.F. (2009) An ortholog of MIXTA-like2 controls epidermal cell shape in flowers of Thalictrum. New Phytol. 183, 718-728.

Dornelas, M.C., Patreze, C.M., Angenent, G.C. and Immink, R.G.H. (2011) MADS: the missing link between identity and growth? Trends Plant Sci. 16, 89-97. 
Dudareva, N., Murfitt, L.M., Mann, C.J., Gorenstein, N., Kolosova, N., Kish, C.M., Bonham, C. and Wood, K. (2000) Developmental regulation of methyl benzoate biosynthesis and emission in snapdragon flowers. Plant Cell, 12, 949-961.

Dudareva, N., Martin, D., Kish, C.M., Kolosova, N., Gorenstein, N., Faldt, J., Miller, B. and Bohlmann, J. (2003) $(E)$ - $\beta$-ocimene and myrcene synthase genes of floral scent biosynthesis in snapdragon: function and expression of three terpene synthase genes of a new terpene synthase subfamily. Plant Cell, 15, 12271241.

Egea Gutierrez-Cortines, M. and Davies, B. (2000) Beyond the ABCs: ternary complex formation in the control of floral organ identity. Trends Plant Sci. 5, 473-478.

Egea-Cortines, M., Saedler, H. and Sommer, H. (1999) Ternary complex formation between the MADS-box proteins SQUAMOSA, DEFICIENS and GLOBOSA is involved in the control of floral architecture in Antirrhinum majus. EMBO J. 18, 5370-5379.

Espinosa-Soto, C., Padilla-Longoria, P. and Alvarez-Buylla, E.R. (2004) A gene regulatory network model for cellfate determination during Arabidopsis thaliana flower development that is robust and recovers experimental gene expression profiles. Plant Cell,16, 2923-2939.

Ferrandiz, C., Gu, Q., Martienssen, R. and Yanofsky, M.F. (2000) Redundant regulation of meristem identity and plant architecture by FRUITFULL, APETALA1 and CAULIFLOWER. Development, 127, 725-734.

Fujiwara, T., O'Geen, H., Keles, S., Blahnik, K., Linnemann, A.K., Kang, Y.A., Choi, K., Farnham, P.J. and Bresnick, E.H. (2009) Discovering hematopoietic mechanisms through genome-wide analysis of GATA factor chromatin occupancy. Mol. Cell, 36,667-681.

Geuten, K., Viaene, T. and Irish, V.F. (2011) Robustness and evolvability in the B-system of flower development. Ann. Bot. 107,1545-1556.

Goodwin, S., Kolosova, N., Kish, C.M., Wood, K.V., Dudareva, N. and Jenks, M.A. (2003) Cuticle characteristics and volatile emissions of petals in Antirrhinum majus. Physiol. Plant. 117, 435-443. Erratum in Physiol. Plant. 119, 605.

Halfter, U., Ali, N., Stockhaus, J., Ren, L. and Chua, N.H. (1994) Ectopic expression of a single homeotic gene, the Petunia gene green petal, is sufficient to convert sepals to petaloid organs. EMBO J. 13, 1443-1449.

Heintzen, C., Nater, M., Apel, K. and Staiger, D. (1997) AtGRP7, a nuclear RNA-binding protein as a component of a circadian-regulated negative feedback loop in Arabidopsis thaliana. Proc. Natl Acad. Sci. USA, 94, 8515-8520.

Helliwell, C. and Waterhouse, P. (2003) Constructs and methods for high-throughput gene silencing in plants. Methods, 30,289-295.

Honma, T. and Goto, K. (2000) The Arabidopsis floral homeotic gene PISTILLATA is regulated by discrete ciselements responsive to induction and maintenance signals. Development, 127, 2021-2030.

Irish, V.F. and Yamamoto, Y.T. (1995) Conservation of floral homeotic gene function between Arabidopsis and Antirrhinum. Plant Cell, 7, 1635-1644.

Jackson, D., Roberts, K. and Martin, C. (1992) Temporal and spatial control of expression of anthocyanin biosynthetic genes in developing flowers of Antirrhinum majus. Plant J. 2, 425-434.

Kalir, S., Mangan, S. and Alon, U. (2005) A coherent feed-forward loop with a SUM input function prolongs flagella expression. Escherichia coli. Mol. Syst. Biol. 1, 2005.0006.

Kaufmann, K., Muino, J.M., Jauregui, R., Airoldi, C.A., Smaczniak, C., Krajewski, P. and Angenent, G.C. (2009) Target genes of the MADS transcription factor SEPALLATA3: integration of developmental and hormonal pathways in the Arabidopsis flower.PLoS Biol. 7, 854-875.

Kaufmann, K., Nagasaki, M. and Jauregui, R. (2010a) Modelling the molecular interactions in the flower developmental network of Arabidopsis thaliana. In Silico Biol. 10, 125-143.

Kaufmann, K., Wellmer, F., Muino, J.M. et al. (2010b) Orchestration of floral initiation by APETALA1. Science, $328,85-89$.

Kempin, S.A., Savidge, B. and Yanofsky, M.F. (1995) Molecular basis of the cauliflower phenotype in Arabidopsis. Science, 267,522-525.

Kolosova, N., Sherman, D., Karlson, D. and Dudareva, N. (2001) Cellular and subcellular localization of Sadenosyl-I-methionine: benzoic acid carboxyl methyltransferase, the enzyme responsible for biosynthesis of the volatile ester methylbenzoate in snapdragon flowers. Plant Physiol. 126, 956-964. 
Krizek, B.A. and Meyerowitz, E.M. (1996) The Arabidopsis homeotic genes APETALA3 and PISTILLATA are sufficient to provide the B class organ identity function. Development, 122, 11-22.

Kuckuck, H. and Schick, R. (1930) Die Erbfaktoren bei Antirrhinum majus und ihre Bezeichnung. Z. Indukt. Abstamm. Vererbungsl.56, 51-83.

Laitinen, R.A.E., Pollanen, E., Teeri, T.H., Elomaa, P. and Kotilainen, M. (2007) Transcriptional analysis of petal organogenesis in Gerbera hybrida. Planta, 226, 347-360.

Lenser, T., Theissen, G. and Dittrich, P. (2009) Developmental robustness by obligate interaction of class B floral homeotic genes and proteins. PLoS Comput. Biol. 5, e1000264.

Ma, W., Lai, L., Ouyang, Q. and Tang, C. (2006) Robustness and modular design of the Drosophila segment polarity network. Mol. Syst. Biol. 2, 70.

Maier, A.T., Stehling-Sun, S., Wollmann, H., Demar, M., Hong, R.L., Haubeiss, S., Weigel, D. and Lohmann, J.U. (2009) Dual roles of the bZIP transcription factor PERIANTHIA in the control of floral architecture and homeotic gene expression. Development, 136, 1613-1620.

Mallona, I., Lischewsky, S., Weiss, J., Hause, B. and Egea-Cortines, M. (2010) Validation of endogenous genes as controls for quantitative real-time PCR during leaf and flower development in Petunia hybrida. BMC Plant Biol. 10, 4.

Mallona, I., Weiss, J. and Egea-Cortines, M. (2011) PcrEfficiency: a web tool for PCR amplification efficiency calculus. BMC Bioinformatics, 12, 404.

Martin, C. and Gerats, T. (1993) Control of pigment biosynthesis genes during petal development. Plant Cell, 5, 1253-1264.

Martin, C., Prescott, A., Mackay, S., Bartlett, J. and Vrijlandt, E. (1991) Control of anthocyanin biosynthesis in flowers ofAntirrhinum majus. Plant J. 1, 37-49.

Melzer, R. and Theissen, G. (2009) Reconstitution of floral quartets in vitro involving class B and class E floral homeotic proteins. Nucleic Acids Res. 37, 2723-2736.

Noda, K., Glover, B.J., Linstead, P. and Martin, C. (1994) Flower colour intensity depends on specialized cell shape controlled by a Myb-related transcription factor. Nature, 369, 661-664.

Pelaz, S., Ditta, G.S., Baumann, E., Wisman, E. and Yanofsky, M.F. (2000) B and C floral organ identity functions require SEPALLATA MADS-box genes. Nature, 405, 200-203.

Perez-Rodriguez, M., Jaffe, F.W., Butelli, E., Glover, B.J. and Martin, C. (2005) Development of three different cell types is associated with the activity of a specific MYB transcription factor in the ventral petal of Antirrhinum majus flowers.Development, 132, 359-370.

Pfaffl, M.W., Horgan, G.W. and Dempfle, L. (2002) Relative expression software tool (RESTC) for group-wise comparison and statistical analysis of relative expression results in real-time PCR. Nucleic Acids Res. 30, e36.

Pnueli, L., Hareven, D., Broday, L., Hurwitz, C. and Lifschitz, E. (1994) The Tm5 MADS box gene mediates organ differentiation in the three inner whorls of tomato flowers. Plant Cell, 6, 175-186.

Reale, L., Porceddu, A., Lanfaloni, L., Moretti, C., Zenoni, S., Pezzotti, M., Romano, B. and Ferranti, F. (2002) Patterns of cell division and expansion in developing petals of Petunia hybrida. Sex. Plant Reprod. 15, 123-132.

Rijpkema, A.S., Royaert, S., Zethof, J., van der Weerden, G., Gerats, T. and Vandenbussche, M. (2006) Analysis of the Petunia TM6 MADS box gene reveals functional divergence within the DEF/AP3 lineage. Plant Cell, 18, 1819-1832.

Schwanhäusser, B., Busse, D., Li, N., Dittmar, G., Schuchhardt, J., Wolf, J., Chen, W. and Selbach, M. (2011) Global quantification of mammalian gene expression control. Nature, 473, 337-342.

Schwarz-Sommer, Z., Huijser, P., Nacken, W., Saedler, H. and Sommer, H. (1990) Genetic control of flower development by homeotic genes in Antirrhinum majus. Science, 250, 931-936.

Schwarz-Sommer, Z., Hue, I., Huijser, P., Flor, P.J., Hansen, R., Tetens, F., Lonnig, W.E., Saedler, H. and Sommer, $\mathrm{H}$. (1992)Characterization of the Antirrhinum floral homeotic MADS-box gene deficiens- evidence for DNA-binding and autoregulation of its persistent expression throughout flower development. EMBO J. 11, 251-263.

Schwarz-Sommer, Z., Gubitz, T., Weiss, J., Gomez-di-Marco, P., Delgado-Benarroch, L., Hudson, A. and EgeaCortines, M. (2010) A molecular recombination map of Antirrhinum majus. BMC Plant Biol. 10, 275. 
Sieburth, L.E., Running, M.P. and Meyerowitz, E.M. (1995) Genetic separation of third and fourth whorl functions of AGAMOUS. Plant Cell, 7, 1249-1258.

Smaczniak, C., Immink, R.G.H., Muino, J.M. et al. (2012) Characterization of MADS-domain transcription factor complexes in Arabidopsis flower development. Proc. Natl Acad. Sci. USA, 109, 1560-1565.

Sommer, H., Beltran, J.P., Huijser, P., Pape, H., Lonnig, W.E., Saedler, H. and Schwarz-Sommer, Z. (1990) Deficiens, a homeotic gene involved in the control of flower morphogenesis in Antirrhinum majus: the protein shows homology to transcription factors. EMBO J. 9, 605-613.

Stubbe, H. (1966) Genetik und Zytologie von Antirrhinum L. sect. Antirrhinum. Germany: Veb Gustav Fischer Verlag, Jena.

Szecsi, J., Joly, C., Bordji, K., Varaud, E., Cock, J.M., Dumas, C. and Bendahmane, M. (2006) BIGPETALp, a bHLH transcription factor is involved in the control of Arabidopsis petal size. EMBO J. 25, 3912-3920.

Theissen, G. and Saedler, H. (2001) Plant biology - floral quartets. Nature, 409, 469-471.

Trobner, W., Ramirez, L., Motte, P., Hue, I., Huijser, P., Lonnig, W.E., Saedler, H., Sommer, H. and SchwarzSommer, Z. (1992 )GLOBOSA: a homeotic gene which interacts with DEFICIENS in the control of Antirrhinum floral organogenesis. EMBO J. 11,4693-4704.

Vainstein, A., Lewinsohn, E., Pichersky, E. and Weiss, D. (2001) Floral fragrance. New inroads into an old commodity. Plant Physiol. 127, 1383-1389.

Vandenbussche, M., Zethof, J., Souer, E., Koes, R., Tornielli, G.B., Pezzotti, M., Ferrario, S., Angenent, G.C. and Gerats, T.(2003) Toward the analysis of the Petunia MADS box gene family by reverse and forward transposon insertion mutagenesis approaches: B, C, and D floral organ identity functions require SEPALLATA-like MADS box genes in Petunia. Plant Cell, 15,2680-2693.

Vandenbussche, M., Zethof, J., Royaert, S., Weterings, K. and Gerats, T. (2004) The duplicated B-class heterodimer model: whorl-specific effects and complex genetic interactions in Petunia hybrida flower development. Plant Cell, 16, 741-754.

Varghese, J. and Cohen, S.M. (2007) microRNA miR-14 acts to modulate a positive autoregulatory loop controlling steroid hormone signaling in Drosophila. Genes Dev. 21, 2277-2282.

Vincent, C.A. and Coen, E.S. (2004) A temporal and morphological framework for flower development in Antirrhinum majus. Can. J. Bot. 82, 681-690.

Wang, Y.Q., Melzer, R. and Theissen, G. (2010) Molecular interactions of orthologues of floral homeotic proteins from the gymnosperm Gnetum gnemon provide a clue to the evolutionary origin of 'floral quartets'. Plant J. 64, 177-190.

Weiss, D., Vanderluit, A.H., Kroon, J.T.M., Mol, J.N.M. and Kooter, J.M. (1993) The Petunia homolog of the Antirrhinum majus candi and Zea mays A2 flavonoid genes; homology to flavanone 3-hydroxylase and ethylene-forming enzyme. Plant Mol. Biol.22, 893-897.

Whitney, H.M., Chittka, L., Bruce, T.J. and Glover, B.J. (2009a) Conical epidermal cells allow bees to grip flowers and increase foraging efficiency. Curr. Biol. 19, 948-953.

Whitney, H.M., Kolle, M., Andrew, P., Chittka, L., Steiner, U. and Glover, B.J. (2009b) Floral iridescence, produced by diffractive optics, acts as a cue for animal pollinators. Science, 323, 130-133.

Whitney, H.M., Poetes, R., Steiner, U., Chittka, L. and Glover, B.J. (2011) Determining the contribution of epidermal cell shape to petal wettability using isogenic Antirrhinum lines. PLoS One, 6, e17576.

Winter, K.U., Weiser, C., Kaufmann, K., Bohne, A., Kirchner, C., Kanno, A., Saedler, H. and Theissen, G. (2002) Evolution of class $B$ floral homeotic proteins: obligate heterodimerization originated from homodimerization. Mol. Biol. Evol. 19, 587-596.

Yu, H., Ito, T., Zhao, Y., Peng, J., Kumar, P. and Meyerowitz, E.M. (2004) Floral homeotic genes are targets of gibberellin signaling in flower development. Proc. Natl Acad. Sci. USA, 101, 7827-7832.

Zachgo, S., Silva, E., Motte, P., Trobner, W., Saedler, H. and Schwarz-Sommer, Z. (1995) Functional analysis of the Antirrhinum floral homeotic DEFICIENS gene in vivo and in vitro by using a temperature-sensitive mutant. Development, 121, 2861-2875. 


\section{Supporting Information}

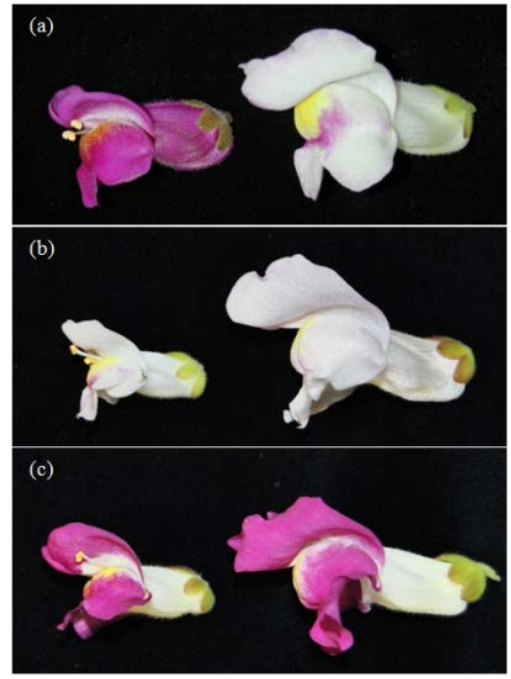

Figure S1. Segregation of colour genes in a compacta genetic background. The genes delila, nivea and pallida recurrens segregate in a cross of the Antirrhinum majus lines Sippe50 x 165E. Flowers of co on the left and wild-type on the right with wild-type color (a); double mutant niv pal (b); and delila (c).

(a)

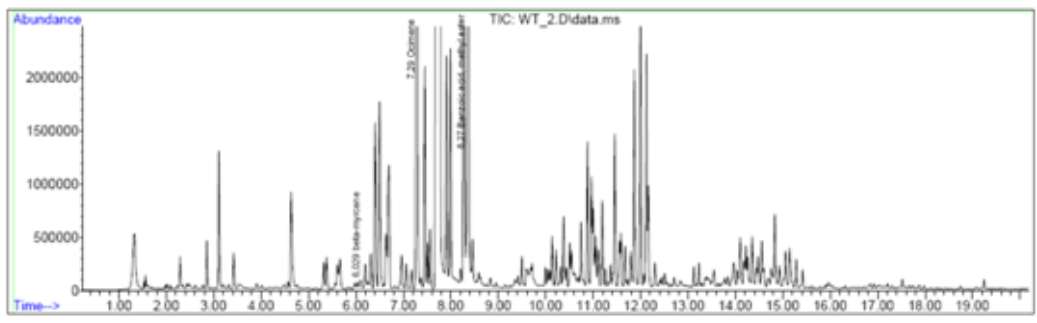

(b)

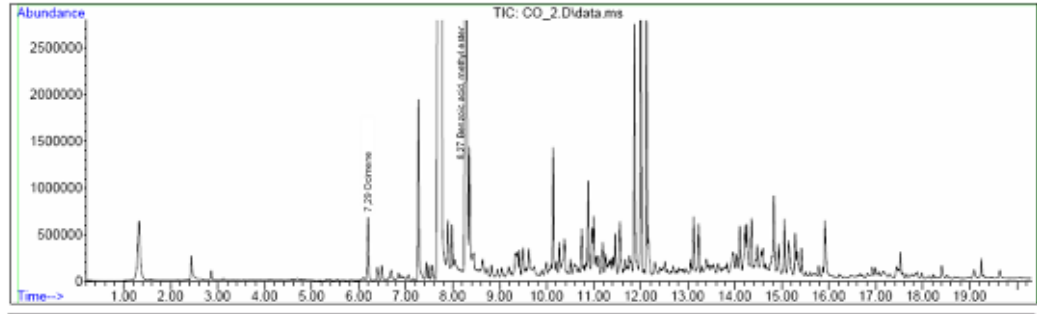

(c)

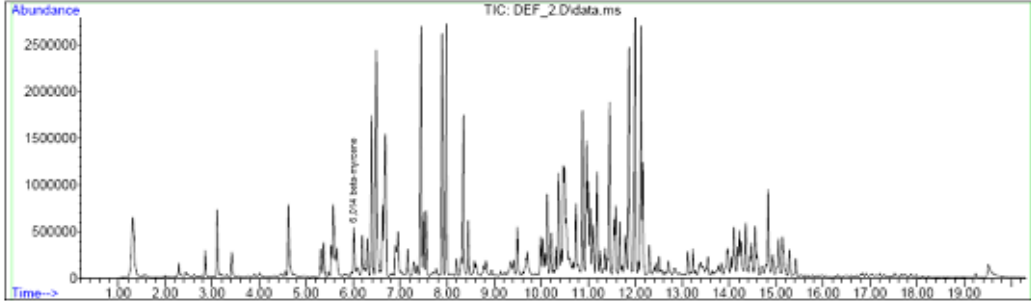

(d)

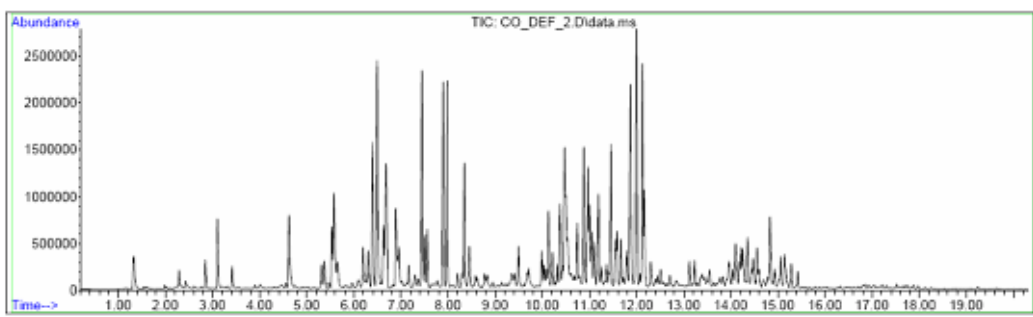

Figure S2. Volatile profiles of wild-type, co, defic and co def ${ }^{\text {nic }}$ double mutants. Chromatographic peak identification of the Antirrhinum majus scent profiles. The peak resolved at retention times of 6.029 for myrcene, 7.29 for ocimene and 8.27 for methyl benzoate. Chromatograms correspond to (a) Wild-type; (b) co; (c) def and (d) co def fic double mutants. 


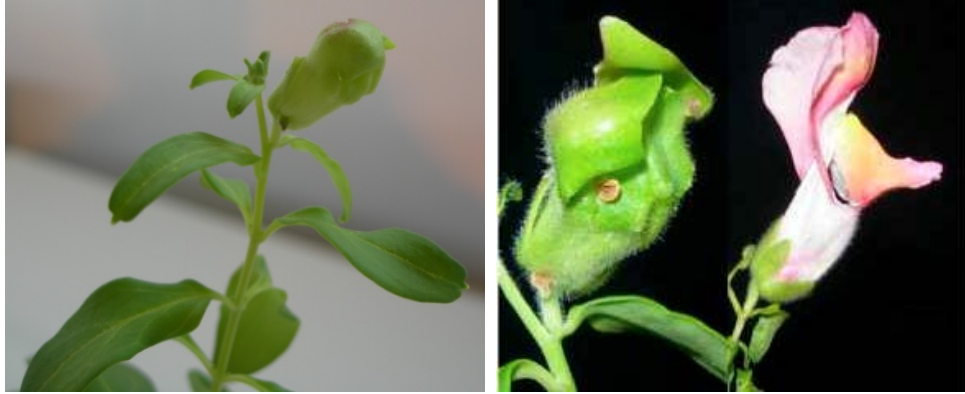

Figure S3. Additional RNAi-DEF line with a weak phenotype.

Table S1. Primers for RT-qPCR and cloning.

\begin{tabular}{|l|l|}
\hline \multicolumn{1}{|c|}{ PRIMER } & \multicolumn{1}{c|}{ SEQUENCE } \\
\hline Am DEF forward & 5' GATGCAAGGAGAGAGGATC 3' \\
\hline Am DEF reverse & 5' CTATAACATATATCGATCATACCATTAATT 3' \\
\hline Am GLO forward & 5' TTGTCCGGATGATGAGG 3' \\
\hline Am GLO reverse & 5' CGGAACGCGAAAGG 3' \\
\hline Am MIXTA forward & 5' CACCAACTACTCCGCACGTCC 3' \\
\hline Am MIXTA reverse & 5' CCATTGACGACGACGAGGCC 3' \\
\hline Am Ubiq. forward & 5' GCCGATGGAAGTATATGTTTGGACATC 3' \\
\hline Am Ubiq. reverse & 5' CTAACTTTGCGGTTATAATCTCGTTTA 3' \\
\hline pH12 forward & 5'-GTTGGCAGCATCACCCGA-3' \\
\hline pH12 reverse & 5'-AAACTAGAAATTTACCTGCAC-3' \\
\hline
\end{tabular}

\section{Appendix S1. Detailed Antirrhinum majus transformation protocol.}

\section{Development of a reliable transformation protocol for Antirrhinum}

One major problem in the development of Antirrhinum as a model in the last decade has been the difficulty of developing a reliable transformation protocol for transgenic approaches (Heidmann et al. 1998) Previous studies in Antirrhinum have used hypocotyls as explants for transformation (Cui et al. 2004). Growth of hypocotyls, is partly due to cell expansion and it has been shown that in the dark, there is considerable endoreduplication in Arabidopsis hypocotyls (Gendreau et al. 1997). This suggests that using old hypocotyls might encounter the problem of obtaining explants with a mesoploid structure, where the number of diploid cells able to regenerate might decrease with time. We tested the developmental window of Antirrhinum majus hypocotyls as explants for regeneration and transformation. After about two weeks, hypocotyls that belonged to the four-week old treatment had not shown any sign of regeneration whereas regeneration occurred in the plates with hypocotyls from two-week old germinated seedlings. After about 5 weeks, the difference between two and four-week old hypocotyls, was seen by visual inspection. Whilst most hypocotyls from two-week old explants had produced calluses four-week old explants were not reactive to the regeneration medium and the percentage producing calluses was close to zero. 


\section{Antirrhinum majus transformation}

\section{PLANT MATERIAL AND AGROBACTERIUM STRAIN}

We have used the laboratory line 165E for transformation. The Agrobacterium strain used is EHA105.

\section{SEED STERILIZATION AND IN VITRO CULTIVATION:}

- Place the seeds in a microfuge tube.

- Add $1 \mathrm{ml} 70 \%$ ethanol to the tube and vortex.

- Remove ethanol with a $200 \mu$ l pipette (seeds are larger than the tip).

- Add $1 \mathrm{ml} 20 \%$ bleach + detergent. Occasionally mix the seeds. After $10 \mathrm{~min}$ remove the bleach with a $200 \mu$ l pipette.

- Rinse the seeds with sterile distilled water, three times for 5 minutes. Remove the water using a $200 \mu$ pipette each time.

- Put the seeds into a Petri dish with MS-medium.

- Grow 2 weeks.

\section{MEDIUM:}

- SIM medium (per litre):

- Sodium citrate $2 \mathrm{H}_{2} \mathrm{O}$

$5.882 \mathrm{~g}$

- Sucrose

$20.0 \mathrm{~g}$

- Acetosyringone

$500 \mu \mathrm{M}$

- Adjust the $\mathrm{pH}$ to 5.5

- Sterilize by autoclaving for 15 minutes at 121 ㅇC

- Murashige \& Skoog medium (per litre):

- MS

$4.4 \mathrm{~g}$

- Sucrose

$25.0 \mathrm{~g}$

- Gelrite

$2.5 \mathrm{~g}$

- Adjust the $\mathrm{pH}$ to $5.7-5.9$

- Sterilize by autoclaving for 15 minutes at 121 으

- Co-cultivation medium (per litre):

- MS

- Sucrose

- Gelrite

- Adjust the $\mathrm{pH}$ to $5.7-5.9$

- Sterilize by autoclaving for 15 minutes at 121 으. After letting it cool down to $50^{\circ} \mathrm{C}$ aprox. add:
O NAA
$0.25 \mathrm{mg}$
o Zeatine
$2.0 \mathrm{mg}$
o Acetosyringone
$100 \mu \mathrm{M}$

- Tras-cultivation medium (per litre):

- MS

- Sucrose

- Gelrite

$2.5 \mathrm{~g}$

- Adjust the $\mathrm{pH}$ to $5.7-5.9$

- Sterilize by autoclaving for 15 minutes at $121^{\circ} \mathrm{C}$. After letting it cool down to $50^{\circ} \mathrm{C}$ aprox. add:
o NAA
$0.25 \mathrm{mg}$
o Zeatine
$2.0 \mathrm{mg}$
o Cefotaxime
$300 \mathrm{mg}$
o Kanamycin
$100 \mathrm{mg}$ 


$$
\text { o Vancomycin } 200 \mathrm{mg}
$$

- $\quad$ Root medium (per litre):

- MS

- Sucrose

- Gelrite

- Adjust the $\mathrm{pH}$ to $5.7-5.9$

- Sterilize by autoclaving for 15 minutes at $121^{\circ} \mathrm{C}$. After letting it cool down to $50^{\circ} \mathrm{C}$ aprox. add:

$\begin{array}{llr}\text { o } & \text { NAA } & 0.20 \mathrm{mg} \\ \text { o } & \text { Cefotaxime } & 300 \mathrm{mg} \\ \text { o } & \text { Kanamycin } & 50 \mathrm{mg} \\ \text { o } & \text { Vancomycin } & 200 \mathrm{mg}\end{array}$

\section{MATERIALS}

- Co-cultive medium liquid

- Sterile circles of filter paper as big as a Petri plate

- Scalpels and forcepses

\section{PREPARATION}

DAY 0

- Friday before, spread the Agrobacterium containing your plasmid in a Petri plate with fresh medium and the appropriate antibiotics. Grow it for the weekend at $27^{\circ} \mathrm{C}$.

DAY 3

- Monday, put a colony in $10 \mathrm{ml} \mathrm{LB}$ with antibiotics at midday. Grow it o.n. at $27^{\circ} \mathrm{C}$ and shaking at $180 \mathrm{rpm}$.

DAY 4

- Tuesday, centrifuge the Agrobacterium culture at $3000 \mathrm{rpm}$ for $15 \mathrm{~min}$ in a Falcon.

- Remove the supernatant quickly and carefully.

- $\quad$ Resuspend the pellet in $10 \mathrm{mI}$ SIM medium without antibiotics or AS

- Measure the $\mathrm{OD}_{600 \mathrm{~nm}}$, it should be in stationary phase.

- Dilute the culture to $O D_{600 \mathrm{~nm}}=0.2$ in a final volume of $25 \mathrm{ml}$ of SIM medium with antibiotics and AS $500 \mu \mathrm{M}$

- Grow the culture for 24 hours at 25 으 shaking at $180 \mathrm{rpm}$.

DAY 5

- Centrifugate the culture at 3000 rpm for 15 min in a Falcon

- Remove the supernatant quickly and carefully.

- Resuspend the pellet in $25 \mathrm{ml}$ liquid co-cultive medium (without gelrite), without antibiotics.

- Measure the $O D_{600 n m}$

- $\quad$ Dilute the culture in liquid co-cultive medium until $\mathrm{OD}_{600 \mathrm{~nm}}=0.02$.

\section{TRANSFORMATION}

- Excise the hypocotyls/leaves from seedling and place on a filter paper lined co-cultivation medium plate.

- Add $10 \mathrm{ml}$ of Agrobacterium diluted in liquid co-cultive medium until $\mathrm{OD}_{600 \mathrm{~nm}}=0.02$ to each Petri plate and leave it for $15 \mathrm{~min}$.

- Remove the Agrobacterium solution with a sterile disposable syringe. Dry the explants with sterile filter paper.

- Seal plate with parafilm and incubate in the dark for 2 days in the growth chamber. 


\section{DAY 7}

- Prepare fresh trans-culture medium plates.

- Transfer the explants to these selective medium plates (25 per plate). Seal with parafilm. Incubate in the dark for a week, and then start to adapt them to full light by putting on growth chamber with light. Pile on the top 4-5 sheets of filter paper and remove one per day till full light is achieved.

DAY 20

- Transfer the explants to fresh trans-culture medium plates.

2 MONTHS...

- After 6-8 weeks shoots should appear. Transfer the explants each 20 days to fresh selection plates with trans-culture fresh medium. Excise shoots of $1.5-2.0 \mathrm{~cm}$, and put them on root medium.

Major pitfalls encountered include:

1- Old seed failing to germinate or excess of bleach treatment causing lack of germination.

2- Transgenic plant death after regeneration and during the adaptation to the greenhouse.

\section{References:}

Cui, M.L., Ezura, H., Nishimura, S., Kamada, H. and Handa, T. (2004) A rapid Agrobacterium-mediated transformation of Antirrhinum majus L. by using direct shoot regeneration from hypocotyl explants. Plant Sci, 166, 873-879.

Gendreau, E., Traas, J., Desnos, T., Grandjean, O., Caboche, M. and Hofte, H. (1997) Cellular basis of hypocotyl growth in Arabidopsis thaliana. Plant Physiol, 114, 295-305.

Heidmann, I., Efremova, N., Saedler, H. and Schwarz-Sommer, Z. (1998) A protocol for transformation and regeneration of Antirrhinum majus. Plant J, 13, 723-728. 

Chapter 3 



\section{Chapter 3: Validation of Aintegumenta as a gene to modify floral size in ornamental plants}

María Manchado-Rojo ${ }^{1}$; Julia Weiss ${ }^{1}$ and Marcos Egea-Cortines ${ }^{1 *}$

Genetics, ETSIA, Instituto de Biotecnología Vegetal, Universidad Politécnica de Cartagena, Paseo Alfonso XIII 48, 30203 Cartagena, Spain.

*Correspondence: (Telf.: +34868071077; FAX +34968325433; e-mail: marcos.egea@upct.es)

Keywords: floral size, cell expansion, Aintegumenta, transgenic Antirrhinum, network motif

Manchado-Rojo, M., Weiss, J., \& Egea-Cortines, M. (2014). Validation of Aintegumenta as a gene to modify floral size in ornamental plants. Plant Biotechnology Journal. 12(8):1053-65. doi: 10.1111/pbi.12212. 


\section{Summary}

The gene AINTEGUMENTA (AtANT) is an APETALA2 transcription factor in Arabidopsis activating growth downstream of auxin signalling. Lateral organ size is positively correlated with ANT expression in Arabidopsis. We tested the use of AtANT as a tool to modify floral size in two different plants used as model organisms and ornamental crops, Petuniaxhybrida and Antirrhinum majus. Petunia plants expressing PhANT RNAi showed a decrease in PhANT expression correlated with smaller petal limbs. In contrast Petunia plants overexpressing AtANT had larger petal limbs. Petal tube length was less affected in downregulation of PhANT or overexpression of AtANT. Overexpression of AtANT in Antirrhinum caused increased flower size via increased petal limb width and tube length. Downregulation of PhANT showed an effect on cell size while overexpression of AtANT in Petunia and Antirrhinum caused significant increases in cell expansion that could explain the differences in floral organ size. The endogenous expression levels of PhANT and AmANT tended to be higher in the limb than in the tube in both Antirrhinum and Petunia. AtANT overexpression caused significant AmANT upregulation in Antirrhinum limbs but not of PhANT in Petunia, indicating differences in the regulatory network. The differential effect of AtANT on limb and tube in Petunia and Antirrhinum correspond to phenotypic differences observed in natural variation in the corresponding genus indicating a relation between the phenotypic space of a genus and the effect of modified $A N T$ levels, validating $A N T$ as a gene to modify floral size.

\section{Introduction}

Floral size is a trait subject to strong selection in those species that display an allogamous reproductive strategy coupled to insect-based pollination (Krizek and Anderson, 2013). The genus Petunia for instance shows a distinct pollination syndrome with a suite of traits that attract hummingbirds or hawk moths including floral colour, scent and size (Hermann and Kuhlemeier, 2011). Changes in floral size can be genetically dissected into two separate regions, the tube and the limb that seem to play distinct roles in pollination (Stuurman et al., 2004; Venail et al., 2010). In the genus Antirrhinum, there is an important range in flower size indicating local adaptation to insect pollinators (Feng et al., 2009). Petunia and Antirrhinum are used as model systems but are also sold as ornamentals. As a result they have undergone major screens for traits including amongst others increased and decreased floral size, depending on the market requirements.

A proper flower shape and size requires correct floral organ identity as mutations in genes affecting organ identity strongly affect cell division and expansion (Egea-Cortines and Weiss, 2013; Dornelas et al., 2011; Delgado-Benarroch et al., 2010; Manchado-Rojo et al., 2012). A model for floral 
development was originally proposed with the so-called A, B and C combinatorial functions (Coen and Meyerowitz, 1991).The A function is fulfilled in Arabidopsis by the APETALA1 and APETALA2 genes, but the level of implication of the corresponding orthologs in petal development varies to a large extent in different plants including Petunia and Antirrhinum (Maes et al., 2001; Keck et al., 2003; Egea Gutierrez-Cortines et al., 2000; Causier et al., 2010). Petal development occurs mainly by activation of the so-called B-function organ identity genes that form ternary complexes with other MADS box genes (Causier et al., 2003; Egea-Cortines et al., 1999; Ferrario et al., 2003; Honma and Goto, 2001). Several studies have shown that petal development occurs by an early phase of cell division followed by a late stage of cell expansion (Reale et al., 2002). Thus modified floral size can be the result of increased cell proliferation and/or cell expansion. Current data in Arabidopsis and Antirrhinum indicate that modified periods of cell proliferation produce overall changes in floral size (Delgado-Benarrochet al., 2009a; Disch et al., 2006; Szecsi et al., 2006). Genes involved in control of cell expansion also cause changes in petal size. For example, regulatory genes like SUPERMAN (SUP) have been shown to repress cell expansion in Petunia and Arabidopsis flowers (Kater et al., 2000), indicating a tight control of cell size during flower development. Genes directly controlling cell wall metabolism also show dose response effects in petal size as in case of Petunia, where down regulation of the EXPANSIN (EXP). PhEXP causes a strong decrease in petal size as a result of reduced cell size (Zenoni et al., 2004). In contrast, overexpression of the same gene causes increased petal limb size via enhanced cell enlargement (Zenoni et al., 2011).

Floral size changes can be achieved by increasing the number of organs, the size of the organs or both parameters. Changes in the number of petals as a result of changes in organ identity and loss of floral meristem determinacy are typical of loss of C-function in Arabidopsis and Antirrhinum (Bradley et al., 1993; Yanofsky et al., 1990). Changes in petal number leading to double flowers is correlated in the ranunculid Thalictrum thalictroides with loss of protein-protein interaction between a C-function AGAMOUS gene (ThtAG1) and its SEPALLATA partner (ThtSEP3) (Galimba et al., 2012). Further evidence for changes in C-function has been described in rose where allele-specific restriction of the expression domain of the C-function AGAMOUS (RhAG) is correlated with increases in the number of petal whorls (Dubois et al., 2010). A second group of ornamentals show changes as a result of modifying floral organ size. This is typically seen in flowers like orchids, Petunia or Antirrhinum (Gawenda et al., 2012; Weiss et al., 2005). The genes involved in changes in floral organ size in ornamentals have not been described.

The gene AINTEGUMENTA (ANT) is an APETALA2 transcription factor, originally identified in a screen for female sterile plants, and is required for ovule initiation in Arabidopsis (Klucher et al., 1996; Elliott 
et al., 1996). Later work has shown that the overexpression of ANT in Arabidopsis causes increases in organ size (Krizek, 1999; Mizukami and Fischer, 2000). The ANT group comprises the AINTEGUMENTA-LIKE (AIL) genes involved in growth-related processes in a variety of plants. Expression of AIL genes correlate with nucellar development in coconut (Dona et al., 2010). Overexpression of AIL-6 in Arabidopsis shows a variety of phenotypes including modified floral size (Krizek and Eaddy, 2011), indicating a general role of ANT and AIL genes in growth control. The PLETHORA (PLT) genes form a second group of the AP2 transcription factors involved in root stem cell maintenance and shoot phyllotaxis (Galinha et al., 2007; Prasad et al., 2011; Aida et al., 2004). A gene duplication event in Arabidopsis points towards a role of ANT in overall growth control in a dose-response fashion (Horiguchi et al., 2009). Experiments with the mutant argos (arg) (Hu et al., 2003) places ANT downstream of ARG transducing auxin signals related to growth promotion. Expression of ANT is thought to control meristematic competence (Mizukami and Fischer, 2000), thus affecting the timing of cell division. Although the function of ANT makes it an attractive candidate gene to modify lateral organ growth in plants, there is no data available outside Arabidopsis.

Here we show that modifying the expression levels of ANT in two ornamental plants, Petunia and Antirrhinum, causes changes in floral size. We down-regulated PhANT in Petunia using a PhANT RNAi construct leading to decreased floral size. We overexpressed the Arabidopsis AtANT gene in Petunia and Antirrhinum. Petunia plants displayed increased petal limb and small increases in petal tube whereas Antirrhinum showed increased petal tube and petal limb width resembling the natural phenotypic variability that exists within each genus. Floral size phenotypes resulting from AtANT overexpression were caused mainly by increased cell expansion. The effect of AtANT on the endogenous levels of PhANT and AmANT also differed with a significant up-regulation of AmANT but not PhANT, indicating differences in the ANT regulation of tube and limb and between Petunia and Antirrhinum. We discuss our results in terms of the genus specific genetic context, and the biotechnological potential of $A N T$ as a gene to modify floral size.

\section{Results}

\section{Cloning of an AINTEGUMENTA gene fragment from Petunia for functional analysis}

We defined two experiments to evaluate $A N T$ as a gene to manipulate floral size in ornamentals. One based on loss of function via a RNAi construct and by gain of function of the Arabidopsis ANT gene. We needed first to isolate the Petunia ANT (PhANT) to develop RNAi constructs. In order to identify an ANT clone from Petunia we searched the Solanaceae public database (solgenomics.net) using the ANT gene from Arabidopsis. We were not able to identify a homolog of Petuniaxhybrida but we 
retrieved the sequence of a tomato clone (SGN-U599088 Tomato 200607) with high homology (E Value 3e-89; Identity 85\%) to the ANT gene from Arabidopsis. Previous work in our laboratory had shown that direct usage of primer combinations from tomato in Petunia had over $60 \%$ of success rate (unpublished data). Thus we amplified and cloned a Petunia fragment using primers designed on the basis of tomato sequence. Sequence comparison showed that the Petunia fragment was virtually identical to the tomato sequence from the database. We performed standard RACE PCR and obtained several fragments that together comprise $1.2 \mathrm{~kb}$ of coding sequence of PhANT (Genebank accession AHC98702).The isolated fragment comprising identified as closest homolog the ANT gene from Arabidopsis in the Arabidopsis genome (BLASTP 1e-97). A direct comparison of the PhANT translated protein showed a degree of identity of $38.9 \%$ with AtANT and of $27.3 \%$ with AIL-5.The $A N T$ gene belongs to the AP2 family of transcription factors, divided in the eUAP2 and ANT lineages (Kim et al., 2006; Shigyo et al., 2006; Shigyo and Ito, 2004). In order to confirm the homology of the isolated clone to the ANT lineage, we performed a phylogenetic analysis using predicted proteins from the AP2ANT family. These included genes of the AP2 lineage, PLETHORA (PLT) and CBF/DREB involved in cold response (Jaglo-Ottosen et al., 1998) (Table S1). We performed a phylogenetic analysis using two open source phylogenetic software pipelines with identical results (see materials and methods). The phylogenetic tree obtained comprised four major clades (Figure 1). One was formed by the $A P 2$ orthologs and genes involved in abiotic responses like CBF1, SICBF1 or DREB2A (Liu et al., 1998; Weiss and Egea-Cortines, 2009; Jaglo-Ottosen et al., 1998). A second distinct clade contained the AINTEGUMENTA LIKE (AIL) genes, Brassica napus BABYBOOM (BBM) and PLT1 and 2. The genes PhANT and AmANT were inside a clade containing the ANT gene from Nicotiana tabacum (Rieu et al., 2005), and other ANT genes from Solanaceae like Solanum lycopersicon and Nicotiana benthamiana as closest homologs while genes of Santalales like Phoradendron serotinum and Comandraum bellata clustered together. The closest clade contained the ANT from Arabidopsis that clustered with ANT2 from Brassica. The clade containing PhANT and AmANT was clearly separated from the AP2 group comprising AP2, the Petunia PhAP2A (Maes et al., 2001) and the Antirrhinum paralogs LIPLESS 1 and 2 (LIP1 and 2)(Keck et al., 2003). These results indicate that the PhANT gene isolated and used for further analysis displays a high degree of homology to AtANT and is a likely ortholog. 


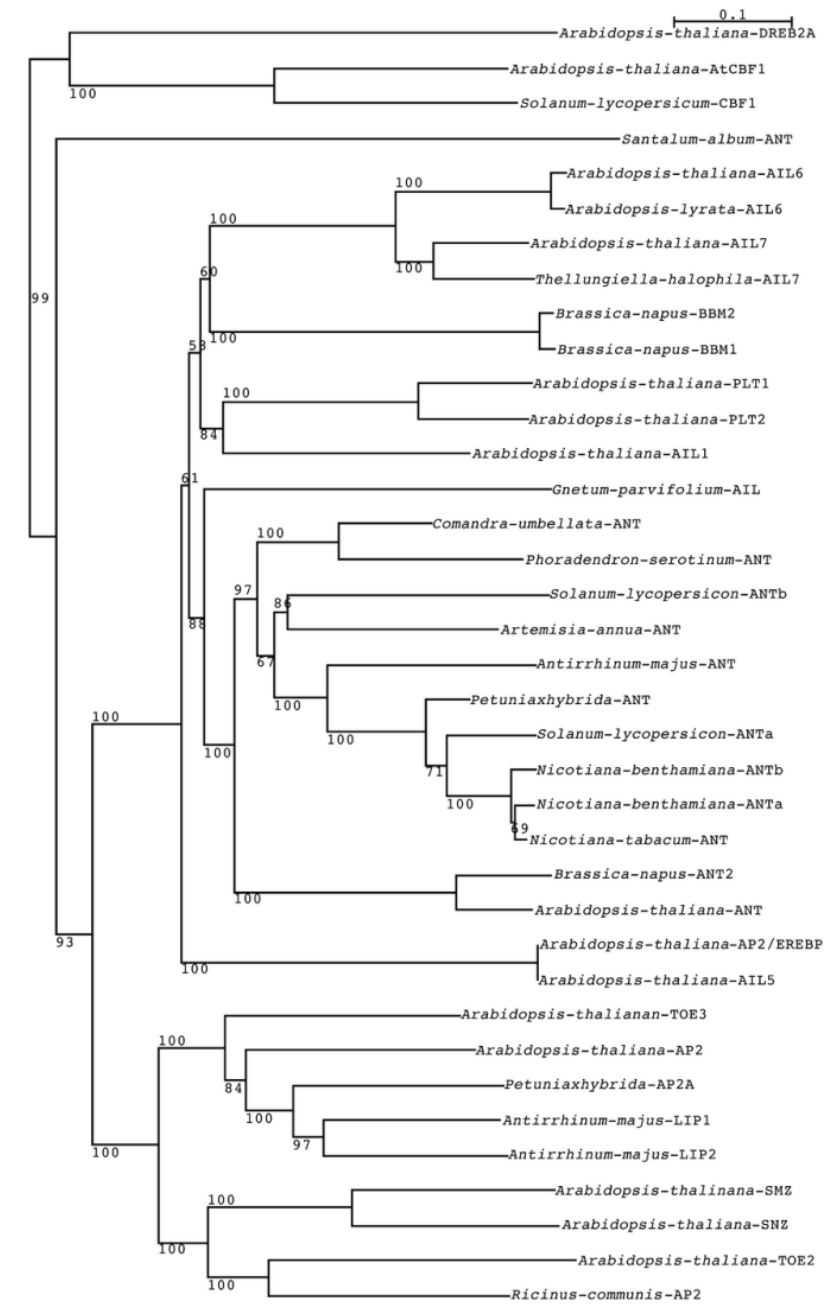

Figure 1. Phylogenetic tree of APETALA2 related predicted proteins.

Numbers on branches correspond to number of bootstraps supporting them.

\section{Differential effect of PhANT RNAi in limb and tube of Petunia}

Although AP2 transcription factors are involved in activation of cell division and play a role in stem cell maintenance and patterning in Arabidopsis (Wurschum et al., 2006), we obtained kanamycin resistant plants in Petuniaxhybrida Mitchell containing an RNAi construct targeting the endogenous PhANT (PhRNAi::ANT) indicating that a certain down regulation of PhANT by PhRNAi::ANT is compatible with in vitro regeneration in this cultivar. We cannot rule out that the calli with stronger initial expression of the transgene did not regenerate. All the kanamycin resistant $\mathrm{T} 1$ plants, obtained by selfing the TO generation, showed flowers that appeared smaller than non-transformed control plants. A careful inspection of the segregating populations revealed three distinct phenotypic classes, one displaying very small flowers, a second one with intermediate size and a third that displayed wild-type flowers (Figure $2 a, 2 b$ and $2 c$ ). Plants with wild-type flowers turned out to be those that had segregated out the NPTII gene and did not harbour the T-DNA insertion. We used these nontransgenic siblings as control plants for further experiments. 

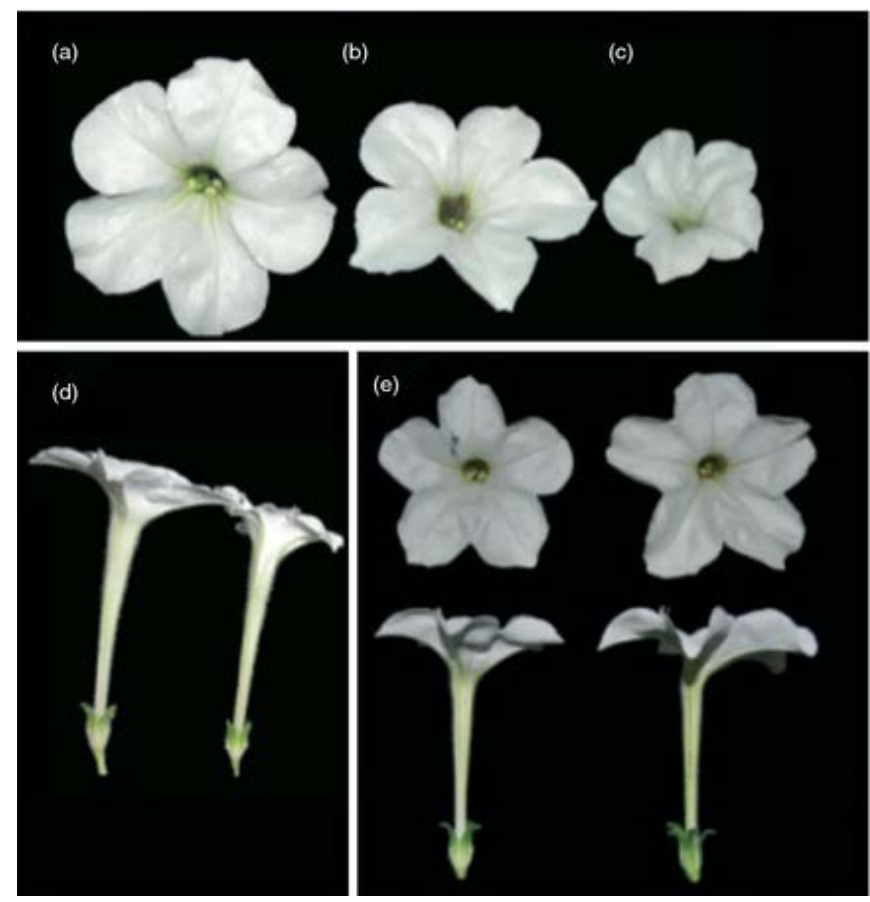

Figure 2. Phenotype of Petunia flowers with silencing of PhANT gene or overexpression of AtANT. Effect of the silencing of PhANT gene in (a) limb of Petunia hybrida, non-transformed (b) intermediate sized line and (c) small sized line. Side view showing the tube of (d) nontransformed on the left and smaller line on the right. (e) Comparison between wild-type (on the left) and 35S::AtANT (on the right).

In the smallest flowers, we observed a significant reduction of $40 \%$ in the diameter of the limb compared to the wild-type phenotypes $(p=0.0)$ (Table 1$)$. Tube length reduction was smaller $(13 \%)$ albeit significant (Figure 2d). Stamen length reduction was not significant while stigmas were significantly smaller. In contrast, sepal size was not affected (Table 1).

Table 1: Comparison of floral parameters between wild-type and transgenic lines.

\begin{tabular}{|c|c|c|c|c|c|}
\hline & Corolla & Tube & Stamen & Stigma & Sepal \\
\hline wild-type & $36.8 \pm 2.3$ & $43.1 \pm 2.8$ & $35.5 \pm 2.8$ & $38.1 \pm 1.4$ & $12.1 \pm 1.3$ \\
\hline $\begin{array}{c}\text { Petunia RNAi-ANT } \\
\text { medium }\end{array}$ & $28.8 \pm 0.4^{* * *}$ & $39.9 \pm 0.7$ & $33.7 \pm 0.5$ & $37.2 \pm 0.6$ & $11.7 \pm 0.5^{* * *}$ \\
\hline $\begin{array}{c}\text { \% Petunia RNAi-ANT } \\
\text { medium }\end{array}$ & -21.8 & -7.5 & -5.1 & -2.6 & -3.6 \\
\hline $\begin{array}{c}\text { Petunia RNAi-ANT } \\
\text { small }\end{array}$ & $21.9 \pm 0.8^{* * *}$ & $37.4 \pm 1.2$ & $30.4 \pm 1.3$ & $33.2 \pm 1.4$ & $12.7 \pm 0.9^{* * *}$ \\
\hline $\begin{array}{c}\text { \% Petunia RNAi-ANT } \\
\text { small }\end{array}$ & -40.5 & -13.2 & -14.3 & -12.9 & +5.0 \\
\hline Petunia 35S::ANT & $52.5 \pm 3.6^{* *}$ & $48.5 \pm 3.5$ & $43.4 \pm 2.7 * *$ & $46.0 \pm 1.9 * *$ & $13.2 \pm 1.4^{* * *}$ \\
\hline \% Petunia 35S::ANT & +42.7 & +12.6 & +9.2 & +22.4 & +20.5 \\
\hline
\end{tabular}

Values correspond to averages $(\mathrm{mm}) \pm$ standard error $(\mathrm{n}=20)$. P-values are represented with ${ }^{*} \mathrm{p}<0.05,{ }^{* *} \mathrm{p}<0.01$ and ${ }^{* * *} \mathrm{p}<0.001$

\section{Overexpression of AtANT in Petunia}

We produced 18 independent Petunia transgenic lines expressing the AtANT gene driven by the $35 \mathrm{~S}$ promoter (Krizek, 1999). Transformed Petunia plants were selfed and T1 plants segregating positive for kanamycin had flowers that were significantly larger than non-transformed siblings (Figure 2e). Plants overexpressing the AtANT gene from Arabidopsis had larger floral organs. Flower limbs 
showed a stronger phenotype with $44 \%$ bigger flower limb diameter as compared to nontransformed plants $(p=0.01)$. At first sight tubes looked similar but careful analysis showed a small (12\%) but significant increase in tube length (Table 1). Both stamen and style were also significantly bigger but size changes were small. Regarding the length of the sepal, the transgenic lines displayed non-significantly larger (20\%) first whorl organs (Table 1 ).

As we had observed in the PhRNAi::ANT plants, overexpression of AtANT caused significant size changes in the petal limb and smaller albeit significant changes in tube length.

\section{Changes in expression levels of ANT in Petunia expressing RNAi constructs and overexpressing AtANT.}

In order to verify if the observed floral phenotypes were correlated with changes in the endogenous levels of PhANT expression, we analysed transcript levels by RT-qPCR. As the 355 promoter is known to be active in all aerial parts of the plant, but changes in organ size were not homogenous (Figure 2; Table 1), we analysed the expression of the gene PhANT in tube and limb of the PhANT RNAi lines. Plants expressing the PhRNAi::ANT construct showed a progressive decrease in gene expression of the endogenous PhANT that correlated with the size of the flower. We used the normal size siblings as control of wild-type PhANT gene expression (value 100\%), as they corresponded to siblings that segregated without kanamycin resistance. Petal limbs of middle-sized flowers displayed significantly lower expression of PhANT (60\%; $p=0.0$ ) compared to siblings with wild-type size flowers while the smaller flowers showed an even stronger down regulation to $25 \%$ compared to wild-type siblings $(p=0.0)$ (Figure 3a). Surprisingly, we could not find significant differences in the down regulation of PhANT in the tubes of intermediate $(96 \% ; p=0.760)$ or small flowers $(93 \% ; p=0.895)$ (Figure $3 b)$. Finally we analysed for the presence of the AtANT mRNA in plants that were positive for kanamycin and displayed larger flowers. We did not expect downregulation of the endogenous gene resulting from co-supression as the sequences of AtANT and PhANT are very different. The endogenous PhANT in the limb was indeed similar to that found in non-transgenic siblings with normal sized flowers. However, the expression of AtANT was close to 42 fold higher than the endogenous PhANT gene expression (Figure 3c). The expression levels were different in the tube as the expression levels of AtANT were roughly two fold higher than the endogenous PhANT levels (Figure $3 \mathrm{~d}$ ). The differences in gene expression levels of AtANT, correlate with the different phenotypic effects found in both petal regions. 

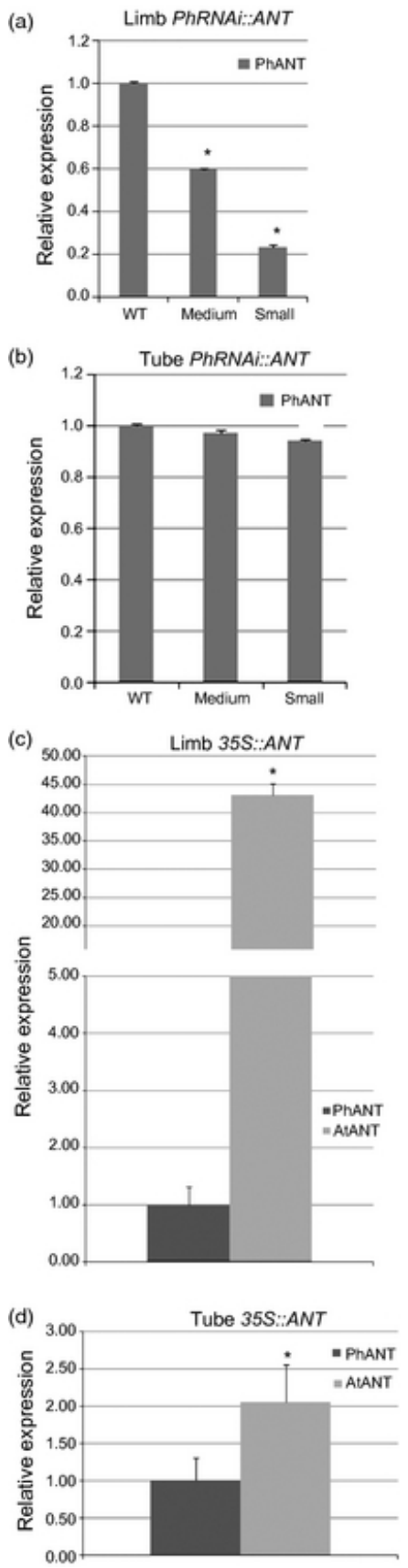

Figure 3. Expression of AtANT and PhANT in flowers of transgenic lines. Downregulation of PhRNAi::ANT gene compared to non-transgenic siblings (value $=1$ ) in the (a) limb and (b) tube of transgenic lines PhANT. Expression of AtANT and PhANT in plants with overexpression of AtANT in (c) limb and (d) tube or Petunia flowers compared to the endogenous PhANT. P-values are represented with *<0.05.

\section{Effects of modified ANT expression levels on cell size and morphology in Petunia}

As both gain and loss of function of $A N T$ in Arabidopsis affect organ size in a complex way regarding cell division and expansion (Krizek, 1999; Mizukami and Fischer, 2000), we measured cell area in three parts of the Petunia petal using scanning electron microscopy and image analysis (Figure 4). 

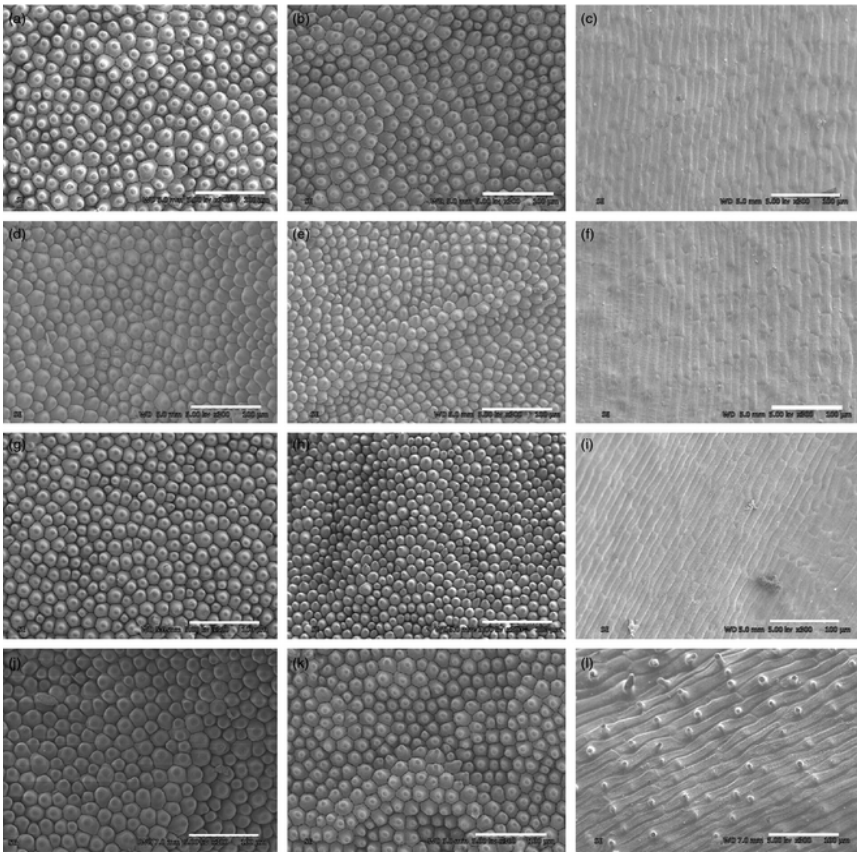

Figure 4. Cell size in Petunia transgenic lines. Comparison among the cell size in wild-type (on the top), the phenotypes obtained from silencing of PhANT gene, intermediate size (second row) and smaller size (third row); and the phenotypes of the overexpresion of AtANT (on the bottom). (a, d, g, j) are cells from the petal limb distal region. (b, e, h, k) correspond to cells from the petal limb proximal region. (c, $\mathrm{f}, \mathrm{i}, \mathrm{l})$ cells from the petal tube.

In plants expressing PhRNAi::ANT, cells from the distal petal region were significantly bigger in small flowers $(p=0.002)$ and intermediate size flowers $(p=0.0)$ compared to non-transgenic sibling plants with an increase of $12 \%$ and $38 \%$, respectively. In contrast, cells from the proximal part of the petal were significantly smaller in the intermediate size flowers $(p=0.019)$ and small flowers $(p=0.0)$ with a reduction of $9 \%$ and $26 \%$, respectively, compared to non-transformed plants (Table 2). Tube cells were significantly smaller than in non-transformed plants in both intermediate size flowers $(5 \%$, $p=0.035)$ and small flowers $(10 \% p=0.0086)$, indicating that the effect on petal tube length was the result of decreased cell expansion. Petal tube cell morphology was the typical expected for wild-type Petunia (Baumann et al., 2007) in non-transgenic siblings. In contrast, plants with reduced PhANT expression lacked the typical protrusions (Figure $4 \mathrm{f}, \mathrm{i}$ ), uncovering a possible effect of PhANT on petal tube epidermal cell differentiation.

Table 2: Cell size of Petunia flowers. Total number of cell measured for each organ/mutant $=100$

\begin{tabular}{|c|c|c|c|}
\hline & Petal 1 $\left(\mu \mathrm{m}^{2}\right)$ & Petal 2 $\left(\mu \mathrm{m}^{2}\right)$ & Tube $\left(\mu \mathrm{m}^{2}\right)$ \\
\hline wild-type & $372.8 \pm 13.8$ & $377.3 \pm 7.6$ & $729.6 \pm 14.2$ \\
\hline Petunia 35S::ANT & $908.2 \pm 49.3^{* * *}$ & $416.2 \pm 10.7^{*}$ & $1932.9 \pm 47.2^{* *}$ \\
\hline \% Petunia 35S::ANT & +143.6 & +10.3 & +164.9 \\
\hline Petunia RNAi-ANT medium & $514.5 \pm 12.5^{* * *}$ & $341.7 \pm 7.2^{* *}$ & $682.8 \pm 13.9^{*}$ \\
\hline \% Petunia RNAi-ANT medium & +38.0 & -9.4 & -6.4 \\
\hline Petunia RNAi-ANT small & $416.6 \pm 9.4^{* *}$ & $306.1 \pm 8.2^{* * *}$ & $656.2 \pm 27.2^{* *}$ \\
\hline \% Petunia RNAi-ANT small & +11.7 & -18.9 & -10.1 \\
\hline
\end{tabular}

Values represent mean $\left(\mu \mathrm{m}^{2}\right) \pm$ typical error. P-values correspond to ${ }^{*} p<0.05,{ }^{* *} p<0.01$ and ${ }^{* * *} p<0.001$ 
Differences in cell size reduction between the proximal region of the limb and tube in PhRNAi::ANT plants coincide with the differences observed in the size of these organs. Our data also indicate that the effect of PhANT silencing on cell size is not homogenous throughout the limb and tube.

In plants overexpressing AtANT, cells from the distal petal region $(p=0.0)$, proximal petal region $(p=0.03)$ and the tube $(p=0.002)$ were significantly bigger than wild-type, increasing up to approx. 2.5 fold in the distal petal region and tube. We also found that like in wild-type plants, epidermal tube cells showed protrusions (Figure 4 I). Our results indicate a possible requirement of PhANT for the final stage of petal epidermal differentiation. We can conclude that overexpression of AtANT causes increased cell expansion in all regions analyzed. Our results indicate that the tube length increase is the result of increased cell expansion.

\section{Overexpression of Aintegumenta in Antirrhinum}

We obtained 15 independent lines of Antirrhinum resistant to kanamycin and positive for the 35S::AtANT construct. The transgenic Antirrhinum plants had been developed using the commercial genetic background Vilmorin nain (www.vilmorin.com), a semi-dwarf bushy variety with extremely large flowers (Weiss et al., 2012). We were able to identify two plants with flowers that exceeded the large size of this cultivar (Figure 5). The transgenic lines showed normal growth habit (Figure 5a). From two lines that showed extremely large flowers (Figure 5a), we were able to identify overexpression of the AtANT gene in flower limbs and tubes (Figure 5 b,c). All the flowers found were significantly larger than the original cultivar but the construct did not affect leaf area (Figure $5 \mathrm{~d}$-g). Antirrhinum plants expressing AtANT were completely sterile as expected if we consider the experimental evidence from Arabidopsis (Mizukami and Fischer, 2000; Krizek, 1999). As the Antirrhinum flower has a more complex architecture than that of Petunia, we measured twelve floral parameters (Bayo-Canha et al., 2007; Delgado-Benarroch., et al., 2009b) in order to identify the parts of the flower with significant changes in size. Seven parameters were significantly increased, comprising tube length (118\%; $p=0.00018)$, bottom floral length (14\%; $p=0.041$ ), petal width (53\%; $p=0.031$ ), sepal length (97.5\%; $p=0.00091$ ), ventral petal width $(103 \% ; p=0.00058)$, dorsal petal $(78 \% ; p=0.0044)$ and palate $(68 \% ; p=0.0093)$ (Table 3). In contrast, top floral length, tube width, stamen and gynoecium size were not significantly affected by the 35S::AtANT expression. Changes in floral size in Antirrhinum were the result of increased tube length and petal width, while petal length was significantly increased but to a lesser extent. 
Table 3. Comparison of floral parameters between wild-type and transgenic lines

\begin{tabular}{|c|c|c|c|c|c|c|c|c|c|c|c|}
\hline & $\begin{array}{l}\text { Tube } \\
\text { length }\end{array}$ & $\begin{array}{c}\text { Bottom } \\
\text { petal } \\
\text { length }\end{array}$ & $\begin{array}{c}\text { Top } \\
\text { petal } \\
\text { length }\end{array}$ & $\begin{array}{l}\text { Petal } \\
\text { width }\end{array}$ & $\begin{array}{l}\text { Sepal } \\
\text { length }\end{array}$ & $\begin{array}{l}\text { Tube } \\
\text { width }\end{array}$ & $\begin{array}{c}\text { Ventral } \\
\text { petal } \\
\text { width }\end{array}$ & $\begin{array}{c}\text { Dorsal } \\
\text { petal } \\
\text { width }\end{array}$ & $\begin{array}{l}\text { Stamen } \\
\text { length }\end{array}$ & $\begin{array}{c}\text { Gynoeci. } \\
\text { length }\end{array}$ & $\begin{array}{l}\text { Palate } \\
\text { width }\end{array}$ \\
\hline Wild-type & $11.1 \pm 0.4$ & $14.5 \pm 0.2$ & $16.1 \pm 0.3$ & $14.2 \pm 0.3$ & $120 \pm 0.0$ & $15.9 \pm 0.2$ & $11.7 \pm 0.3$ & $12.9 \pm 0.4$ & $153 \pm 0.4$ & $16.3 \pm 0.3$ & $13.4 \pm 0.3$ \\
\hline $\begin{array}{c}\text { Antirrhinum } \\
\text { 35S::ANT }\end{array}$ & $243 \pm 0.1^{* * *}$ & $21.7 \pm 0.6 *$ & $20.3 \pm 0.8$ & $21.8 \pm 0.4 *$ & $23.7 \pm 03^{* * *}$ & $21.6 \pm 0.1$ & $23.9 \pm 0.5^{* * *}$ & $22.9 \pm 1.1 *$ & $210 \pm 0.3$ & $21.2 \pm 0.2$ & $225 \pm 0.2^{* *}$ \\
\hline $\begin{array}{c}\% \\
\text { Antirrhinum } \\
\text { 35S::ANT }\end{array}$ & $118 \%$ & $14 \%$ & $26 \%$ & $53 \%$ & $97.5 \%$ & $36 \%$ & $103 \%$ & $78 \%$ & $37 \%$ & $30 \%$ & $68 \%$ \\
\hline
\end{tabular}

Values correspond to averages $(\mathrm{mm}) \pm$ standard error $(n=20)$. $P$-values are represented with $*<0.05, * *<0.01$ and $* * *<0.001$.
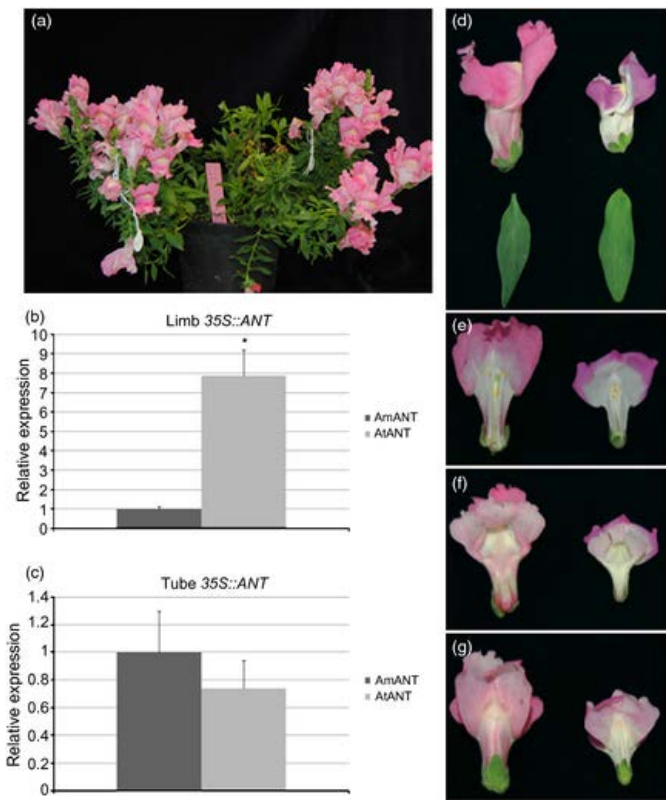

Figure 5. Expression of AtANT in transgenic Antirrhinum and phenotypes of Antirrhinum overexpressing AtANT. Transgenic Antirrhinum plant overexpressing AtANT (a). Expression of AtANT in limb (b) and tube (c) compared to the endogenous level of AmANT (value = 1). Floral and vegetative phenotypes of wild-type (on the right) compared to transgenic line of Antirrhinum overexpressing AtANT (on the left) flowers in lateral position and leaves (d) longitudinal section (e) frontal view (f) and dorsal position (g).P-values are represented with $*<0.05$.

\section{Effect of AtANT on size in Antirrhinum}

We measured the effects of AtANT overexpression on cell size by scanning electron microscopy. Cells from the distal region and proximal region of the limb, representing zones of conical and flat cells, were significantly bigger $(p=0.0)$ than wild-type with a 2 fold and 1.7 fold increase, respectively (Figure 6, Table 4). Likewise the size of cells from the tube was 1.8 fold bigger $(p=0.0)$. In summary, the effect of AtANT in Antirrhinum is a linear increase in cell size in all petal regions analysed. Cell size changes can explain larger petal organs.

Table 4. Cell size of Antirrhinum flowers.

\begin{tabular}{|c|c|c|c|}
\hline & Region $3\left(\mu \mathrm{m}^{2}\right)$ & Region $\mathbf{8}\left(\boldsymbol{\mu m}^{2}\right)$ & Tube $\left(\mu \mathrm{m}^{2}\right)$ \\
\hline wild-type & $1569.3 \pm 30.8$ & $1264.7 \pm 27.9$ & $3867.7 \pm 125.7$ \\
\hline Antirrhinum 35S::ANT & $3320.9 \pm 69.3 * * *$ & $2212.1 \pm 44.8^{* * *}$ & $6881.4 \pm 185.7^{* * *}$ \\
\hline \% Antirrhinum 35S::ANT & +111.6 & +74.9 & +77.9 \\
\hline
\end{tabular}

Total number of cell measured for each organ/mutant $=100$. Values represent mean $\left(\mu \mathrm{m}^{2}\right) \pm$ typical error. P-values correspond to $* p<0.05, * * p<0.01$ and ${ }^{* * *} p<0.001$ 

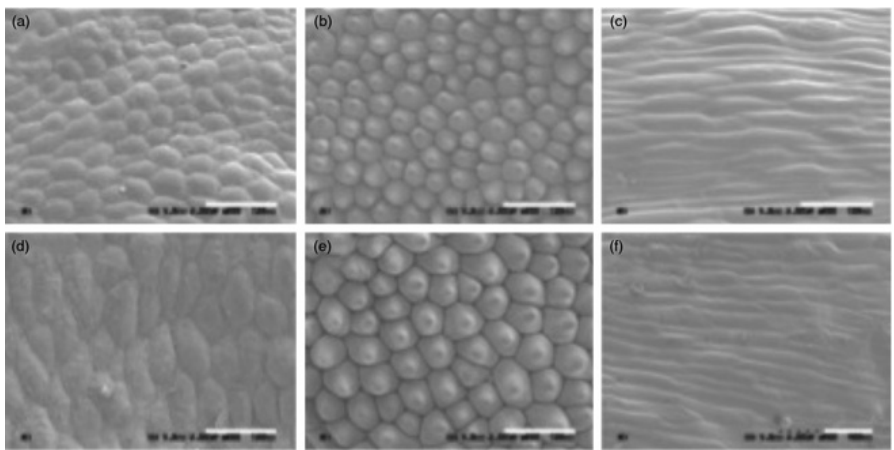

Figure 6. Cell size in Antirrhinum. Comparison between cell size of wild-type (on the top) and transgenic line with overexpression of AtANT (on the bottom) (a) and (d) cells from the proximal region of the petal (b) and (e) cells from the distal region of the petal limb (c) and (f) cells from the petal tube.

Overexpression of AtANT in Arabidopsis causes modifications of lateral organ size partly by changes in cell division and expansion (Mizukami and Fischer, 2000; Krizek, 1999). However, the main conclusion we could draw from the parallel experiments in Petunia and Antirrhinum are a major effect of $A N T$ overexpression on cell expansion.

\section{Differential effects of AtANT on endogenous ANT in Petunia and Antirrhinum}

We found recently that the structure of gene regulatory network motifs can change during ontogeny (Manchado-Rojo et al., 2012). We wondered if the detected differences between limb and tube could also be reflected in changes in the ANT network topology. We compared the levels of the endogenous PhANT and AmANT between limb and tube in Petunia and Antirrhinum. We found that during the stage of flower opening, the levels of $A N T$ transcription tended to be lower in the limb compared to the tube in both flowers (Fig. 7 a). However, these differences in expression levels were significant in Antirrhinum (down to $0.312, p=0.004$ ) but not in Petunia (down to 0.509, $p=0.142$ ).
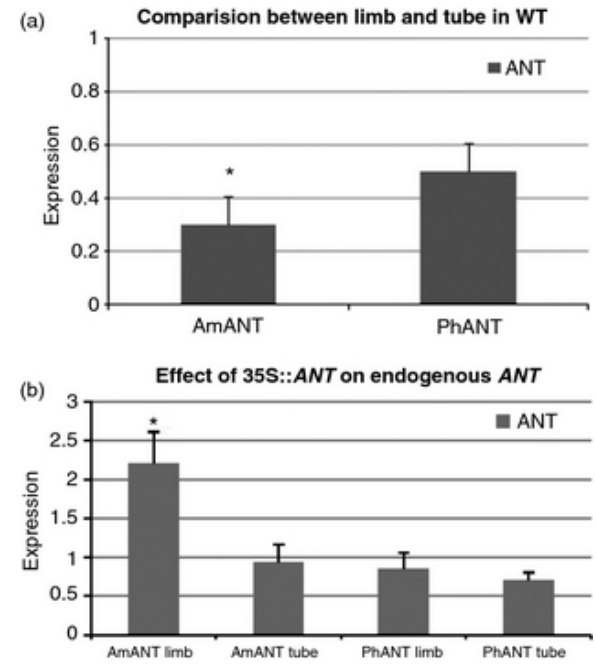

Figure 7. Levels of endogenous AINTEGUMENTA in limb and tube in non-transgenic and transgenic plants. Relative differences in endogenous AmANT and PhANT expression in limb (value $=1$ ) and tube (a). Effect of 35S::AtANT on the endogenous expression of AmANT and PhANT. Comparison of expression levels between limb and tube in non-transformed flowers (value $=1)(b)$. $P$-values are represented with * $<0.05$ 
As the results obtained in Petunia and Antirrhinum show a trend but are not identical, we suspected that the ANT regulatory network could be different. We compared the endogenous levels of PhANT in non-transgenic and transgenic lines overexpressing AtANT. These data should identify if ANT has some type of self-regulatory network motif, as positive or negative autoregulation. We would not expect RNAi-based co-supression of the endogenous ANT genes that display dissimilar DNA sequence as compared to Arabidopsis. In Petunia, PhANT was not regulated in the limb as a result of AtANT expression (0.802, p=0.386; Figure 7b). In contrast in Antirrhinum, AtANT caused a significant upregulation of the endogenous AmANT in the $\operatorname{limb}(2.2$ fold $\mathrm{p}=0.0)$. The AtANT expression did not affect the levels of PhANT or AmANT in the tube. Our data shows that Petunia and Antirrhinum share a common structure of regulatory network of the ANT gene in the tube where it is not subject to positive autoregulation. However a positive autoregulation exists in the limb of Antirrhinum but not in Petunia showing here an evolutionary divergence concerning the ANT regulatory network.

\section{Discussion}

The ANT gene belongs to the AP2 family of plant-specific transcription factors. The AP2 gene family comprises two major clades, one defined by AP2 and a second one by ANT (Kim et al., 2006; Shigyo et al., 2006). The ANT lineage is present in the moss Physcomitrella patens but not in the green algae Chlamydomonas reinhadtii, indicating that it is a group formed later in evolution (Shigyo and Ito, 2004). The gene ANT from Arabidopsis has been described as a gene involved in growth control (Krizek, 1999; Mizukami and Fischer, 2000). In spite of its potential in Arabidopsis, its use as a biotechnological tool has not been established. We had previously cloned and characterized the ANT ortholog from Antirrhinum, AmANT (Delgado-Benarroch et al., 2009a). It shows a heterochronic change in gene expression and its upregulation in inflorescences and young floral buds of the formosa mutant compared to wild-type could explain the larger flowers of this mutant. This made it especially attractive as a candidate gene to study modification of floral size in ornamentals. In this work we have cloned an ANT homolog from Petunia and we have performed a functional study in Petunia and Antirrhinum by modification of gene expression.

Loss of function of ANT in Arabidopsis causes a general decrease in lateral organ size and sterility (Mizukami and Fischer, 2000; Krizek, 1999). The overexpression of AtANT in Arabidopsis has three major phenotypic effects. Firstly at the macroscopic level, it causes a general increase in lateral organ size. Contrasting evidence shows increased petal size caused by cell division (Mizukami and Fischer, 2000) or cell expansion (Krizek, 1999). Finally 35S::AtANT causes plant sterility (Mizukami and Fischer, 2000; Krizek, 1999). Thus we expected three possible effects of ANT overexpression in Petunia and Antirrhinum. 
Overexpression of AtANT in Petunia and Antirrhinum does not cause similar macroscopic phenotypic changes. We obtained clear results of increased limb sizes in Petunia, and a general increase in petal limb and tube in Antirrhinum but the petal tube was less affected in Petunia. Genetic separation of limb and tube are found in the genus Petunia, where at least five loci control tube size (Galliot, Hoballah, et al., 2006; Stuurman et al., 2004). Differences in limb versus tube size are considered part of its pollination syndrome and adaptation to day and night pollinators (Galliot, Stuurman, et al., 2006). Additional evidence for a distinct control of limb and tube have been obtained by misexpression of EXPANSIN showing a preferential effect on petal limb size whereas tube length is less affected (Zenoni et al., 2004; Zenoni et al., 2011). These results coincide with our data obtained in the Mitchell background, indicating that at least part of the floral size control in the genus Petunia differs between limb and tube.

In the Antirrhinum genus, natural variation of floral size shows increases and decreases of overall floral size but it does not display this clear separation of tube and limb as in Petunia (Feng et al., 2009). Our results show that in Antirrhinum, AtANT causes increased growth as a result of larger tube and petal width, and importantly it does not cause a differential growth of the limb versus the tube. We can conclude that misexpression of AtANT does modify floral size, but the exact outcome might be constrained by the genomic environment where the gene is expressed, as the phenotypic spaces obtained resemble those seen in the genus.

We found that changes in the expression levels of PhANT by RNAi or overexpression of AtANT caused a complex cellular phenotype. As changes in cell size were larger than those observed in tube size we conclude that a compensation mechanism could take place in the Petunia tube. Compensation mechanisms are a cellular phenotype described in Drosophila and found also in plants where changes in genes affecting cell division would cause increases or decreases in cell expansion that would balance to some extent the effect on organ size (Neufeld et al., 1998). This compensation mechanism has been extensively studied in leaf, ovule and flower development (Delgado-Benarroch et al., 2009c; Ferjani et al., 2007; Horiguchi and Tsukaya, 2006; Truernit and Haseloff, 2008). One current view is the existence of an underlying coordination between cell division and expansion in order to maintain a certain organ size, giving as a result a special resilience of an organ or organ region to changes in their proportions.

Overexpression of AtANT in Arabidopsis causes increased organ size as a result of cell division and cell expansion (Krizek, 1999; Mizukami and Fischer, 2000). In the formosa mutant of Antirrhinum a heterochronic effect is observed where AmANT is overexpressed in petals that are larger than wildtype as a result of increased cell division (Luciana Delgado-Benarroch, Causier, et al., 2009). This 
indicates that ANT might well function enhancing the cellular process involved in growth at a certain developmental window and overexpression at later stages of petal development also causes cell expansion. As we found a major effect on cell expansion in Petunia and Antirrhinum, we might conclude that AtANT is a general gene suitable to modify lateral organ size, by a combination of cell division and expansion, as we cannot rule out increased cell division at a certain point.

We found contrasting phenotypes concerning fertility in plants overexpressing AtANT. While Petunia was fertile, Antirrhinum showed complete sterility, as observed for Arabidopsis plants expressing 35S::AtANT. From an industrial perspective, having transgenic plants that are sterile could be an asset, as environmental issues of horizontal gene transfer can be ruled out. Furthermore the horticultural industry is heavily based on vegetative propagation from shoots and vegetative cuttings (Hartmann and Kester, 1975). Thus transgenic lines can be multiplied at will.

As ANT is a gene with multiple functions, and the phenotypes found in Petunia and Antirrhinum share some common features, we analysed the differential levels of ANT in tube and limb and the effect of AtANT expression on the endogenous ANT. These experiments should shed light on the structure of the ANT regulatory network. First, it is surprising that in both Petunia and Antirrhinum the endogenous ANT expression tended to be lower in limb compared to tube. These data give some molecular support to the studies on petal size in Petunia and Antirrhinum showing differences between these two organ compartments (Stuurman et al., 2004; Hermann and Kuhlemeier, 2011; Galliot, et al., 2006; Delgado-Benarroch, et al., 2009c). Additional support for a difference between petal limb and tube were found because the endogenous ANT expression in the tube of Petunia and Antirrhinum showed no changes as a result of expression of AtANT. However, the differences in positive autoregulation found in the Antirrhinum petal limb indicates that the ANT regulatory network (Alon, 2007) might differ between organ regions. Overall our data show that petal limb and tube might be considered separate organs in terms of genetic modification when it comes to size.

Altogether our data validates $A N T$ as candidate gene to modify floral size in ornamental species. Although orthology can predict to a large extent the degree of conservation beyond the biochemical function, the annotation of single genes validated to modify biological functions in a predictable way is an on going effort in biology that is required to have universal biotechnological tools. Obtaining both larger and smaller flowers has been a major aim in breeding of Petunia and other ornamentals (Weiss et al., 2006). The ANT gene might be seen as a potential target to obtain gain and loss of function alleles. Non-transgenic approaches like TILLING (Till et al., 2003) or emerging technologies 
like TALEN nuclease mediated genome engineering (Gaj et al., 2013) could deliver new cultivars with modified floral size based on ANT alleles.

\section{Experimental Procedures}

\section{Plant material and transformation}

Seeds of Petunia $x$ hybrida line Mitchell and Antirrhinum majus nana were surface-sterilized and sown on Murashige and Skoog medium (www.duchefa.com) solidified with $4 \mathrm{~g} / \mathrm{L}$ of Phytagel (www.sigmaaldrich.com) and were placed on growth chambers under a photoperiod of 16/8 hours of light/dark and $25 \circ \mathrm{C} / 18 \circ \mathrm{C}$ temperature.

We carried out Antirrhinum transformation following the protocol based on hypocotyls previously described (Manchado-Rojo et al., 2012). For Petunia we used leaf disks as described (Horsch et al., 1985).

Plants corresponding to primary transformants (T0) and selfed plants (T1) were genotyped for presence of the NPTII gene by PCR. A positive control was performed using the gene UBIQUITINE $(U B I)$ for all reactions to rule out a negative result caused by low quality DNA. Plants positive for UBI and negative for NPTII were considered as non-transgenic in TO or as plants segregating out the transgenic construct in T1 after self pollination. We obtained a total of 20 lines for PhRNAi::ANT, 18 for 35S::AtANT in Petunia and 2 for 35S::AtANT in Antirrhinum. We genotyped ten T1 plants per line of all the lines obtained. Floral, cellular and molecular phenotypes correspond to the average of all the flowers of all the lines ordered by phenotype (large, medium or small for Petunia, and transgenic and non-transgenic for Antirrhinum).

\section{Aintegumenta cloning and vector construction}

We amplified a fragment of 198bp (ANT for 5'-GGAAAAGTTGGCTGGAAACA-3' and ANT rev 5'ACTCTGCCTGCTGGTGAATT-3') from Petunia Mitchell genomic DNA, using the primers based on the tomato ANT coding sequence. The corresponding PCR fragment was reamplified with primers containing attb1 and attb2 specific sequences in order to obtain recombination ready fragments in a two-step PCR. First, two attb1 and attb2 partial tails were introduced by PCR and a second amplification was performed with attb1 and attb2 external primers (supplementary Table S2). The corresponding product was recombined by GATEWAY technology into pDONR221 vector (www.invitrogen.com), using BP recombinase. The resulting $p D O N R:: P h A N T$ was further recombined with LR recombinase into the pHELLSGATE12 vector (Helliwell and Waterhouse, 2003). Correct orientation and presence of two fragments in opposite direction was detected by PCR as described in 
the www.agrikola.org protocol. We used the sequence obtained from Petunia to perform RACE PCR and clone $1.2 \mathrm{~Kb}$ of PhANT cDNA (Genebank accession KF754796). Overexpression of ANT was performed using the construct from Arabidopsis pCGN1547 35S::ANT (Krizek, 1999).

\section{Phylogenetic analysis}

Phylogenetic analysis was performed using CLUSTALX for alignment. Aligned sequences (Figure S1) were used for tree construction with the PHYLIP NJ algorithm (Larkin et al., 2007) and trees were rendered with NJ plot (Perrière and Gouy, 1996). We confirmed the phylogenetic analysis using an online pipe (http://www.phylogeny.fr/version2 cgi/index.cgi) (Dereeper et al., 2010; Dereeper et al., 2008). The pipeline comprises a sequence alignment set for maximum accuracy with MUSCLE (Edgar, 2004). Aligned sequences are automatically curated from poorly aligned positions and blocks with Gblocks (Castresana, 2000). The phylogenetic analysis is performed by PhyML that uses a Near Neighbour Interchange algorithm (Guindon and Gascuel, 2003) and trees are rendered by Treedyn (Chevenet et al., 2006). Percentages of protein similarity were identified using the NeedlemanWunsch algorithm implemented in the NEEDLE program (www.ebi.ac.uk).

\section{Measurements}

To determinate quantitative differences in floral parameters describing floral size, we measured in Petunia sepal, petal, stamen and style length. For petal size we measured the diameter of the limb, the length of the tube from its inception till the tilt of the tube into the limb. Stamen and style length were measured from the bottom of the flower. For Antirrhinum, the floral parameters measured were tube length, lower length, petal height, sepal length, tube width, upper (total) length, lower petal width, upper petal width, stamen length and gynoecium length (Delgado-Benarroch, et al., 2009a). All the measurements were performed with a scalimeter when the flowers were fully open.

\section{Scanning electron microscopy}

In Petunia the petal was separated in limb and floral tube with a scalpel blade. Limbs of Petunia were further divided into a distal outer zone and a proximal zone near the tube in order to measure the cell area (Figure S1). For Antirrhinum we measured the cells from the region 3 and 8 of the limb corresponding to proximal and distal cells from the upper petal (Delgado-Benarroch et al., 2009a).

Petal tissue was sliced into $5 \mathrm{~mm}^{2}$ approximately. Sections were washed in wash buffer $\mathrm{pH} 7.2$ $\left(112 \mathrm{mM} \mathrm{NaH}_{2} \mathrm{PO}_{4}\right.$ and $\left.288 \mathrm{mM} \mathrm{Na}_{2} \mathrm{HPO}_{4}\right)$, fixed overnight in glutaraldehyde $2 \%$, dehydrated in a 
graded ethanol series, placed in acetone $100 \%$ and finally dehydrated by critical point drying with liquid $\mathrm{CO}_{2}$ (Delgado-Benarroch et al., 2009a).

In order to analyse the cell size we measured the area of 100 cells from the limb and the tube, using the free software ImageJ (http://rsbweb.nih.gov/ij/). The data showed non-normal distributions, therefore they were analysed with the Kruskall-Wallis Test.

\section{RT-qPCR}

Total RNA was isolated with the NucleoSpin RNA plant kit (MACHEREY-NAGEL, www.mn-net.com) containing DNAase. The concentration of RNA was measured spectrophotometrically. We used $1 \mu \mathrm{g}$ of total RNA in order to synthesize the first strand cDNA using the Maxima ${ }^{\mathrm{TM}}$ First Strand cDNA Synthesis Kit (Fermentas, www.fermentas.com).

Real-Time PCRs were performed in a Stratagene MX3000P QPCR system (Agilent Technologies, www.home.agilent.com) using a SYBR Green based PCR assay with ROX as reference dye (Brilliant II SYBR Green QPCR Master Mix. Stratagene, www.genomics.agilent.com). Primers were designed using PCREfficiency (supplementary Table S2) (Mallona et al., 2011).

We used three biological replicas and two technical replicas for each sample. We obtained takeoffs and efficiency values from raw data (Mallona et al., 2011) and computed differences in gene expression analysis as described previously using randomized group-wise statistical comparison using the REST program (Pfaffl et al., 2002).

For relative quantification we used as reference genes the RIBOSOMAL PROTEIN SAND 13 in the case of Petunia (Mallona et al., 2010) and UBIQUITIN for Antirrhinum. The takeoff values of the genes UBI, RSP13, AmANT and PhANT were similar enough (supplementary Table S3) and stable to give reproducible results and be mathematically accepted by the REST program.

\section{Statistical analysis}

We used the R package for statistical analysis (www.r-project.org) or the StatGraphics programme, to perform analysis of variance. Data showing non-normality were analysed using the Kruskal-Wallis test. 


\section{Acknowledgements}

We would like to thank Beth Krizek (University of South Carolina, USA) for the pCGN1547 35S::ANT construct. This work was performed as partial fulfilment of the PhD degree of María Manchado Rojo. Fundación Séneca project 11895/PI/09 and MICINN-FEDER BFU-2010-15843 funded this work. María Manchado Rojo received a predoctoral fellowship from the UPCT.

\section{References}

Achard, P., Herr, A., Baulcombe, D.C. and Harberd, N.P. (2004) Modulation of floral development by a gibberellin-regulated microRNA. Development, 131, 3357-65.

Adams, M.D., Kelley, J.M., Gocayne, J.D., et al. (1991) Complementary DNA sequencing: expressed sequence tags and human genome project. Sci. , 252 , 1651-1656. Available at: http://www.sciencemag.org/ content/252/5013/1651.abstract.

Aida, M., Beis, D., Heidstra, R., et al. (2004) The PLETHORA genes mediate patterning of the Arabidopsis root stem cell niche. Cell, 119, 109-120.

Allen, R.S., Li, J., Stahle, M.I., Dubroué, A., Gubler, F. and Millar, A.A. (2007) Genetic analysis reveals functional redundancy and the major target genes of the Arabidopsis miR159 family. Proc. Natl. Acad. Sci. U. S. A., 104, 16371-6.

Alon, U. (2007) Network motifs: theory and experimental approaches. Nat Rev Genet, 8, 450-461.

Altschul, S.F., Gish, W., Miller, W., Myers, E.W. and Lipman, D.J. (1990) Basic local alignment search tool. J. Mol. Biol., 215, 403-410.

An, S., Park, S., Jeong, D.-H., et al. (2003) Generation and Analysis of End Sequence Database for T-DNA Tagging Lines in Rice. Plant Physiol. , 133 , 2040-2047. Available at: http://www.plantphysiol.org/content/ 133/4/2040.abstract.

Anastasiou, E., Kenz, S., Gerstung, M., Maclean, D., Timmer, J., Fleck, C. and Lenhard, M. (2007) Control of Plant Organ Size by KLUH/CYP78A5-Dependent Intercellular Signaling. Dev. Cell, 13, 843-856.

Andriankaja, M., Dhondt, S., Bodt, S. De, et al. (2012) Exit from proliferation during leaf development in Arabidopsis thaliana: a not-so-gradual process. Dev. Cell, 22, 64-78.

Anon (1999) The FlyBase database of the Drosophila Genome Projects and community literature. Nucleic Acids Res., 27, 85-88.

Ashburner, M., Ball, C.A., Blake, J.A., et al. (2000) Gene ontology: tool for the unification of biology. The Gene Ontology Consortium. Nat. Genet., 25, 25-9.

Ball, C.A., Dolinski, K., Dwight, S.S., et al. (2000) Integrating functional genomic information into the Saccharomyces Genome Database. Nucleic Acids Res. , 28 , 77-80. Available at: http://nar.oxfordjournals.org/content/28/1/77.abstract.

Baumann, K., Perez-Rodriguez, M., Bradley, D., Venail, J., Bailey, P., Jin, H.L., Koes, R., Roberts, K. and Martin, C. (2007) Control of cell and petal morphogenesis by R2R3 MYB transcription factors. Development, 134, 1691-1701. 
Baur, E. (1924) Untersuchungen iiber das Wesen, die Entstehung und die Vererbung yon Rassenunterschieden bei Antirrhinum magus. Bibl. Genet. IV.

Bayo-Canha, A., Delgado-Benarroch, L., Weiss, J. and Egea-Cortines, M. (2007) Artificial decrease of leaf area affects inflorescence quality but not floral size in Antirrhinum majus. Sci. Hortic. (Amsterdam)., 113, 383386.

Belhaj, K., Chaparro-Garcia, A., Kamoun, S., Patron, N.J. and Nekrasov, V. (2015) Editing plant genomes with CRISPR/Cas9. Curr. Opin. Biotechnol., 32, 76-84.

Benfey, P.N. and Chua, N.-H. (1990) The cauliflower mosaic virus 35S promoter: combinatorial regulation of transcription in plants. Science (80-. )., 250, 959.

Blake, J.A., Eppig, J.T., Richardson, J.E., Davisson, M.T. and the Mouse Genome Database Group (2000) The Mouse Genome Database (MGD): expanding genetic and genomic resources for the laboratory mouse. Nucleic Acids Res. , 28 , 108-111. Available at: http://nar.oxfordjournals.org/content/28/1/108.abstract.

Bombarely, A., Moser, M., Amrad, A., Bapaume, L. and Barry, C.S. Whole genome sequences of the wild parents of the garden petunia give insights into the evolution of Solanaceae genomes.

Bradley, D., Carpenter, R., Sommer, H., Hartley, N. and Coen, E. (1993) Complementary floral homeotic phenotypes result from opposite orientations of a transposon at the plena locus of Antirrhinum. Cell, 72, 85-95.

Brioudes, F., Joly, C., Szécsi, J., Varaud, E., Leroux, J., Bellvert, F., Bertrand, C., Bendahmane, M. and Szecsi, J. (2009) Jasmonate controls late development stages of petal growth in Arabidopsis thaliana. Plant J.

Brown, D.M., Zeef, L.A.H., Ellis, J., Goodacre, R. and Turner, S.R. (2005) Identification of Novel Genes in Arabidopsis Involved in Secondary Cell Wall Formation Using Expression Profiling and Reverse Genetics. Plant Cell , 17 , 2281-2295. Available at: http://www.plantcell.org/content/17/8/2281.abstract.

Carpenter, R. and Coen, E.S. (1990) Floral homeotic mutations produced by transposon-mutagenesis in Antirrhinum majus. Genes Dev., 4, 1483.

Castresana, J. (2000) Selection of conserved blocks from multiple alignments for their use in phylogenetic analysis. Mol. Biol. Evol., 17, 540-552.

Causier, B., Cook, H. and Davies, B. (2003) An Antirrhinum ternary complex factor specifically interacts with Cfunction and SEPALLATA-like MADS-box factors. Plant Mol. Biol., 52, 1051-1062.

Causier, B., Schwarz-Sommer, Z. and Davies, B. (2010) Floral organ identity: 20 years of ABCs. Semin Cell Dev Biol, 21, 73-79.

Cecchetti, V., Altamura, M.M., Falasca, G., Costantino, P. and Cardarelli, M. (2008) Auxin Regulates Arabidopsis Anther Dehiscence, Pollen Maturation, and Filament Elongation. Plant Cell , 20 , 1760-1774. Available at: http://www.plantcell.org/content/20/7/1760.abstract.

Chevenet, F., Brun, C., Bañuls, A.-L., Jacq, B. and Christen, R. (2006) TreeDyn: towards dynamic graphics and annotations for analyses of trees. BMC Bioinformatics, 7, 439.

Coen, E.S. and Meyerowitz, E.M. (1991) The War of the Whorls - Genetic Interactions Controlling Flower Development. Nature, 353, 31-37.

Colombo, L., Franken, J., Koetje, E., Went, J. van, Dons, H.J., Angenent, G.C. and Tunen, A.J. van (1995) The petunia MADS box gene FBP11 determines ovule identity. Plant Cell, 7, 1859-1868. Available at: http://www.ncbi.nlm.nih.gov/pmc/articles/PMC161044/. 
Cong, L., Ran, F.A., Cox, D., et al. (2013) Multiplex Genome Engineering Using CRISPR/Cas Systems. Sci. , 339 , 819-823. Available at: http://www.sciencemag.org/content/339/6121/819.abstract.

Consortium, T.G.O. (2001) Creating the Gene Ontology Resource: Design and Implementation. Genome Res. , 11 , 1425-1433. Available at: http://genome.cshlp.org/content/11/8/1425.abstract.

Cubas, P., Lauter, N., Doebley, J. and Coen, E. (1999) The TCP domain: a motif found in proteins regulating plant growth and development. Plant J., 18, 215-222.

Davies, B., Davies, G., Preece, C., Puliyadi, R., Szumska, D. and Bhattacharya, S. (2013) Site specific mutation of the Zic2 locus by microinjection of TALEN mRNA in mouse CD1, C3H and C57BL/6J oocytes. PLoS One, 8, e60216. Available at: http://dx.doi.org/10.1371/journal.pone.0060216 [Accessed October 7, 2015].

Delgado-Benarroch, L., Causier, B., Weiss, J. and Egea-Cortines, M. (2009) FORMOSA controls cell division and expansion during floral development in Antirrhinum majus. Planta, 229, 1219-1229.

Delgado-Benarroch, L., Weiss, J. and Egea-Cortines, M. (2009) Floral organ size control: interplay between organ identity, developmental compartments and compensation mechanisms. Plant Signal. Behav., 9, 14.

Delgado-Benarroch, L., Weiss, J. and Egea-Cortines, M. (2010) Sizing up the flower. In M. Yaish and J. Colasanti, eds. The Flowering Process and its Control in Plants: Gene Expression and Hormone Interaction.

Delgado-Benarroch, L., Weiss, J. and Egea-Cortines, M. (2009) The mutants compacta ähnlich, Nitida and Grandiflora define developmental compartments and a compensation mechanism in floral development in Antirrhinum majus. J. Plant Res., 122, 559-69.

Dereeper, A., Audic, S., Claverie, J.-M. and Blanc, G. (2010) BLAST-EXPLORER helps you building datasets for phylogenetic analysis. BMC Evol. Biol., 10, 8.

Dereeper, A., Guignon, V., Blanc, G., et al. (2008) Phylogeny.fr: robust phylogenetic analysis for the nonspecialist. Nucleic Acids Res., 36, W465-9.

Disch, S., Anastasiou, E., Sharma, V.K., Laux, T., Fletcher, J.C. and Lenhard, M. (2006) The E3 ubiquitin ligase BIG BROTHER controls Arabidopsis organ size in a dosage-dependent manner. Curr. Biol., 16, 272-279.

Ditta, G., Pinyopich, A., Robles, P., Pelaz, S. and Yanofsky, M.F. (2004) The SEP4 Gene of Arabidopsis thaliana Functions in Floral Organ and Meristem Identity. Curr. Biol., 14, 1935-1940. Available at: http://www.sciencedirect.com/science/article/pii/S0960982204008152.

Dona, D.H., Dunwell, J. and Gibbings, J. (2010) Characterization of Aintegumenta-like Gene in Coconut (Cocos nucifera L) and Its Expression During Embryogenesis. Vitr. Cell. Dev. Biol., 46, S123-S124.

Dornelas, M.C., Patreze, C.M., Angenent, G.C. and Immink, R.G.H. (2011) MADS: the missing link between identity and growth? Trends Plant Sci., 16, 89-97.

Draper, B.W., McCallum, C.M., Stout, J.L., Slade, A.J. and Moens, C.B. (2004) A high-throughput method for identifying N-ethyl-N-nitrosourea (ENU)-induced point mutations in zebrafish. Methods Cell Biol., 77, 91112.

Dubois, A., Raymond, O., Maene, M., Baudino, S., Langlade, N.B., Boltz, V., Vergne, P. and Bendahmane, M. (2010) Tinkering with the C-Function: A Molecular Frame for the Selection of Double Flowers in Cultivated Roses. PLoS One, 5.

Edgar, R.C. (2004) MUSCLE: multiple sequence alignment with high accuracy and high throughput. Nucleic Acids Res., 32, 1792-1797. 
Egea Gutierrez-Cortines, M. and Davies, B. (2000) Beyond the ABCs: ternary complex formation in the control of floral organ identity. Trends Plant Sci., 5, 473-478.

Egea Gutierrez-Cortines, M., Davies, B. and Gutierrez-Cortines, M.E. (2000) Beyond the ABCs: ternary complex formation in the control of floral organ identity. Trends Plant Sci., 5, 473-478.

Egea-Cortines, M., Saedler, H. and Sommer, H. (1999) Ternary complex formation between the MADS-box proteins SQUAMOSA, DEFICIENS and GLOBOSA is involved in the control of floral architecture in Antirrhinum majus. EMBO J., 18, 5370-5379.

Egea-Cortines, M. and Weiss, J. (2013) Control of plant organ size. eLS. Wiley.

Elliott, R.C., Betzner, A.S., Huttner, E., Oakes, M.P., Tucker, W.Q.J., Gerentes, D., Perez, P. and Smyth, D.R. (1996) AINTEGUMENTA, an APETALA2-like gene of Arabidopsis with pleiotropic roles in ovule development and floral organ growth. Plant Cell, 8, 155-168.

Feng, X., Wilson, Y., Bowers, J., Kennaway, R., Bangham, A., Hannah, A., Coen, E. and Hudson, A. (2009) Evolution of Allometry in Antirrhinum. Plant Cell, 21, 2999-3007.

Ferjani, A., Horiguchi, G., Yano, S. and Tsukaya, H. (2007) Analysis of leaf development in fugu mutants of Arabidopsis reveals three compensation modes that modulate cell expansion in determinate organs. Plant Physiol., 144, 988-999.

Ferrario, S., Immink, R.G.H., Shchennikova, A., Busscher-Lange, J. and Angenent, G.C. (2003) The MADS box gene FBP2 is required for SEPALLATA function in petunia. Plant Cell, 15, 914-925.

Fire, A., Xu, S., Montgomery, M.K., Kostas, S.A., Driver, S.E. and Mello, C.C. (1998) Potent and specific genetic interference by double-stranded RNA in Caenorhabditis elegans. Nature, 391, 806-811. Available at: http://dx.doi.org/10.1038/35888.

Foster, E., Hattori, J., Labbé, H., Ouellet, T., Fobert, P.R., James, L.E., Iyer, V.N. and Miki, B.L. (1999) A tobacco cryptic constitutive promoter, tCUP, revealed by T-DNA tagging. Plant Mol. Biol., 41, 45-55. Available at: http://europepmc.org/abstract/MED/10561067.

Fru, C., Ramirez-Parra, E., Lo, M.A., Lopez-Matas, M.A., Frundt, C., Gutierrez, C., López-Matas, M.A. and Fründt, C. (2004) Role of an atypical E2F transcription factor in the control of arabidopsis cell growth and differentiation. Plant Cell, 16, 2350-2363.

Gaj, T., Gersbach, C.A. and Barbas, C.F. (2013) ZFN, TALEN, and CRISPR/Cas-based methods for genome engineering. Trends Biotechnol., 31, 397-405.

Galimba, K.D., Tolkin, T.R., Sullivan, A.M., Melzer, R., Theissen, G. and Stilio, V.S. Di (2012) Loss of deeply conserved C-class floral homeotic gene function and C- and E-class protein interaction in a doubleflowered ranunculid mutant. Proc. Natl. Acad. Sci. U. S. A., 109, E2267-E2275.

Galinha, C., Hofhuis, H., Luijten, M., Willemsen, V., Blilou, I., Heidstra, R. and Scheres, B. (2007) PLETHORA proteins as dose-dependent master regulators of Arabidopsis root development. Nature, 449, 10531057.

Galliot, C., Hoballah, M.E., Kuhlemeier, C. and Stuurman, J. (2006) Genetics of flower size and nectar volume in Petunia pollination syndromes. Planta, 225, 203-212.

Galliot, C., Stuurman, J. and Kuhlemeier, C. (2006) The genetic dissection of floral pollination syndromes. Curr. Opin. Plant Biol., 9, 78-82.

Game, J.C. and Cox, B.S. (1972) Epistatic interactions between four rad loci in yeast. Mutat. Res. Mol. Mech. 
Mutagen., 16, 353-362. Available at: http://www.sciencedirect.com/science/article/pii/ 0027510772902035 [Accessed October 14, 2015].

Gawenda, I., Schroder-Lorenz, A. and Debener, T. (2012) Markers for ornamental traits in Phalaenopsis orchids: population structure, linkage disequilibrium and association mapping. Mol. Breed., 30, 305-316.

Gerats, T. and Vandenbussche, M. (2005) A model system for comparative research: Petunia. Trends Plant Sci., 10, 251-6. Available at: http://www.ncbi.nlm.nih.gov/pubmed/15882658 [Accessed November 5, 2014].

Grishok, A., Pasquinelli, A.E., Conte, D., et al. (2001) Genes and mechanisms related to RNA interference regulate expression of the small temporal RNAs that control C. elegans developmental timing. Cell, 106, 23-34.

Guindon, S. and Gascuel, O. (2003) A Simple, Fast, and Accurate Algorithm to Estimate Large Phylogenies by Maximum Likelihood. Syst. Biol., 52, 696-704.

Harris, M.A., Clark, J., Ireland, A., et al. (2004) The Gene Ontology (GO) database and informatics resource. Nucleic Acids Res., 32, D258-61. Available at: http://nar.oxfordjournals.org/cgi/content/long /32/suppl_1/D258 [Accessed February 23, 2015].

Hartmann, H.T. and Kester, D.E. (1975) Plant propagation: principles and practices. 3rd edition.

Haughn, G.W. and Somerville, C.R. (1988) Genetic control of morphogenesis in Arabidopsis. Dev. Genet., 9, 7389. Available at: http://dx.doi.org/10.1002/dvg.1020090202.

Helliwell, C. and Waterhouse, P. (2003) Constructs and methods for high-throughput gene silencing in plants. Methods, 30, 289-295.

Hermann, K. and Kuhlemeier, C. (2011) The genetic architecture of natural variation in flower morphology. Curr. Opin. Plant Biol., 14, 60-5.

Hernalsteens, J.-P., Vliet, F. Van, Beuckeleer, M. De, Depicker, A., Engler, G., Lemmers, M., Holsters, M., Montagu, M. Van and Schell, J. (1980) The Agrobacterium tumefaciens Ti plasmid as a host vector system for introducing foreign DNA in plant cells.

Herrera-Estrella, L., Depicker, A., Montagu, M. Van and Schell, J. (1983) Expression of chimaeric genes transferred into plant cells using a Ti-plasmid-derived vector. Nature, 303, 209-213.

Hertwig, P. (1926) Ein neuer Fall von multiplem Allelomorphismus bei Antirrhinum. Mol. Gen. Genet. MGG, 41, 42-47.

Holtorf, S., Apel, K. and Bohlmann, H. (1995) Comparison of different constitutive and inducible promoters for the overexpression of transgenes in Arabidopsis thaliana. Plant Mol. Biol., 29, 637-646. Available at: http://dx.doi.org/10.1007/BF00041155.

Honma, T. and Goto, K. (2001) Complexes of MADS-box proteins are sufficient to convert leaves into floral organs. Nature, 409, 525-529.

Horiguchi, G., Gonzalez, N., Beemster, G.T.S., Inze, D. and Tsukaya, H. (2009) Impact of segmental chromosomal duplications on leaf size in the grandifolia-D mutants of Arabidopsis thaliana. Plant J., 60, 122-133.

Horiguchi, G., Kim, G.-T.T. and Tsukaya, H. (2005) The transcription factor AtGRF5 and the transcription coactivator AN3 regulate cell proliferation in leaf primordia of Arabidopsis thaliana. Plant J., 43, 68-78.

Horiguchi, G. and Tsukaya, H. (2006) A mechanism that monitors the number of leaf cells and its role in the determination of cell size and leaf size. Plant Cell Physiol., 47, S118-S118. 
Horsch, R.B., Fry, J.E., Hoffmann, N.L., Eichholtz, D., Rogers, S.G. and Fraley, R.T. (1985) A Simple and GeneralMethod for Transferring Genes into Plants. Science (80-. )., 227, 1229-1231.

Horvath, P. and Barrangou, R. (2010) CRISPR/Cas, the Immune System of Bacteria and Archaea. Sci. , 327 , 167170. Available at: http://www.sciencemag.org/content/327/5962/167.abstract.

Hu, Y., Poh, H.M. and Chua, N.-H. (2006) The Arabidopsis ARGOS-LIKE gene regulates cell expansion during organ growth. Plant J., 47, 1-9.

Hu, Y.X., Xie, O., Chua, N.H. and Xie, Q. (2003) The Arabidopsis auxin-inducible gene ARGOS controls lateral organ size. Plant Cell, 15, 1951-1961.

Hwang, W.Y., Fu, Y., Reyon, D., Maeder, M.L., Tsai, S.Q., Sander, J.D., Peterson, R.T., Yeh, J.-R.J. and Joung, J.K. (2013) Efficient genome editing in zebrafish using a CRISPR-Cas system. Nat Biotech, 31, 227-229. Available at: http://dx.doi.org/10.1038/nbt.2501.

Ishiguro, S. (2001) The DEFECTIVE IN ANTHER DEHISCENCE1 Gene Encodes a Novel Phospholipase A1 Catalyzing the Initial Step of Jasmonic Acid Biosynthesis, Which Synchronizes Pollen Maturation, Anther Dehiscence, and Flower Opening in Arabidopsis. PLANT CELL ONLINE, 13, 2191-2209.

Jack, T., Brockman, L.L. and Meyerowitz, E.M. (1992) The homeotic gene APETALA3 of Arabidopsis thaliana encodes a MADS box and is expressed in petals and stamens. Cell, 68, 683-697.

Jaglo-Ottosen, K.R., Gilmour, S.J., Zarka, D.G., Schabenberger, O. and Thomashow, M.F. (1998) Arabidopsis CBF1 overexpression induces COR genes and enhances freezing tolerance. Science (80-. )., 280, 104-106.

Kachanovsky, D.E., Filler, S., Isaacson, T. and Hirschberg, J. (2012) Epistasis in tomato color mutations involves regulation of phytoene synthase 1 expression by cis-carotenoids. Proc. Natl. Acad. Sci. , 109 , 1902119026. Available at: http://www.pnas.org/content/109/46/19021.abstract.

Kater, M.M., Franken, J., Aelst, A. van and Angenent, G.C. (2000) Suppression of cell expansion by ectopic expression of the Arabidopsis SUPERMAN gene in transgenic petunia and tobacco. Plant J., 23, 407-413.

Kazama, T., Ichihashi, Y., Murata, S. and Tsukaya, H. (2010) The Mechanism of Cell Cycle Arrest Front Progression Explained by a KLUH/CYP78A5-dependent Mobile Growth Factor in Developing Leaves of Arabidopsis thaliana. Plant Cell Physiol., 51, 1046-1054.

Keck, E., McSteen, P., Carpenter, R. and Coen, E. (2003) Separation of genetic functions controlling organ identity in flowers. EMBO J., 22, 1058-1066.

Ketting, R.F., Haverkamp, T.H.., Luenen, H.G.A.. van and Plasterk, R.H.. (1999) mut-7 of C. elegans, Required for Transposon Silencing and RNA Interference, Is a Homolog of Werner Syndrome Helicase and RNaseD. Cell, 99, 133-141. Available at: http://www.sciencedirect.com/science/article/pii/S0092867400816451 [Accessed March 7, 2015].

Kim, J.H., Choi, D.S. and Kende, H. (2003) The AtGRF family of putative transcription factors is involved in leaf and cotyledon growth in Arabidopsis. Plant J., 36, 94-104.

Kim, S., Soltis, P.S., Wall, K. and Soltis, D.E. (2006) Phylogeny and domain evolution in the APETALA2-like gene family. Mol. Biol. Evol., 23, 107-120.

Klucher, K.M., Chow, H., Reiser, L. and Fischer, R.L. (1996) The AINTEGUMENTA gene of Arabidopsis required for ovule and female gametophyte development is related to the floral homeotic gene APETALA2. Plant Cell, 8, 137-153.

Koncz, C., Mayerhofer, R., Koncz-Kalman, Z., Nawrath, C., Reiss, B., Redei, G.P. and Schell, J. (1990) Isolation of a 
gene encoding a novel chloroplast protein by T-DNA tagging in Arabidopsis thaliana. EMBO J., 9, 13371346. Available at: http://www.ncbi.nlm.nih.gov/pmc/articles/PMC551817/.

Kondou, Y., Higuchi, M. and Matsui, M. (2010) High-Throughput Characterization of Plant Gene Functions by Using Gain-of-Function Technology. Annu. Rev. Plant Biol., 61, 373-393. Available at: http://dx.doi.org/ 10.1146/annurev-arplant-042809-112143.

Krizek, B. a and Eaddy, M. (2011) AINTEGUMENTA-LIKE6 regulates cellular differentiation in flowers. Plant Mol Biol, 78, 199-209.

Krizek, B.A. (1999) Ectopic expression of AINTEGUMENTA in Arabidopsis plants results in increased growth of floral organs. Dev. Genet., 25, 224-236. Available at: http://dx.doi.org/10.1002/(SICI)15206408 (1999)25:3<224::AID-DVG5>3.3.CO;2-P.

Krizek, B.A. and Anderson, J.T. (2013) Control of flower size. J. Exp. Bot., 64, 1427-1437.

Laitinen, R.A.E., Immanen, J., Auvinen, P., et al. (2005) Analysis of the floral transcriptome uncovers new regulators of organ determination and gene families related to flower organ differentiation in Gerbera hybrida (Asteraceae). Genome Res., 15, 475-486.

Larkin, M.A., Blackshields, G., Brown, N.P., et al. (2007) Clustal W and Clustal X version 2.0. Bioinformatics, 23, 2947-8.

Li, Y., Zheng, L., Corke, F., Smith, C. and Bevan, M.W. (2008) Control of final seed and organ size by the DA1 gene family in Arabidopsis thaliana. Genes Dev, 22, 1331-1336.

Lin, H.X., Yamamoto, T., Sasaki, T. and Yano, M. (2000) Characterization and detection of epistatic interactions of 3 QTLs, Hd1, Hd2, and Hd3, controlling heading date in rice using nearly isogenic lines. Theor. Appl. Genet., 101, 1021-1028. Available at: http://dx.doi.org/10.1007/s001220051576.

Liu, Q., Kasuga, M., Sakuma, Y., Abe, H., Miura, S., Yamaguchi-Shinozaki, K. and Shinozaki, K. (1998) Two transcription factors, DREB1 and DREB2, with an EREBP/AP2 DNA binding domain separate two cellular signal transduction pathways in drought- and low-temperature-responsive gene expression, respectively, in Arabidopsis. Plant Cell, 10, 1391-1406.

Maes, T., Steene, N. Van de, Zethof, J., Karimi, M., D’Hauw, M., Mares, G., Montagu, M. Van and Gerats, T. (2001) Petunia Ap2-like genes and their role in flower and seed development. Plant Cell, 13, 229-244.

Mallona, I., Weiss, J. and Egea-Cortines, M. (2011) pcrEfficiency: a Web tool for PCR amplification efficiency prediction. BMC Bioinformatics, 12, 404.

Manchado-Rojo, M., Delgado-Benarroch, L., Roca, M.J., Weiss, J. and Egea-Cortines, M. (2012) Quantitative levels of Deficiens and Globosa during late petal development show a complex transcriptional network topology of B function. Plant J., 72, 294-307.

Marks, M.D. and Feldmann, K.A. (1989) Trichome Development in Arabidopsis thaliana. I. T-DNA Tagging of the GLABROUS1 Gene. Plant Cell , 1 , 1043-1050. Available at: http://www.plantcell.org/content/1/11 /1043.abstract.

Marraffini, L.A. and Sontheimer, E.J. (2010) CRISPR interference: RNA-directed adaptive immunity in bacteria and archaea. Nat. Rev. Genet., 11, 181-190. Available at: http://www.ncbi.nlm.nih.gov/pmc/ articles/PMC2928866/.

Martin, C., Bhatt, K., Baumann, K., Jin, H., Zachgo, S., Roberts, K., Schwarz-Sommer, Z., Glover, B. and PerezRodrigues, M. (2002) The mechanics of cell fate determination in petals. Philos. Trans. R. Soc. London $B$ 
Biol. Sci., 357, 809-813. Available at: http://rstb.royalsocietypublishing.org/content/357/ 1422/809.abstract.

Mason, H.S., Ball, J.M., Shi, J.J., Jiang, X., Estes, M.K. and Arntzen, C.J. (1996) Expression of Norwalk virus capsid protein in transgenic tobacco and potato and its oral immunogenicity in mice. Proc. Natl. Acad. Sci. , 93 , 5335-5340. Available at: http://www.pnas.org/content/93/11/5335.abstract.

McCallum, C.M., Comai, L., Greene, E.A. and Henikoff, S. (2000) Targeting Induced LocalLesions IN Genomes (TILLING) for Plant Functional Genomics. Plant Physiol. , 123 , 439-442. Available at: http://www.plantphysiol.org/content/123/2/439.short.

Mizukami, Y. and Fischer, R.L. (2000) Plant organ size control: AINTEGUMENTA regulates growth and cell numbers during organogenesis. Proc. Natl. Acad. Sci., 97, 942-947. Available at: http://www.pnas.org/ cgi/doi/10.1073/pnas.97.2.942 [Accessed October 28, 2014].

Murphy, D.L., Uhl, G.R., Holmes, A., Ren-Patterson, R., Hall, F.S., Sora, I., Detera-Wadleigh, S. and Lesch, K.-P. (2003) Experimental gene interaction studies with SERT mutant mice as models for human polygenic and epistatic traits and disorders. Genes, Brain Behav., 2, 350-364. Available at: http://dx.doi.org/ 10.1046/j.1601-1848.2003.00049.x.

Nag, A., King, S. and Jack, T. (2009) miR319a targeting of TCP4 is critical for petal growth and development in Arabidopsis. Proc. Natl. Acad. Sci. U. S. A., 106, 22534-9.

Nagpal, P., Ellis, C.M., Weber, H., et al. (2005) Auxin response factors ARF6 and ARF8 promote jasmonic acid production and flower maturation. Development, 132, 4107-4118.

Napoli, C., Lemieux, C. and Jorgensen, R. (1990) Introduction of a Chimeric Chalcone Synthase Gene into Petunia Results in Reversible Co-Suppression of Homologous Genes in trans. Plant Cell , 2 , $279-289$. Available at: http://www.plantcell.org/content/2/4/279.abstract.

Nath, U., Crawford, B.C.W., Carpenter, R. and Coen, E. (2003) Genetic control of surface curvature. Science (80-. )., 299, 1404-1407.

Neufeld, T.P., la Cruz, A.F.A. de, Johnston, L.A. and Edgar, B.A. (1998) Coordination of Growth and Cell Division in the Drosophila Wing. Cell, 93, 1183-1193.

Noda, K., Glover, B.J., Linstead, P. and Martin, C. (1994) Flower colour intensity depends on specialized cell shape controlled by a Myb-related transcription factor. Nature, 369, 661-664. Available at: http://dx.doi.org/10.1038/369661a0.

Palatnik, J.F., Allen, E., Wu, X., Schommer, C., Schwab, R., Carrington, J.C. and Weigel, D. (2003) Control of leaf morphogenesis by microRNAs. Nature, 425, 257-263. Available at: http://dx.doi.org/ 10.1038/nature01958.

Papaleo, F., Burdick, M.C., Callicott, J.H. and Weinberger, D.R. (2014) Epistatic interaction between COMT and DTNBP1 modulates prefrontal function in mice and in humans. Mol Psychiatry, 19, 311-316. Available at: http://dx.doi.org/10.1038/mp.2013.133.

Perrière, G. and Gouy, M. (1996) WWW-Query: An on-line retrieval system for biological sequence banks. Biochimie, 78, 364-369.

Pfaffl, M.W., Horgan, G.W. and Dempfle, L. (2002) Relative expression software tool (REST(C)) for group-wise comparison and statistical analysis of relative expression results in real-time PCR. Nucl. Acids Res., 30, e36-. 
Pichersky, E., Raguso, R.A., Lewinsohn, E., Croteau, R. and Eran Pichersky, Robert A. Raguso, E.L. and R.C. (1994) Floral Scent Production in Clarkia (Onagraceae) .1. Localization and Developmental Modulation of Monoterpene Emission and Linalool Synthase Activity. Plant Physiol., 106, 1533-1540.

Prasad, K., Grigg, S.P., Barkoulas, M., et al. (2011) Arabidopsis PLETHORA Transcription Factors Control Phyllotaxis. Curr. Biol., 21, 1123-1128.

Reale, L., Porceddu, A., Lanfaloni, L., Moretti, C., Zenoni, S., Pezzotti, M., Romano, B. and Ferranti, F. (2002) Patterns of cell division and expansion in developing petals of Petunia hybrida. Sex. Plant Reprod., 15, 123-132.

Reeves, P.H., Ellis, C.M., Ploense, S.E., et al. (2012) A regulatory network for coordinated flower maturation. M. F. Yanofsky, ed. PLoS Genet., 8, e1002506.

Rieu, I., Bots, M., Mariani, C. and Weterings, K.A.P. (2005) Isolation and expression analysis of a tobacco AINTEGUMENTA ortholog (NtANTL). Plant Cell Physiol., 46, 803-805.

Rijpkema, A., Gerats, T. and Vandenbussche, M. (2006) Genetics of Floral Development in Petunia. In B. T.-A. in B. Research, ed. Developmental Genetics of the Flower. Academic Press, pp. 237-278. Available at: http://www.sciencedirect.com/science/article/pii/S0065229606440064.

Rijpkema, A.S., Gerats, T. and Vandenbussche, M. (2007) Evolutionary complexity of MADS complexes. Curr. Opin. Plant Biol., 10, 32-38.

Rodriguez, R.E., Mecchia, M.A., Debernardi, J.M., Schommer, C., Weigel, D. and Palatnik, J.F. (2010) Control of cell proliferation in Arabidopsis thaliana by microRNA miR396. Development, 137, 103-12.

Rorth, P., Szabo, K., Bailey, A., et al. (1998) Systematic gain-of-function genetics in Drosophila. Development, 125, 1049-1057. Available at: http://dev.biologists.org/content/125/6/1049.abstract.

Rubio-Somoza, I. and Weigel, D. (2013) Coordination of Flower Maturation by a Regulatory Circuit of Three MicroRNAs L.-J. Qu, ed. PLoS Genet., 9, e1003374.

Sanders, P.M. (2000) The Arabidopsis DELAYED DEHISCENCE1 Gene Encodes an Enzyme in the Jasmonic Acid Synthesis Pathway. PLANT CELL ONLINE, 12, 1041-1062.

Schell, J., Montagu, M. Van, Beuckeleer, M. De, et al. (1979) Interactions and DNA transfer between Agrobacterium tumefaciens, the Ti-plasmid and the plant host. Proc. R. Soc. London B Biol. Sci., 204, 251266.

Schwarz-Sommer, Z., Davies, B. and Hudson, A. (2003) An everlasting pioneer: the story of Antirrhinum research. Nat Rev Genet, 4, 655-664. Available at: http://dx.doi.org/10.1038/nrg1127.

Shigyo, M., Hasebe, M. and Ito, M. (2006) Molecular evolution of the AP2 subfamily. Gene, 366, $256-265$.

Shigyo, M. and Ito, M. (2004) Analysis of gymnosperm two-AP2-domain-containing genes. Dev. Genes Evol., 214, 105-114.

Slade, A.J., Fuerstenberg, S.I., Loeffler, D., Steine, M.N. and Facciotti, D. (2005) A reverse genetic, nontransgenic approach to wheat crop improvement by TILLING. Nat. Biotechnol., 23, 75-81.

Sommer, H., Beltrán, J.P., Huijser, P., Pape, H., Lönnig, W.E., Saedler, H. and Schwarz-Sommer, Z. (1990) Deficiens, a homeotic gene involved in the control of flower morphogenesis in Antirrhinum majus: the protein shows homology to transcription factors. EMBO J., 9, 605-613. Available at: http://www.ncbi.nlm.nih.gov/pmc/articles/PMC551713/. 
Sommer, H., Nacken, W., Beltran, P., Huijser, P., Pape, H., Hansen, R., Flor, P., Saedler, H. and Schwarz-Sommer, Z. (1991) Properties of deficiens, a homeotic gene involved in the control of flower morphogenesis in Antirrhinum majus. Dev. , 113 , 169-175. Available at: http://dev.biologists.org/content/113/ Supplement_1/169.abstract.

Stubbe, H. (1966) Genetik und Zytologie von Antirrhinum L. sect. Antirrhinum Veb Gustav.,.

Stuurman, J., Hoballah, M.E., Broger, L., Moore, J., Basten, C. and Kuhlemeier, C. (2004) Dissection of floral pollination syndromes in petunia. Genetics, 168, 1585-1599.

Sugimoto-Shirasu, K. and Roberts, K. (2003) "Big it up": endoreduplication and cell-size control in plants. Curr. Opin. Plant Biol., 6, 544-553.

Sugimoto-Shirasu, K., Stacey, N.J., Corsar, J., Roberts, K. and McCann, M.C. (2002) DNA topoisomerase VI is essential for endoreduplication in Arabidopsis. Curr. Biol., 12, 1782-6.

Szecsi, J., Joly, C., Bordji, K., Varaud, E., Cock, J.M., Dumas, C., Bendahmane, M. and Szécsi, J. (2006) BIGPETALp, a $b H L H$ transcription factor is involved in the control of Arabidopsis petal size. EMBO J., 25, 3912-3920.

Tabara, H., Sarkissian, M., Kelly, W.G., Fleenor, J., Grishok, A., Timmons, L., Fire, A. and Mello, C.C. (1999) The rde-1 Gene, RNA Interference, and Transposon Silencing in C. elegans. Cell, 99, 123-132. Available at: http://www.sciencedirect.com/science/article/pii/S009286740081644X [Accessed March 7, 2015].

Till, B., Colbert, T., Tompa, R., et al. (2003) High-Throughput TILLING for Functional Genomics. In E. Grotewold, ed. Plant Functional Genomics SE - 13. Methods in Molecular Biology ${ }^{\mathrm{TM}}$. Humana Press, pp. 205-220. Available at: http://dx.doi.org/10.1385/1-59259-413-1\%3A205.

Till, B.J., Reynolds, S.H., Greene, E.A., et al. (2003) Large-scale discovery of induced point mutations with highthroughput TILLING. Genome Res., 13, 524-530.

Trobner, W., Ramirez, L., Motte, P., Hue, I., Huijser, P., Lonnig, W.E., Saedler, H., Sommer, H. and SchwarzSommer, Z. (1992) GLOBOSA: a homeotic gene which interacts with DEFICIENS in the control of Antirrhinum floral organogenesis. EMBO J., 11, 4693-4704.

Tröbner, W., Ramirez, L., Motte, P., Hue, I., Huijser, P., Lönnig, W.E., Saedler, H., Sommer, H. and SchwarzSommer, Z. (1992) GLOBOSA: a homeotic gene which interacts with DEFICIENS in the control of Antirrhinum floral organogenesis. EMBO J., 11, 4693-4704. Available at: http://www.ncbi.nlm.nih.gov/pmc/articles/PMC556944/.

Truernit, E. and Haseloff, J. (2008) Arabidopsis thaliana outer ovule integument morphogenesis: ectopic expression of KNAT1 reveals a compensation mechanism. BMC Plant Biol, 8, 35.

Vandenbussche, M., Zethof, J., Royaert, S., Weterings, K. and Gerats, T. (2004) The Duplicated B-Class Heterodimer Model : Whorl-Specific Effects and Complex Genetic Interactions in Petunia hybrida Flower Development. , 16, 741-754.

Vavouri, T., Semple, J.I. and Lehner, B. (2008) Widespread conservation of genetic redundancy during a billion years of eukaryotic evolution. Trends Genet., 24, 485-488.

Venail, J., Dell'Olivo, A. and Kuhlemeier, C. (2010) Speciation genes in the genus Petunia. Philos. Trans. R. Soc. B-Biological Sci., 365, 461-468.

Waterhouse, P.M., Wang, M.-B. and Lough, T. (2001) Gene silencing as an adaptive defence against viruses. Nature, 411, 834-842. Available at: http://dx.doi.org/10.1038/35081168.

Wefers, B., Meyer, M., Ortiz, O., Hrabé de Angelis, M., Hansen, J., Wurst, W. and Kühn, R. (2013) Direct 
production of mouse disease models by embryo microinjection of TALENs and oligodeoxynucleotides. Proc. Natl. Acad. Sci. , 110 , 3782-3787. Available at: http://www.pnas.org/content/ 110/10/3782.abstract.

Weiss, J., Burgos, L. and Egea Gutierrez-Cortines, M. (2005) Biotechnology applications in crops. In R. Dris, ed. Crops: Growth, quality and biotechnology. Helsinki: WFL Publisher, pp. 1068-1086.

Weiss, J., Cano-Vicente, E. and Egea-Cortines, M. (2006) From the wild to the market: evolution of floral size and architecture in ornamentals. In T. da S. JA, ed. Floriculture, Ornamental and Plant Biotechnology: Advances and Topical Issues. London: Global Science Books.

Weiss, J., Delgado-Benarroch, L. and Egea-cortines, M. (2005) Genetic control of floral size and proportions. Int. J. Dev. Biol., 49, 513-525.

Weiss, J. and Egea-Cortines, M. (2009) Transcriptomic analysis of cold response in tomato fruits identifies dehydrin as marker to study cold acclimation. J. Appl. Genet., 50, 311-319.

Weiss, J., Mallona, I., Gomez-di-Marco, P., Fernández-Valera, J.M. and Egea-Cortines, M. (2012) Genotyping Antirrhinum commercial varieties using miniature inverted-repeat transposable elements (MITEs). Sci. Hortic. (Amsterdam)., 144, 161-167.

White, D.W.R. (2006) PEAPOD regulates lamina size and curvature in Arabidopsis. Proc. Natl. Acad. Sci. U. S. A., 103, 13238-43.

Wright, G.A., Lutmerding, A., Dudareva, N. and Smith, B.H. (2005) Intensity and the ratios of compounds in the scent of snapdragon flowers affect scent discrimination by honeybees (Apis mellifera). J. Comp. Physiol. a-Neuroethology Sens. Neural Behav. Physiol., 191, 105-114.

Wu, M.-F., Tian, Q. and Reed, J.W. (2006) Arabidopsis microRNA167 controls patterns of ARF6 and ARF8 expression, and regulates both female and male reproduction. Development, 133, 4211-8.

Wurschum, T., Gross-Hardt, R. and Laux, T. (2006) APETALA2 regulates the stem cell niche in the Arabidopsis shoot meristem. Plant Cell, 18, 295-307.

Xiong, Y., Jung, J., Zeng, Q., Gallo, M. and Altpeter, F. (2013) Comparison of procedures for DNA coating of micro-carriers in the transient and stable biolistic transformation of sugarcane. Plant Cell, Tissue Organ Cult., 112, 95-99. Available at: http://dx.doi.org/10.1007/s11240-012-0208-8.

Yanofsky, M.F., Ma, H., Bowman, J.L., Drews, G.N., Feldmann, K.A. and Meyerowitz, E.M. (1990) The protein encoded by the Arabidopsis homeotic gene agamous resembles transcription factors. Nature, 346, 35-39.

Zenoni, S., Fasoli, M., Tornielli, G.B., et al. (2011) Overexpression of PhEXPA1 increases cell size, modifies cell wall polymer composition and affects the timing of axillary meristem development in Petunia hybrida. New Phytol, 191, 662-677.

Zenoni, S., Reale, L., Tornielli, G.B., et al. (2004) Downregulation of the Petunia hybrida alpha-expansin gene PhEXP1 reduces the amount of crystalline cellulose in cell walls and leads to phenotypic changes in petal limbs. Plant Cell, 16, 295-308. 


\section{Supporting Information}
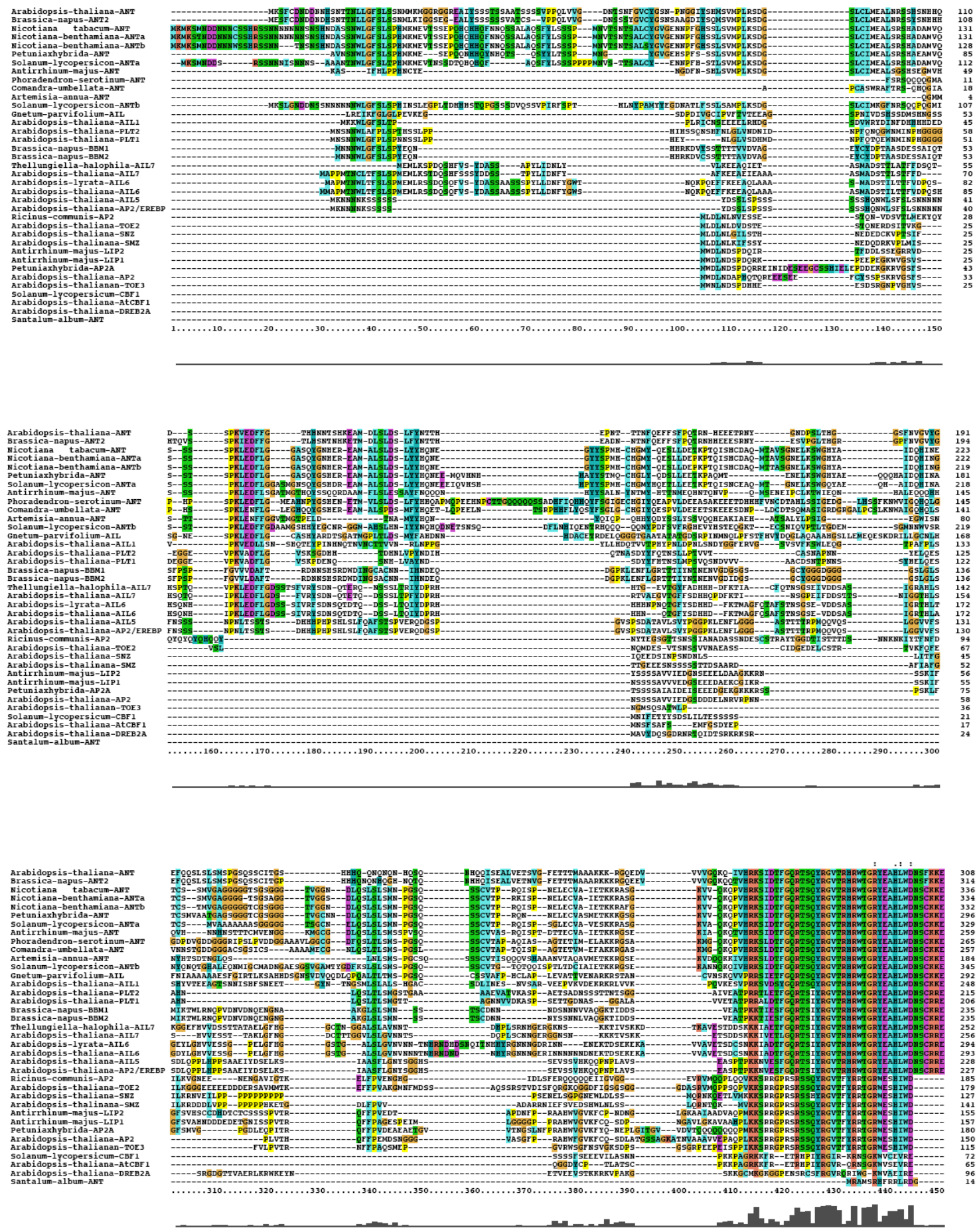

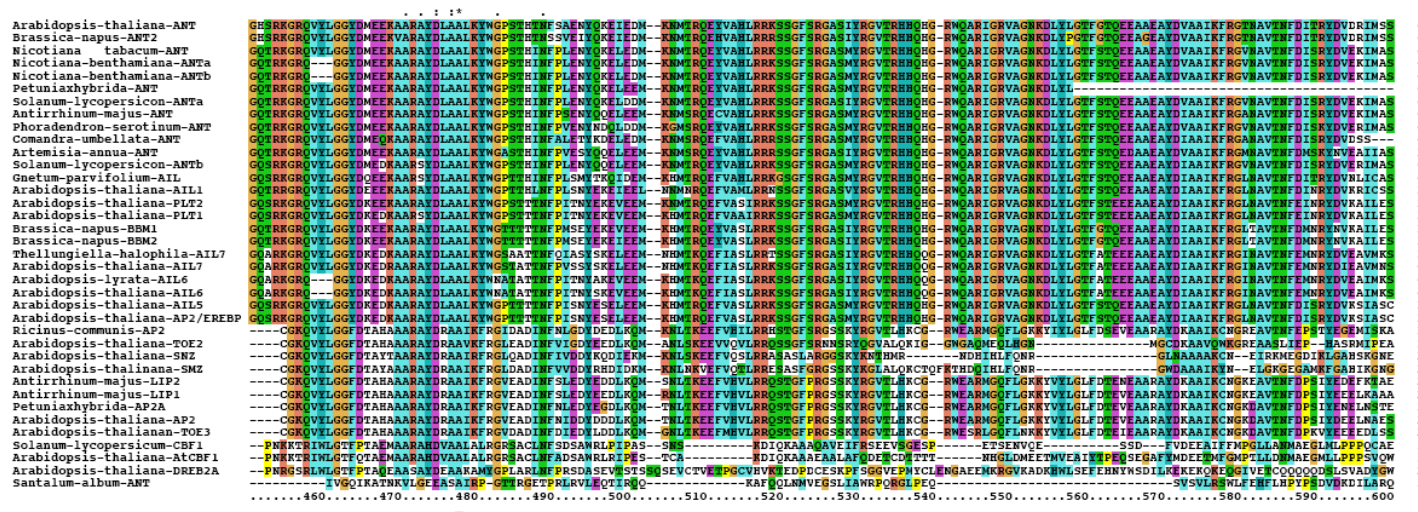

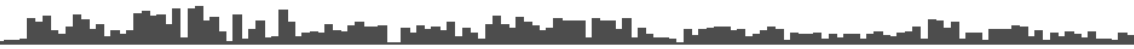
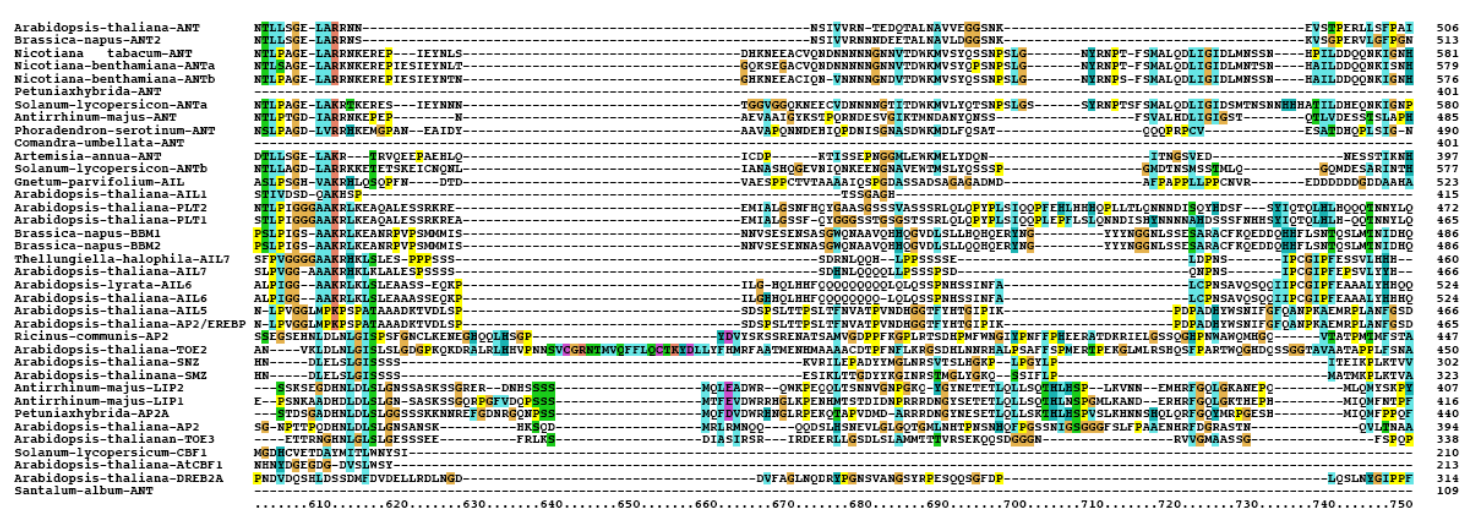

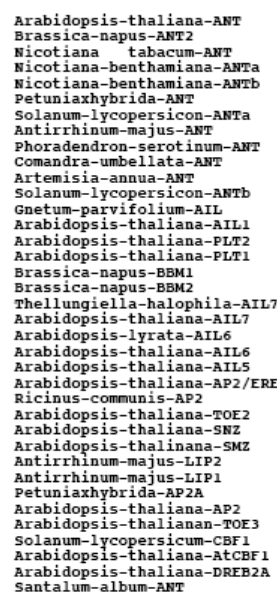

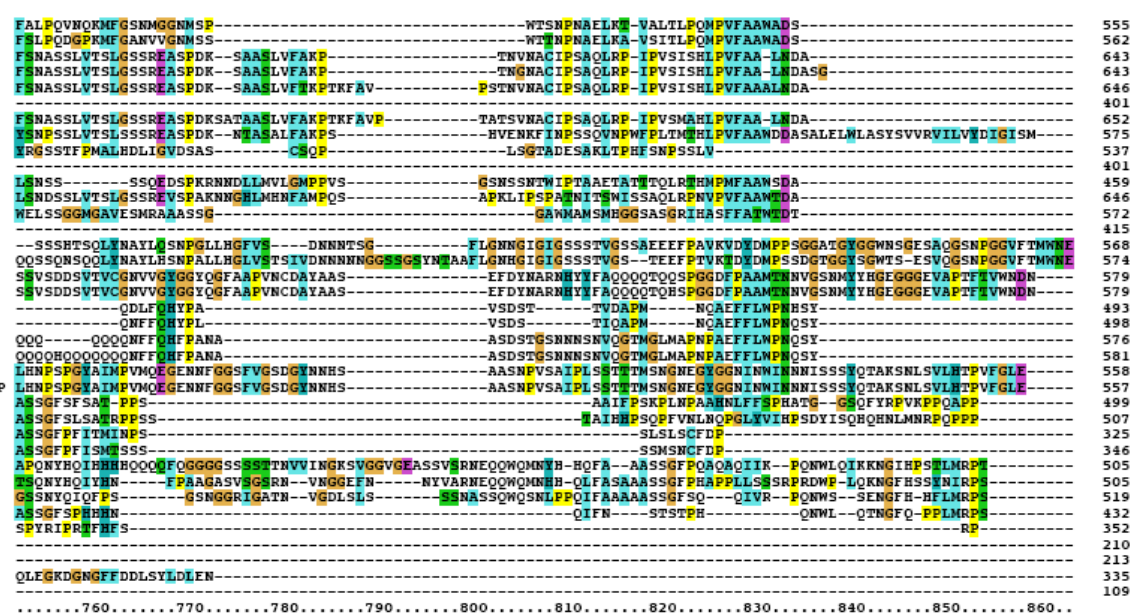

Figure S1: Multiple alignments of $A P 2$ and $A N T$ predicted protein 


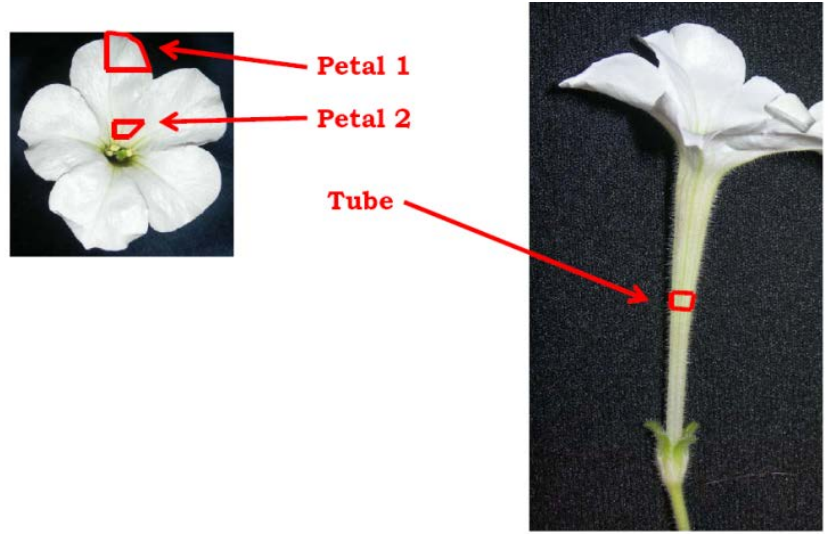

Figure S2: Petunia petal regions used to analyse effects of $A N T$ expression on cell division and expansion.

Table S1: Accession numbers of genes used for phylogenetic analysis

Petunia $x$ hybridaANTAHC98702.1; At4g37750 AtANT;A.majusANT KF975389;Nicotiana tabacum AY461432.1-NICOTIANA-ANTLIKE; FJ542318.1-PHORADENDROM-SEROTINUM-ANTLIKE; FJ542317.1-Comandra-umbellata-ANTLIKE; GQ468547.1-Artemisia-annua-ANT; DQ211970.1-Brassica-napus-ANT2; XM_002530201.1-Ricinus-communis; AB297493.1 Gnetum-parvifolium; XM_002871378.1-ArabidopsisIyrata-ANTLIKE6; NM_125949.6-Arabidopsis-thaliana-AIL7; NM_001125733.1- Arabidopsis-thaliana-AIL6; NM_103997.3 Arabidopsisthaliana-PLT2; NM_112975.2-Arabidopsis-thaliana-PLT1; GI:28894444-AmLIPLESS2; GI:28894442-AmLIPLESS1; GI:5081554-PhAP2A; At5g67180-TOE3; At4g36920g-APETALA2; At2g39250-SNZ; At1g72570-AIL1; At5g57390-AP2/EREBP; AF317904-Brassicanapus BABY BOOM1; AF317905-Brassica napusBABY BOOM2; At1g79700-AP2 like; At5g05410-DREB2A; AT4G25490-AtCBF1; NP_001234123-Solanum licopersiconCBF1;Solyc02g092050.2.1Solanumlycopersicon AINTEGUMENTA-a; Solyc04g077490.2.1Solanumlycopersicon AINTEGUMENTAb; NbS00010330g0101.1Nicotianabenthamiana AINTEGUMENTA-a; NbS00030515g0004.1Nicotianabenthamiana AINTEGUMENTA-b

Table S2: List of primers used for PCR

\begin{tabular}{|c|c|}
\hline PRIMER & SEQUENCE \\
\hline PhANTfor & 5'-ATGAAGTCTATGAATGATGATAAC-3' \\
\hline PhANTrev & $\begin{array}{l}5^{\prime} \text {-TCATGCATCATTCAAAGCTGC-3' } \\
\end{array}$ \\
\hline PaxilarysANTfor & 5'-TAATGATTTGCAATCTTTGAGC-3' \\
\hline PaxilarysANTrev & 5'-CAACATCATATGCTTCAGC-3' \\
\hline PhSAND13 for & 5'-CTTACGACGAGTTCAGATGCC-3' \\
\hline PhSAND13 rev & 5'-TAAGTCCTCAACACGCATGC-3' \\
\hline AmANTfor & 5'-TTGCTGCAATCAAGTTCAGG-3' \\
\hline AmANTrev & 5'-CAATGCCAATCAAATCATGC -3' \\
\hline AmUBIQfor & 5'-GCCGATGGAAGTATATGTTTGGACATC-3' \\
\hline AmUBIQrev & 5'-CTAACTTTGCGGTTATAATCTCGTTTA-3' \\
\hline AtANTfor & 5'-TCTAGTAACACACTCTTGTCTGG-3' \\
\hline AtANTrev & 5'-ATCAGCCCAAGCAGCGAAAAC-3' \\
\hline attb1 & 5'-GGGGACAAGTTTGTACAAAAAAGCAGGCT-3' \\
\hline attb2 & 5'-GGGGACCACTTTGTACAAGAAAGCTGGGTA-3' \\
\hline Attb1PhANTfor & 5'-CAAAAAAGCAGGCTATGAAGTCTATGAAT-3' \\
\hline Attb2PhANTrev & 5'-CAAGAAAGCTGGGTATCATGCATCATTCAA-3' \\
\hline
\end{tabular}


Table S3: Takeoff values of different genes in RT-qPCR experiments

\begin{tabular}{|c|l|l|}
\hline \multicolumn{3}{|c|}{ 35S::ANT PETUNIA } \\
\hline \multirow{2}{*}{ RPS13 } & Tube & $18.95 \pm 1.9$ \\
\cline { 2 - 3 } & Limb & $21.75 \pm 1.2$ \\
\hline \multirow{2}{*}{ PhANT } & Tube & $25.85 \pm 1.5$ \\
\cline { 2 - 3 } & Limb & $22.5 \pm 0.8$ \\
\hline \multirow{3}{*}{ UBIQ 35 :: ANT ANTIRRHINUM } \\
\hline \multirow{2}{*}{ AmANT } & Tube & $22.11 \pm 1.7$ \\
\cline { 2 - 3 } & Limb & $22.78 \pm 0.4$ \\
\hline & Tube & $22.24 \pm 1.3$ \\
\cline { 2 - 3 } & Limb & $22.78 \pm 2.6$ \\
\hline
\end{tabular}


General Conclusions 



\section{General Conclusions}

\section{Chapter 1:}

- Melting point analysis of the 23S rDNA amplicon obtained by RT-qPCR is a useful tool for genotyping Agrobacterium tumefaciens and Escherichia coli.

- The protocol allows to test clones that fail to transform plants as a result of contaminated bacterial stocks.

- The codominant PCR markers amplify from both bacteria in mixed cultures, generating amplicons whose melting curves can be easily differentiated.

- This method should be more useful than Agrobacterium or E. coli -specific PCR markers.

\section{Chapter 2:}

- The gene compacta (co) plays a role for proper homeotic gene function of the B class downstream of $D E F$, affecting activation and maintainance of $D E F$ expression. This was demonstrated by the fact that def $f^{\text {nic }}$ single mutants and co def fic double mutants have similar levels of $D E F$ and $G L O$, but the phenotypes analyzed are more extreme in the double mutant.

- There is a quantitative component in gene function of the homeotic genes DEF and GLO. Recognizable petal development is achieved with $11 \%$ transcription level in the B-loss of function alleles compacta and deficiens. However, these levels do not sustain full organ size with properly developed conical cells and scent production.

- The necessary thresholds of B function are not uniform over all petal regions as indicated by the fact that flowers of def nic , a weak allele of $\mathrm{B}$ function gene $D E F$, and co def $f^{\text {nic }}$ double mutants, only lack the palate of the flower while other petal structures are formed.

- The positive autoregulatory loop is only part of the B function maintenance and a basal level of transcriptional activation is present for both $D E F$ and $G L O$, at least at late stages of development. Positive autoregulation comprises organ specific components and may differ between $D E F$ and GLO. Since linear levels of translation rates are maintained during petal development for DEF and GLO, the changes in mRNA should translate into differing levels of protein. 


\section{Chapter 3:}

- Changes in AINTEGUMENTA gene expression in Petunia and Antirrhinum do not cause similar macroscopic phenotypic changes and the exact outcome might be constrained by the genomic environment where the gene is expressed, as the phenotypic spaces obtained resemble those seen in the genus.

- Changes in the expression levels of PhANT cause a complex cellular phenotype. As changes in cell size were larger than those observed in tube size we conclude that a compensation mechanism could take place in the Petunia tube in order to maintain a certain organ size.

- AtANT overexpression caused significant AmANT up-regulation in Antirrhinum limbs but not of PhANT in Petunia, indicating differences in the regulatory network of ANT between these two species.

- Differences in positive autoregulation were also found between petal limb and tube in Antirrhinum, indicating that the ANT regulatory network might differ between organ regions. Our data show that petal limb and tube might be considered separate organs in terms of genetic modification when it comes to size.

- Altogether our data validates ANT as candidate gene to modify floral size in ornamental species. 
Annex I: Congresses 



\section{Annex I: Congresses}

- Manchado-Rojo, M., Weiss, J. and Egea-Cortines, M. (2014). Validation of Aintegumenta as a gene to modify floral size in ornamental plants. XII Reunión Biología Molecular de Plantas. XII Reunión Biología Molecular de Plantas (Cartagena - Murcia, Spain)

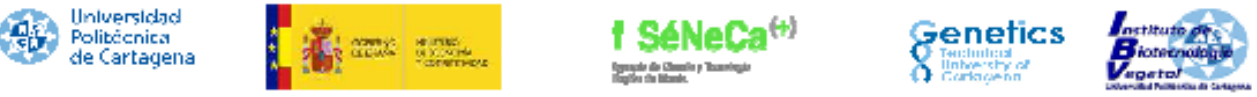

\section{Validation of Aintegumenta as a gene to modify floral size in ornamental plants}

\section{Genética Molecular, Instituto de Biotecnologis Vegetal, Universidad Politécnica de Cartagens, 30202, Cartsgens, Spsin.}

Introduction

Maria Manchado-Rojo; Julia Weiss and Marcos Egea-Cortines

-The gene AINTEGUMENTA (AtANT) is an APETALA2 transcription factor in Arabidopsis activating growth downstream of auxin a ignalling. Lateral organ size is positively correlated with ANT expression in Arabidopsis. We tested the use of AtANT as a tool to modify floral size in two different plants used as mode organisms and ornamental crops, Petunia $x$ hybrido and Antimhinum mojus.

-Changes in floral size can be geneticaly dissected into two separate regions, the tube and the limb, that seem to play distinct roles in pollination

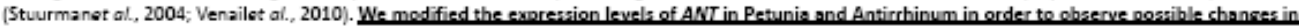
flersl size with soecisl emohosize on differences between netal and limb.

\section{Methodology}

Identification of Petunia ANT (PhANT) based on highly homologous tomato sequence

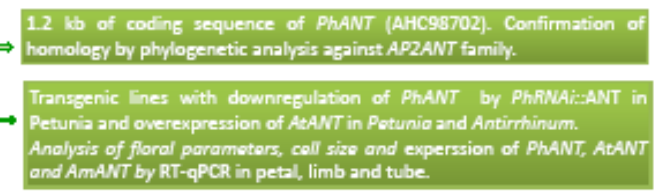

PhRNAi.ANT construction by GATEWAY technology in pHELLSGATEI2 Helliwe and Waterhouse, 20033. Overexpression with construct PCGN1547 35S:ANT (Krizek, 1999) from Arabidopsis.

\section{$\underline{\text { Results }}$ \\ Petunia
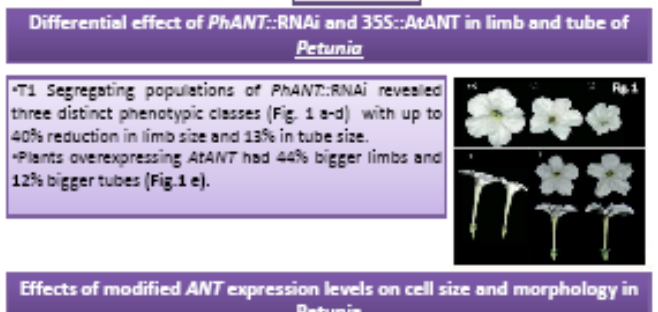
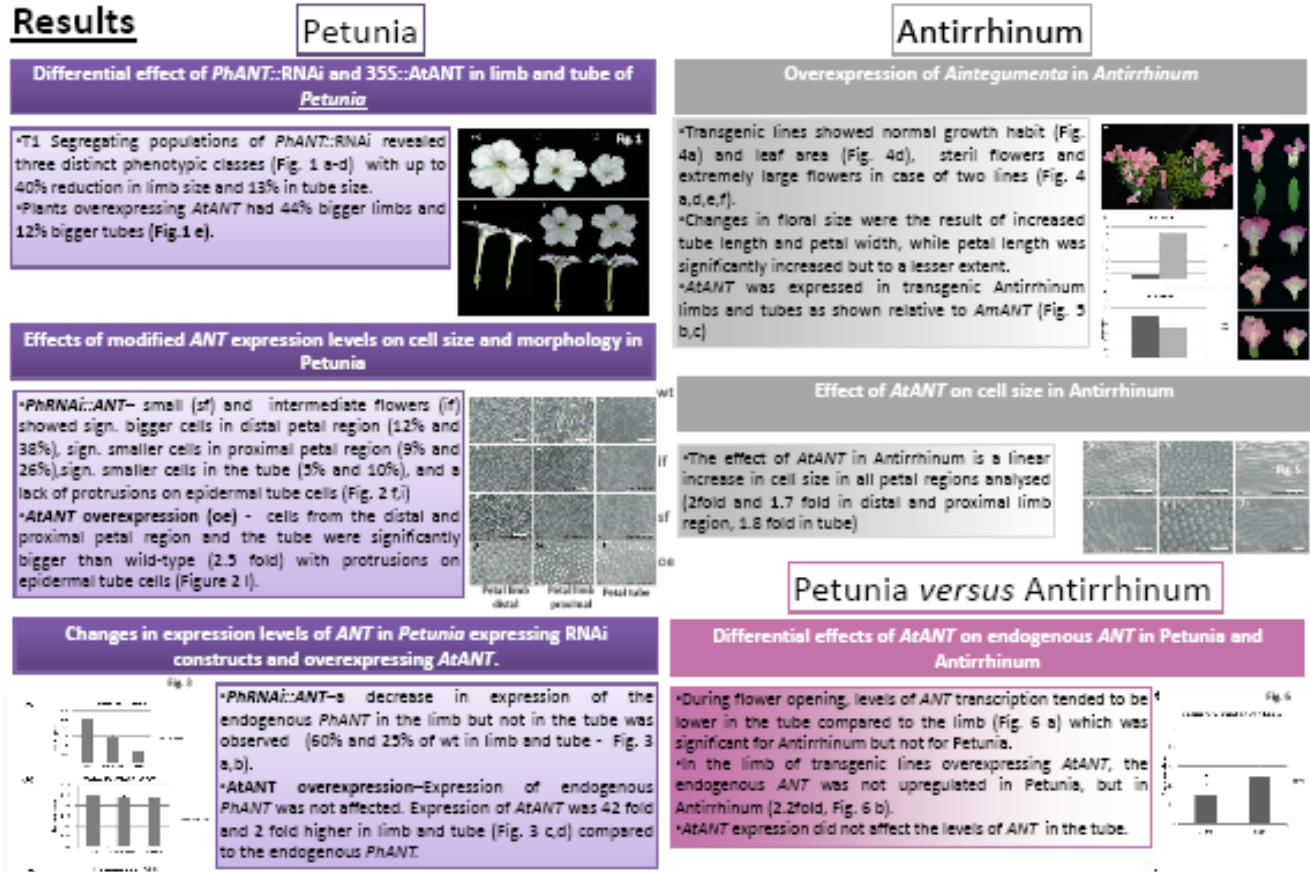

Petunia versus Antirrhinum

\section{Differential effects of AtANT on endogenous ANT in Peturia and}

- During flower opening leve: of ANT transeription tended to be 4

lower in the tube compored to the limb (Fig. 6 s) which wa:

grif cant for Antirminum but not for Fetun i.

an the limo of trantgenic lines overexpressing AtaNT, the

Andogerous avt was not

-AtANT expression did not affect the ieves of $A N T$ in the tuos.
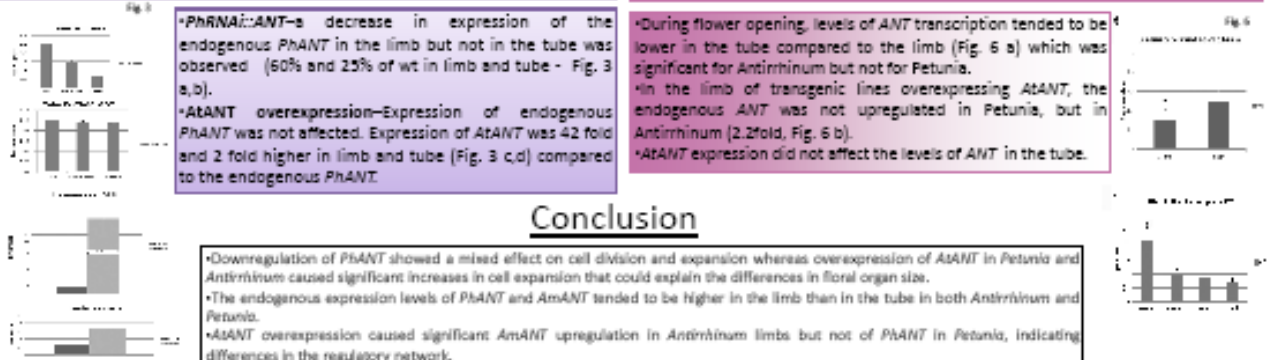

\section{Conclusion}

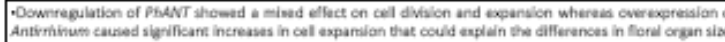

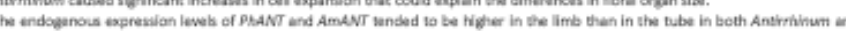

Peturio.

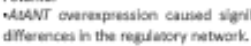

Beferencese

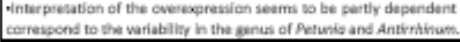

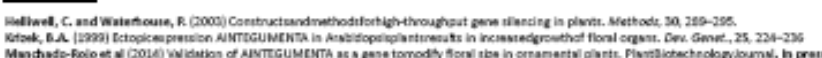

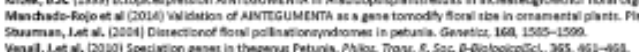

- Manchado-Rojo, M.,Egea-Cortines, M. and Weiss, J. (2011).Functional analysis of pollination syndromes in Petunia and Antirrhinum. XI World Petunia Days (Lyon, Francia). 
Petunia and Antirrhinum have opposite forms of evolution at least in one of the major traits involved in pollination syndromes. In Antirrhinum, single mutants affect floral size and in some cases organ regions (Delgado-Benarroch et al., 2009b; Delgado-Benarroch et al., 2009a). However, studies in natural populations show that evolution in the genus has occurred by changes in pleiotropic genes that affect both vegetative and reproductive development (Feng et al., 2009). In contrast, in the Petunia genus, petal tube and limb have evolved as separate traits (Galliot et al., 2006; Stehmann et al., 2009; Venail et al., 2010). Overexpression of Aintegumenta in Arabidopsis and tobacco causes overall increase of vegetative and reproductive organs, (Mizukami and Fischer, 2000). We have studied the effect of the Aintegumenta gene in transgenic plants of Antirrhinum and Petunia to identify if the opposite evolutionary history is the result of changes in gene function or genomic contest. Petunia $x$ hibrida Mitchell plants expressing RNAi-ANT have smaller flower in a dosage dependent manner. Petal tube was roughly $86 \%$ of WT whereas limb expansion was decreased by nearly $40 \%$. Thus loss of function of ANT resembles changes seen in other species of the genus. Antirrhinum plants overexpressing AtANT showed faster regeneration than those expressing RNAi DEF. Preliminary results indicate that floral size is globally increased. A comparison between Petunia and Antirrhinum flowers will be presented in the congress.

Delgado-Benarroch, L., Weiss, J., and Egea-Cortines, M. (2009a). The mutants compacta ahnlich, Nitida and Grandiflora define developmental compartments and a compensation mechanism in floral development in Antirrhinum majus. J Plant Res 122, 559-569.

Delgado-Benarroch, L., Causier, B., Weiss, J., and Egea-Cortines, M. (2009b). FORMOSA controls cell division and expansion during floral development in Antirrhinum majus. Planta 229, 1219-1229.

Feng, X., Wilson, Y., Bowers, J., Kennaway, R., Bangham, A., Hannah, A., Coen, E., and Hudson, A. (2009). Evolution of Allometry in Antirrhinum. Plant Cell 21, 2999-3007.

Galliot, C., Stuurman, J., and Kuhlemeier, C. (2006). The genetic dissection of floral pollination syndromes. Curr Op Plant Biol 9, 78-82.

Mizukami, Y., and Fischer, R.L. (2000). Plant organ size control: AINTEGUMENTA regulates growth and cell numbers during organogenesis. Proc.Natl.Acad.Sci.U.S.A 97, 942-947.

Stehmann, J.R., Lorenz-Lemke, A.P., Freitas, L.B., and Semir, J. (2009). The Genus Petunia. In Petunia. Evolutionary, developmental and physiological genetics, T. Gerats and J. Strommer, eds (New York: Springer.

Venail, J., Dell'Olivo, A., and Kuhlemeier, C. (2010). Speciation genes in the genus Petunia. Philosophical Transactions of the Royal Society B-Biological Sciences 365, 461-468.

- Manchado-Rojo, M., Portero-Martinez, A., Weiss, J. and Egea-Cortines, M. (2010). An improved protocol for transformation of Antirrhinum majus. XVII Congress of the Federation of European Societies of Plant Biology (Valencia, Spain).

Genetic transformation is a cornerstone to obtain information of gene functions. We have developed an improved protocol for transformation and regeneration of Antirrhinum majus, obtaining a highly reproducible method that has yielded up to a high efficiency, close to $10 \%$ (the final results will be discussed in the congress). Several aspects affect transformation efficiency. We tested two lines, 165E and Vilmorin Nain and two different explants, leaf discs and hypocotyls from seedling of two and four weeks. As a proof of concept we transformed A. majus with a pHellsgate12 construct expressing RNAi of the homeotic gene Deficiens. Two week old hypocotyls explant from the line Vilmorin Nain had the highest transformed rate. Putative transformants were tested by PCR using NPTII primers and by their phenotypes. The resulting plants showed classic phenotypes corresponding to hypomorphic alleles of Def, 
which included sepaloid petals and sterile stamens and fell somewhere in strength between deficiens ${ }^{\text {chlorantha }}$ and deficiens $s^{\text {nicotianoides. }}$.

\section{An improved protocal for tramsiormation of $A$. majus}

Manchado-Rojo, M. ${ }^{1}$, Portero-Martinez, A. ${ }^{1}$, Weiss, J. ${ }^{1}$ and Egea-Cortines, M. ${ }^{1}$

1: Universidad Politécnica de Cartagena, Genetics. Instituto de Biotecnología Vegetal. 30203 Cartagena (Murcia)

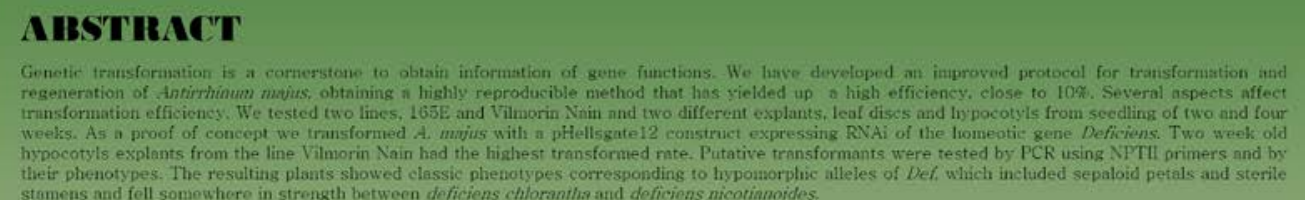

\section{MATERIALS ANI METHOIDS}

PLANT MATERIAL.

We used two lines of Antirnhimum majus, 165E and Nain from Vilmorin.

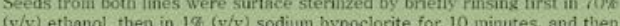
wasthing with sterile dissiled water five times. The seeds were germinated on Murashitige and Skoog medium contrining sucrose $(25$ g/) and gellite $(2.5 \mathrm{z} / 1)$. We tested two-week old and four-week old hypocotyl explants.

AGROBACTERIUM-MEDLATED TRANSFORMATION

Agrobacterium tumefaciens strain EHA105 was used for transformation. We tested silencing of the Deficiens gene using the pHellssote 12 plasmid (Helliwell and Waterhouse, 2003) harbouring 207 bp encompassing the last 60 codons and 27 bp of the 3 TTR of Def, forming a hairpin (Figure 1 . The DCGN1547 (Krizels 1999). We used standard transformation procedures and modified media (Table 1 )

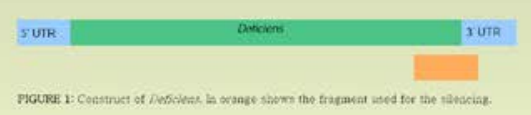

TARUS 1 Comporitise of aedion

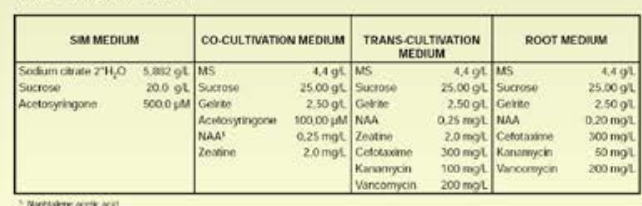

\section{REFERENCES}

Helliwell, C. and Waterhouse, P. (2003). Constructs and methods for high-throughput gene silencing in plants. Nethods 30, 289-295, Krizek, BA. (1999). Ectopic expression of ANTEGUMIENTA in Arabidopsis plants results in increased growth of floral organs. Dev, Genetics 25.
$224-236$.

- Manchado-Rojo, M, Weiss, J. y Egea-Cortines, M. (2009). Development of reverse genetics tools to study shoot gravitropism in Petunia hybrida. X World Petunia Days (CartagenaMurcia, Spain)

Traditionally, cut flowers are transported in the horizontal way. This represent a problem for several species, between them we could stand Antirrhinum majus out, (Halevy and Mayak 1981; Tasakaet al. 1999 y 2001), since their stems have a strong negative gravitropism which 
make the inflorescence stems curve upwards and this imply its commercial depreciation and troubles for marketing.

In Arabidopsis thaliana there are described seven genes related with the negative shoot gravitropism, they are the so call Shoot Gravitropism genes. This genes has been described by Fukaki (1996) (SGR1, SGR2, SGR3), Yamauchi (1997) (SGR4, SGR5, SGR6) and Fukaki (1998) (SGR7). We have identified the ortholog gene to SGR4 in A. majus and the ortholog gene to $S G R 5$ in $P$. hybrida. So far, we are not able to identify more genes involved in shoot gravitropism due to the ESTs sequenced in this species are relatively not many.

A gene library is very important tool in inverse genetic. The cDNA libray is a representation of the genes from the genome of an individual, although they are not always in the same relation. There are genes which are 2000 times more expressed than other genes (Marra et al., 1998). We have carried out a methodology with the aim to obtain a normalized CDNA libray. The analysis of gene expression quantification, to verify the normalization of the CDNA library, have been done by RT-qPCR and after that, the data were analyzed by REST program.

Fukaki, H., Fujisawa, H. and Tasaka, M. (1996) SGR1, SGR2 and SGR3: Novel genetic loci involved in shoot gravitropism in Arabidopsis thaliana. Plant Physiol. 110:945-955.

Fukaki, H., Wysocka-Diller, J., Kato, T., Fujisawa, H., Benfey, P.H. and Tasaka, M. (1998) Genetic evidence that the endodermis is essential for shoot gravitropism in Arabidopsis thaliana. Plant Journal 14(4), 425-430.

Halevy AH, Mayak S (1981) Senescence and postharvest physiology of cut flowers-Part 2. Hort Rev 3:59-143

Marra, M. A., Hillier, L. and Waterston, R.H. (1998). Expressed sequence tags-EST ablishing bridges between genomes. TIG Vol. 14 № 1 4-7.

Tasaka, M., Kato, T. \&Fukaki, H. (1999) The Endodermis and Shoot gravitropism. Trends Plant Sci. 4, 103-107.

Tasaka, M., Kato, T. \&Fukaki, H. (2001) Genetic regulation of gravitropism in higer plants. Int. Rev. Cytol. 206, 135-154.

Yamauchi, Y., Fukaki, H., Fujisawa, H. and Tasaka, M. (1997) Mutations in the SGR4, SGR5 and SGR6 loci of Arabidopsis thaliana alter the shoot gravitropism. Plant Cell Physiol. 38(5):530-535.

- Egea-Gilabert, C., Manchado-Rojo, M, Weiss, J. and Egea-Cortines, M. (2009). Identification of pathogen resistance genes in Petunia hybrida. X World Petunia Days (Cartagena-Murcia, Spain).

We are interested in understanding the evolutionary and molecular basis of resistance genes in Petunia hybrida both for basic and breeding purposes. We have established a PCR strategy to identify oorthologs and paralogs from several gene families. We have used degenerate primers [1] to clone resistancce genes from the Mitchell line. We picked a total of 150 clones and have sequenced 26 clones. We have obtained several clones that correspond to LTR and Ty transposons and at least four resistance genes. These include putative orthologs of a TIRNBS-LRR from Solanumcaripense, P-Loop-ATPase, one gene similar to the N-gene from tobacco (resistance to tobamovirus), and one R3-a like from potato. We are currently expanding the number of genes sequenced in order to have a set of Petunia sequences to be used for evolutionary and breeding purposes as markes and in transgenic experiments.

1. Leister D., Ballvora A., Salamin F.,Gebhardt C.: A PCR-based approach for isolating pathogen resistance genes from potato with potential for wide application in plants. Nat. Genet 1996, 14(4):421429. 
- Manchado-Rojo, M, Weiss, J. y Egea-Cortines, M. (2008). Secuenciado masivo de una genoteca de CADN normalizada de Petunia para estudios de genetica inversa. IV Congreso de Mejora Genética de Plantas (Córdoba,Spain).

La existencia de información de secuencia en una especie, es determinante para poder llevar a cabo abordajes de genética inversa como TILLING, búsquedas de inserciones de transposones o ARN de interferencia. Petunia hybrida es una solanácea que ocupa el primer lugar en las ventas anuales de planta en maceta en Europa. Actualmente, solamente se conocen unas 7.000 ESTs secuenciadas. Hemos desarrollado un protocolo de normalizado y hemos realizado una genoteca ultranormalizada a partir de ARN de hojas, tallos, semillas, meristemos apicales, meristemos florales, primordios florales, y flores en tres estadíos de desarrollo. Mediante un análisis comparativo de la primera hebra de cDNA contra la genoteca normalizada para los genes actina, ciclofilina, GADPH, ubiquitina, PP2A, RAN3, tubulina y factor de elongación $\mathrm{F}$ muestra cambios en los niveles de expresión de los genes analizados, en los que la dispersión disminuye entre 10 y 100 veces. Se ha llevado a cabo una reacción de secuenciado de la genoteca por el sistema 454, y estamos analizando un total de 180.000 ESTs que deberían rendir más de 15.000 unigenes.

- Delgado-Benarroch,L., Manchado-Rojo, M., Gómez-di Marco,P.A.,Weiss,J., y Egea-Cortines, M. (2007). Size matters in floral development. IX World Petunia days (Amsterdam, Holland)

- Manchado-Rojo, M., García-Escudero, M.,García_Martínez, J.L., Delgado-Benarroch, L.,Weiss,J., y Egea-Cortines, M. (2004). Gibberellin signalling in Antirhinum majus. XVth Antirrhinum congress (Salamanca, Spain).

- García-Escudero, N, Weiss,J, L. Bayo-Canha, A. Roca-Hernandez, A, Manchado-Rojo, M y Egea-Cortines, M. (2004). El locus nana define un nuevo gen involucrado en la respuesta a giberelinas en Antirrhinum. VII Congreso de Biología Molecular y Celular de Plantas (Benalmádena-Málaga, Spain) 



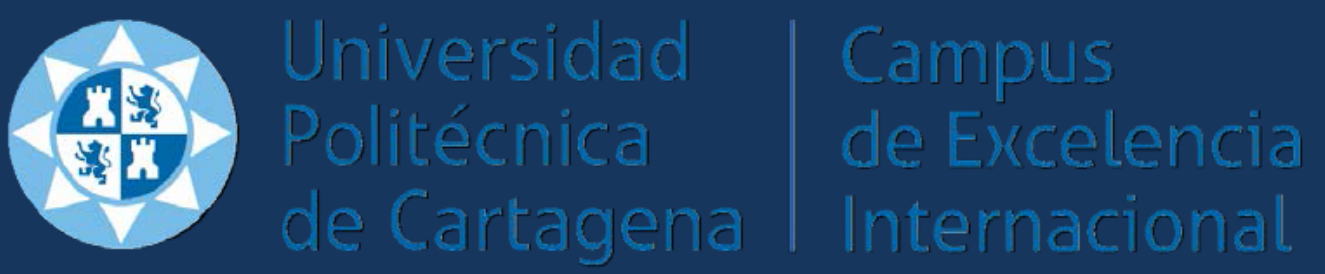

